\title{
ESTABLISHING A JOURNEY ARCHITECTURE
}

\author{
by
}

Shawna Nicole Seligman

B.Arch.Sci, Ryerson University, 2013

A Design Research Thesis

presented to Ryerson University

in partial fulfillment of the

requirements for the degree of

Master of Architecture

in the Program of

Architectural Science

Toronto, Ontario, Canada, 2015

(c) Shawna Nicole Seligman 2015 



\section{AUTHOR'S DECLARATION}

I hereby declare that I am the sole author of this thesis. This is a true copy of the thesis, including any required final revisions, as accepted by my examiners.

I authorize Ryerson University to Iend this thesis to other institutions or individuals for the purpose of scholarly research

I further authorize Ryerson University to reproduce this thesis by photocopying or by other means, in total or in part, at the request of other institutions or individuals for the purpose of scholarly research.

I understand that my thesis may be made electronically available to the public. 



\section{ABSTRACT}

This thesis documents and analyses my research and design that led to the synthesis of a new philosophy called Journey Architecture, the basis of my design work. Journey Architecture utilises movement and emotion to enhance the human experience through constant change. A series of design explorations build the understanding that a journey is never about the end point but rather the creation of a framework of objects, spaces and places to be experienced uniquely by each individual. Through an iterative process of multi-media techniques, methods for representing ideas, both visually and temporally, are illustrated. The final design project, the Dwelling of Walt Whitman, is a representation of a Journey Architecture. The dwelling celebrates life within the spaces by recognising that memory and emotion directly impact our experience of an environment. This thesis removes the limitations of architectural conventions and explores architectural ideas that enhance the continuously changing world around us. 



\section{ACKNOWLEDGEMENTS}

I would like to thank my supervisor, Dr. Kendra Schank Smith, for her endless support throughout this year in my design, research and exploration of unconventional design techniques. A special thank you to my second reader John Cirka for encouraging me to stay true to my design philosophy and providing me with theoretical guidance. To the many other professors I had the pleasure of learning from I must also thank Dimitri Papatheodorou and Arthur Wrigglesworth who inspired my design process throughout my education at Ryerson University.

Thank you to my family for supporting me in every way through a challenging six years. To my parents and part-time cheerleaders thank you for always ensuring I was calm and on task. You nurtured my creativity from birth and ensured I never gave up on this dream. To Mel, Jenn and David thank you for dedicating the time to help me with design ideas, editing and keeping me company on those late nights. And to Dave for being there during all of the emotional, stressful and celebratory times. I could not have done this without the support, encouragement and inspiration of the people who surround me every day. 



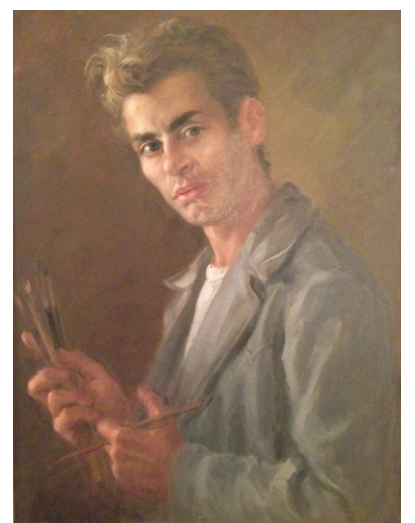

FIGURE 0.1.01

\section{DEDICATION}

This thesis is dedicated to my late grandfather, Zaidy Yidel Podeswa, an artist whose resilient talent produced a family of painters, creative writers, a fashion designer, filmmaker and now a future architect. Without his natural artistic gift and nurturing creativity, my journey would have never led me to the path of architecture and design. 



\section{TABLE OF CONTENTS}

Chapter $\quad 1.0 \ldots \ldots \ldots$. . . . . . . . . Defining Journey Architecture $1.1 \ldots$. . . . . . . Developing the Definition through Design

Chapter $\quad 2.0 \ldots \ldots \ldots$. . . . . . . . . . . . . . Movement

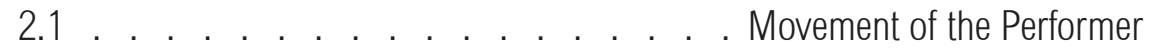

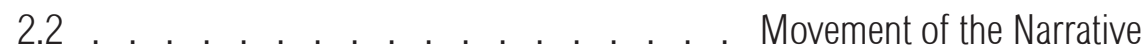
2.3 . . . . . . . Significance of Movement in Journey Architecture

Chapter $\quad 3.0 \ldots \ldots \ldots \ldots$. . . . . . . . . . . Emotion $3.1 \ldots \ldots \ldots$. . . . . . . . . . . . . . . Emotion of the Labyrinth

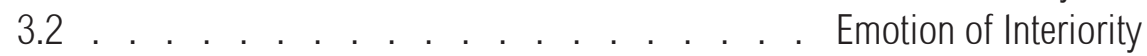
3.3 . . . . . . . . Significance of Emotion in Journey Architecture

Chapter $\quad 4.0 \ldots \ldots \ldots \ldots$. . . . . . . . . . . . Dwelling $4.1 \ldots \ldots$. . . . . . . . . . . . . Whitman as a Reference Point $4.2 \ldots \ldots \ldots$. . . . . . . . . . . Dwelling of Walt Whitman

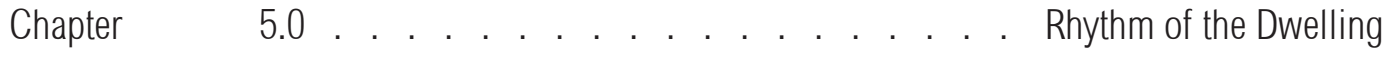

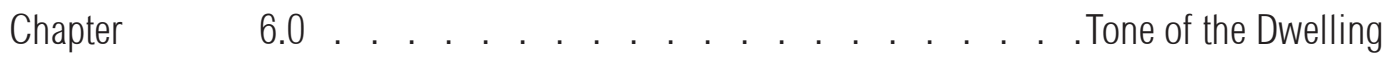

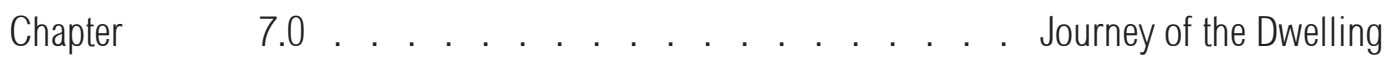

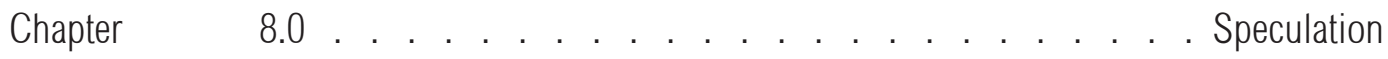

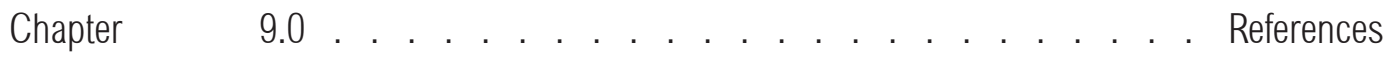




\section{LIST OF FIGURES}

Introduction

Pg.

Figure 0.1.0a Photograph of Oil on Canvas Self-Portrait of Yidel Podeswa. Image Credit Yidel ix Podeswa

Figure 0.1.0b Photograph of Paper Pop-up Model. Image Credit Shawna Seligman Xx

Figure 0.1.0c Photograph of Paper Pop-up Model. Image Credit Shawna Seligman $\quad$ XX

Figure 0.1.0d Photograph of Hinged Wood Model for Relative Space installation. Image Credit $\quad x x$ Shawna Seligman

Chapter 1

Figure 1.0.0a Photograph of Paper Pop-up Model. Image Credit Shawna Seligman 1

Figure 1.0.0b Journey Architecture Definition Diagram. Image Credit Shawna Seligman 3

Figure 1.1.0a Journey Architecture Design Process Diagram. Image Credit Shawna Seligman 7

Chapter 2

Figure 2.0.0a Photograph of Hinged Wood Model in Progress for Relative Space installation. 9-10 Image Credit Shawna Seligman

Figure 2.1.1a The Slow House by Diller and Scofidio. Image Credit https://designstudio2body- 15 andspace.files.wordpress.com/2014/09/dillerscof_slowh1.jpg

Figure 2.1.1b The Slow House by Diller and Scofidio. Image Credit http://www.dsrny.com/proj- 16 ects/slow-house/Upper-Level-Plan.jpg

Figure 2.1.2a Photographed Storyboard of Illusion Design Exploration 1. Image Credit Shawna 17 Seligman

Figure 2.1.2b Photographed Storyboard of Illusion Design Exploration 2. Image Credit Shawna 18 Seligman

Figure 2.1.2c Photographed Storyboard of Roulotte Design Exploration 1. Image Credit Shawna 19 Seligman

Figure 2.1.2d Photographed Storyboard of Roulotte Design Exploration 2. Image Credit Shawna 20 Seligman, Kevin Pu, Matthew Koniuszewski and Bijan Ghazizadeh

Figure 2.2.1a Jewish Museum by Daniel Libeskind. Image Credit Katrin Kalden http://amagazine. 25 com.au/between-the-lines-daniel-libeskind/

Figure 2.2.1b Jewish Museum by Daniel Libeskind. Image Credit http://www.archidiap.com/ 26 opera/museo-ebraico/

Figure 2.2.2a $\quad$ Photographed Installation Music for 18 Musicians. Image Credit Shawna Seligman 27 
Figure 2.2.2b Photographed Installation Music for 18 Musicians. Image Credit Shawna Seligman 27

Figure 2.2.2c Photographed Installation Music for 18 Musicians. Image Credit Shawna Seligman 27

Figure 2.2.2d Photographed Installation Music for 18 Musicians. Image Credit Shawna Seligman 27

Figure 2.2.2e Photographed Installation Music for 18 Musicians. Image Credit Shawna Seligman 29

Figure 2.2.2f Photographed Installation Music for 18 Musicians. Image Credit Shawna Seligman 29

Figure 2.2.2g Photographed Installation Music for 18 Musicians. Image Credit Shawna Seligman 29

Figure 2.2.2h Photographed Installation Music for 18 Musicians. Image Credit Shawna Seligman 29

Figure 2.2.2i Photographed Installation Music for 18 Musicians. Image Credit Shawna Seligman 30

Figure 2.2.2j Photographed Installation Music for 18 Musicians. Image Credit Shawna Seligman 30

Figure 2.2.2k Photographed Installation Music for 18 Musicians. Image Credit Shawna Seligman 30

Figure 2.2.21 Watercolour Diagram for Installation Music for 18 Musicians. Image Credit Shawna 29 Seligman

Figure 2.2.2m Watercolour Diagram for Installation Music for 18 Musicians. Image Credit Shawna 29 Seligman

Figure 2.2.2n Watercolour Diagram for Installation Music for 18 Musicians. Image Credit Shawna 30 Seligman

Figure 2.2.20 Watercolour Diagram for Installation Music for 18 Musicians. Image Credit Shawna 30 Seligman

Chapter 3

Figure 3.0.0a Photograph of Paper Pop-up Model. Image Credit Shawna Seligman 33-34

Figure 3.1.0a Photograph of Hinged Wood Model for Relative Space installation. Image Credit 38 Shawna Seligman

Figure 3.1.1a Brion Cemetery by Carlo Scarpa. Image Credit http://www.designlinesItd.com/a- 39 closer-look-carlo-scarpa/

Figure 3.1.1b Brion Cemetery by Carlo Scarpa. Image Credit https://rupalsourendre.wordpress. 40 com/2010/03/25/carlo-scarpa-\%E2\%80\%93-intervening-with-history-19561937-\%E2\% 80\% 93-lecture-11/

Figure 3.1.2a Photograph of Hinged Wood Model for Relative Space installation. Image Credit 41 Shawna Seligman

Figure 3.1.2b Photograph of Hinged Wood Model for Relative Space installation. Image Credit 41 Shawna Seligman

Figure 3.1.2c Photograph of Hinged Wood Model for Relative Space installation. Image Credit 41 Shawna Seligman

Figure 3.1.2d Photograph of Hinged Wood Model for Relative Space installation. Image Credit 41 Shawna Seligman 
Figure 3.2.0a Photograph of Hinged Wood Model Interiors for Relative Space installation. Image 43-44 Credit Shawna Seligman

Figure 3.2.1a Therme Vals Spa by Peter Zumthor. Image Credit http://c1038.r38.cf3.rackcdn.com/ 47 group1/building2978/media/tijj__1288298107thermevalsplan01.jpg

Figure 3.2.1b Therme Vals Spa by Peter Zumthor. Image Credit http://www.veluxstiftung.ch/ 48 userfiles/Therme_3(2).jpg

Figure 3.2.2a Photograph of Sectional Paper Book Model for Lower Queen project. Image Credit 49 Shawna Seligman

Figure 3.2.2b Photograph of Sectional Paper Book Model for Lower Queen project. Image Credit 49 Shawna Seligman

Figure 3.2.2c Photograph of Sectional Paper Book Model for Lower Queen project. Image Credit 49 Shawna Seligman

Figure 3.2.2d Experiential Section Drawing for Lower Queen project. Image Credit Shawna Selig- 50, man

Chapter 4

Figure 4.0.0a South East Exterior Rendering of the Dwelling of Walt Whitman project. Image Credit 56 Shawna Seligman

Figure 4.1.0a Photograph of Leaves of Grass 1856 Edition Frontispiece and Title Page. Image 59 Credit http://depts.drew.edu/lib/collections/whitman/images/LoG1856(frontis\&title)_tif.jpg

Figure 4.2.0a North West Exterior Rendering of the Dwelling of Walt Whitman project. Image Cred- 62 it Shawna Seligman

Chapter 5

Figure 5.0.0a Photograph of Journey Path Model through the Dwelling of Walt Whitman project. 64 Image Credit Shawna Seligman

Figure 5.0.0b Photograph of Journey Path Model through the Dwelling of Walt Whitman project. 65 Image Credit Shawna Seligman

Figure 5.0.0c Floor Plan Level 1 of the Dwelling of Walt Whitman project. Image Credit Shawna 67-68 Seligman

Figure 5.0.0d Floor Plan Level 1.5 of the Dwelling of Walt Whitman project. Image Credit Shawna 69-70 Seligman

Figure 5.0.0e Floor Plan Level 2 of the Dwelling of Walt Whitman project. Image Credit Shawna 71-72 Seligman 
Figure 5.1.0a Threshold Moment Drawing of the Dwelling of Walt Whitman project. Image Credit 73-74 Shawna Seligman

Figure 5.2.0a Photograph of Sectional Paper Book Model for the Dwelling of Walt Whitman proj- 75 ect. Image Credit Shawna Seligman

Figure 5.3.0a Photograph of Sectional Paper Book Model for the Dwelling of Walt Whitman proj- 77 ect. Image Credit Shawna Seligman

Chapter 6

Figure 6.0.0a Interior Rendered Foldout Drawing of the Dwelling of Walt Whitman project. Image 80 Credit Shawna Seligman

Figure 6.0.0b Photographs of Interior Rendered Foldout Drawing of the Dwelling of Walt Whitman 81 project. Image Credit Shawna Seligman

Figure 6.1.0a Photograph of Hinged Wood Model for the Dwelling of Walt Whitman project. Image 83 Credit Shawna Seligman

Figure 6.1.0b Photograph of Hinged Wood Model for the Dwelling of Walt Whitman project-Jour- 83 ney A. Image Credit Shawna Seligman

Figure 6.1.0c Photograph of Hinged Wood Model for the Dwelling of Walt Whitman project-Journey B. Image Credit Shawna Seligman

Figure 6.2.0a Photograph of Hinged Wood Model for the Dwelling of Walt Whitman project. Image 85 Credit Shawna Seligman

Figure 6.2.0b Photograph of Hinged Wood Model for the Dwelling of Walt Whitman project. Image 85 Credit Shawna Seligman

Figure 6.2.0c Photograph of Hinged Wood Model for the Dwelling of Walt Whitman project. Image 85-86 Credit Shawna Seligman

Figure 6.2.0d Photograph of Hinged Wood Model for the Dwelling of Walt Whitman project. Image 86 Credit Shawna Seligman

Figure 6.2.0e Photograph of Hinged Wood Model for the Dwelling of Walt Whitman project. Image 86 Credit Shawna Seligman

Figure 6.3.0a North Elevation Drawing of the Dwelling of Walt Whitman project. Image Credit 87 Shawna Seligman

Figure 6.3.0b West Elevation Drawing of the Dwelling of Walt Whitman project. Image Credit 88 Shawna Seligman

Figure 6.3.0c South Elevation Drawing of the Dwelling of Walt Whitman project. Image Credit 89 Shawna Seligman

Figure 6.3.0d East Elevation Drawing of the Dwelling of Walt Whitman project. Image Credit Shaw- 90 na Seligman 
Chapter 7

Figure 7.1.0a Photograph of Paper Pop-up Model Concept for the Dwelling of Walt Whitman 91 project. Image Credit Shawna Seligman

Figure 7.1.0b Photograph of Paper Pop-up Model Concept for the Dwelling of Walt Whitman proj- 91 ect. Image Credit Shawna Seligman

Figure 7.1.0c Photograph of Paper Pop-up Model Concept for the Dwelling of Walt Whitman proj- 91 ect. Image Credit Shawna Seligman

Figure 7.1.0d Photograph of Paper Pop-up Model Concept for the Dwelling of Walt Whitman proj- 91 ect. Image Credit Shawna Seligman

Figure 7.1.0e Photograph of Paper Pop-up Model Concept for the Dwelling of Walt Whitman proj- 92 ect. Image Credit Shawna Seligman

Figure 7.1.0f Photograph of Paper Pop-up Model Concept for the Dwelling of Walt Whitman proj- 92 ect. Image Credit Shawna Seligman

Figure 7.1.0g Photograph of Paper Pop-up Model Concept for the Dwelling of Walt Whitman proj- 92 ect. Image Credit Shawna Seligman

Figure 7.1.0h Moment Drawing of the Entering Space in the Dwelling of Walt Whitman project. 93-94 Image Credit Shawna Seligman

Figure 7.1.0j Interior Rendering of the Threshold from the Entering Space in the Dwelling of Walt 95 Whitman project. Image Credit Shawna Seligman

Figure 7.1.0k Interior Rendering of the Entering Space in the Dwelling of Walt Whitman project. 96 Image Credit Shawna Seligman

Figure 7.2.0a Photograph of Paper Pop-up Model Concept for the Dwelling of Walt Whitman proj- 97 ect. Image Credit Shawna Seligman

Figure 7.2.0b Photograph of Paper Pop-up Model Concept for the Dwelling of Walt Whitman proj- 97 ect. Image Credit Shawna Seligman

Figure 7.2.0c Photograph of Paper Pop-up Model Concept for the Dwelling of Walt Whitman proj- 97 ect. Image Credit Shawna Seligman

Figure 7.2.0d Photograph of Paper Pop-up Model Concept for the Dwelling of Walt Whitman proj- 97 ect. Image Credit Shawna Seligman

Figure 7.2.0e Photograph of Paper Pop-up Model Concept for the Dwelling of Walt Whitman proj- 98 ect. Image Credit Shawna Seligman

Figure 7.2.0f Photograph of Paper Pop-up Model Concept for the Dwelling of Walt Whitman proj- 98 ect. Image Credit Shawna Seligman

Figure 7.2.0g Photograph of Paper Pop-up Model Concept for the Dwelling of Walt Whitman proj- 98 ect. Image Credit Shawna Seligman

Figure 7.2.0h Building Section (through the Gathering Space) Watercolour Drawing for the Dwell- 99-100 ing of Walt Whitman project. Image Credit Shawna Seligman 
Figure 7.2.0j Building Section (through the Gathering Space) Photograph of Sectional Paper Book 102 Model for the Dwelling of Walt Whitman project. Image Credit Shawna Seligman

Figure 7.2.0k Interior Rendering of the Threshold to the Gathering Space in the Dwelling of Walt 103 Whitman project. Image Credit Shawna Seligman

Figure 7.2.0I Interior Rendering of the Gathering Space in the Dwelling of Walt Whitman project. 104 Image Credit Shawna Seligman

Figure 7.3.0a Photograph of Paper Pop-up Model Concept for the Dwelling of Walt Whitman proj- 105 ect. Image Credit Shawna Seligman

Figure 7.3.0b Photograph of Paper Pop-up Model Concept for the Dwelling of Walt Whitman proj- 105 ect. Image Credit Shawna Seligman

Figure 7.3.0c Photograph of Paper Pop-up Model Concept for the Dwelling of Walt Whitman proj- 105 ect. Image Credit Shawna Seligman

Figure 7.3.0d Photograph of Paper Pop-up Model Concept for the Dwelling of Walt Whitman proj- 105 ect. Image Credit Shawna Seligman

Figure 7.3.0e Photograph of Paper Pop-up Model Concept for the Dwelling of Walt Whitman proj- 106 ect. Image Credit Shawna Seligman

Figure 7.3.0f Photograph of Paper Pop-up Model Concept for the Dwelling of Walt Whitman proj- 106 ect. Image Credit Shawna Seligman

Figure 7.3.0g Photograph of Paper Pop-up Model Concept for the Dwelling of Walt Whitman proj- 106 ect. Image Credit Shawna Seligman

Figure 7.3.0h Moment Drawing of the Resting Space in the Dwelling of Walt Whitman project. 107Image Credit Shawna Seligman 108

Figure 7.3.0j Interior Rendering of the Resting Space in the Dwelling of Walt Whitman project. 109 Image Credit Shawna Seligman

Figure 7.4.0a Photograph of Paper Pop-up Model Concept for the Dwelling of Walt Whitman proj- 111 ect. Image Credit Shawna Seligman

Figure 7.4.0b Photograph of Paper Pop-up Model Concept for the Dwelling of Walt Whitman proj- 111 ect. Image Credit Shawna Seligman

Figure 7.4.0c Photograph of Paper Pop-up Model Concept for the Dwelling of Walt Whitman proj- 111 ect. Image Credit Shawna Seligman

Figure 7.4.0d Photograph of Paper Pop-up Model Concept for the Dwelling of Walt Whitman proj- 112 ect. Image Credit Shawna Seligman

Figure 7.4.0e Photograph of Paper Pop-up Model Concept for the Dwelling of Walt Whitman proj- 112 ect. Image Credit Shawna Seligman

Figure 7.4.0f Photograph of Paper Pop-up Model Concept for the Dwelling of Walt Whitman proj- 112 ect. Image Credit Shawna Seligman

Figure 7.4.0g Building Section (through the Nourishing Space) Watercolour Drawing for the 113Dwelling of Walt Whitman project. Image Credit Shawna Seligman 
Figure 7.4.0h Building Section (through the Nourishing Space) Photograph of Sectional Paper 116 Book Model for the Dwelling of Walt Whitman project. Image Credit Shawna Seligman

Figure 7.4.0j Interior Rendering of the Threshold to the Nourishing Space in the Dwelling of Walt 117 Whitman project. Image Credit Shawna Seligman

Figure 7.4.0k Interior Rendering of the Nourishing Space in the Dwelling of Walt Whitman project. 118 Image Credit Shawna Seligman

Figure 7.5.0a Photograph of Paper Pop-up Model Concept for the Dwelling of Walt Whitman proj- 119 ect. Image Credit Shawna Seligman

Figure 7.5.0b Photograph of Paper Pop-up Model Concept for the Dwelling of Walt Whitman proj- 119 ect. Image Credit Shawna Seligman

Figure 7.5.0c Photograph of Paper Pop-up Model Concept for the Dwelling of Walt Whitman proj- 119 ect. Image Credit Shawna Seligman

Figure 7.5.0d Photograph of Paper Pop-up Model Concept for the Dwelling of Walt Whitman proj- 119 ect. Image Credit Shawna Seligman

Figure 7.5.0e Photograph of Paper Pop-up Model Concept for the Dwelling of Walt Whitman proj- 120 ect. Image Credit Shawna Seligman

Figure 7.5.0f Photograph of Paper Pop-up Model Concept for the Dwelling of Walt Whitman proj- 120 ect. Image Credit Shawna Seligman

Figure 7.5.0g Photograph of Paper Pop-up Model Concept for the Dwelling of Walt Whitman proj- 120 ect. Image Credit Shawna Seligman

Figure 7.5.0h Moment Drawing of the Cleansing Space in the Dwelling of Walt Whitman project. 121Image Credit Shawna Seligman 122

Figure 7.5.0J Interior Rendering of the Threshold to the Contemplation Space in the Dwelling of 123 Walt Whitman project. Image Credit Shawna Seligman

Figure 7.5.0K Interior Rendering of the Contemplation Space in the Dwelling of Walt Whitman 124 project. Image Credit Shawna Seligman

Figure 7.6.0a Photograph of Paper Pop-up Model Concept for the Dwelling of Walt Whitman proj- 125 ect. Image Credit Shawna Seligman

Figure 7.6.0b Photograph of Paper Pop-up Model Concept for the Dwelling of Walt Whitman proj- 125 ect. Image Credit Shawna Seligman

Figure 7.6.0c Photograph of Paper Pop-up Model Concept for the Dwelling of Walt Whitman proj- 125 ect. Image Credit Shawna Seligman

Figure 7.6.0d Photograph of Paper Pop-up Model Concept for the Dwelling of Walt Whitman proj- 125 ect. Image Credit Shawna Seligman

Figure 7.6.0e Photograph of Paper Pop-up Model Concept for the Dwelling of Walt Whitman proj- 125 ect. Image Credit Shawna Seligman

Figure 7.6.0f Photograph of Paper Pop-up Model Concept for the Dwelling of Walt Whitman proj- 125 ect. Image Credit Shawna Seligman 
Figure 7.6.0g Photograph of Paper Pop-up Model Concept for the Dwelling of Walt Whitman proj- 125 ect. Image Credit Shawna Seligman

Figure 7.6.0h Building Section (through the Cleansing Space) Watercolour Drawing for the Dwell- 127ing of Walt Whitman project. Image Credit Shawna Seligman 128

Figure 7.6.0j Building Section (through the Cleansing Space) Photograph of Sectional Paper Book 130 Model for the Dwelling of Walt Whitman project. Image Credit Shawna Seligman

Figure 7.6.0k Interior Rendering of the Threshold to the Cleansing Space in the Dwelling of Walt 131 Whitman project. Image Credit Shawna Seligman

Figure 7.6.0I Interior Rendering of the Cleansing Space in the Dwelling of Walt Whitman project. 132 Image Credit Shawna Seligman 


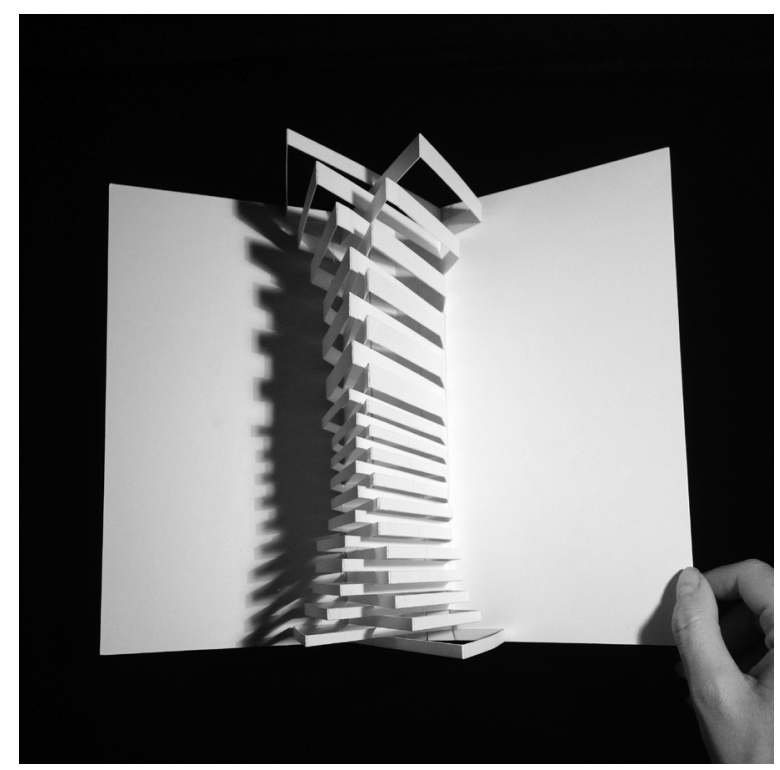

FIgURE 0.1.0B Paper Pop-up Model

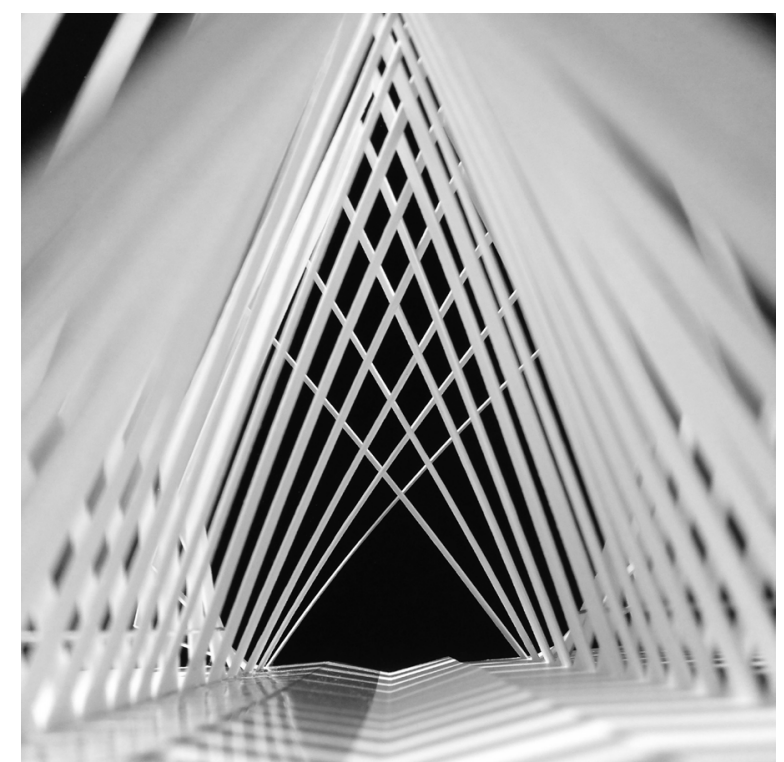

FIGURE 0.1.0C Paper Pop-up Model

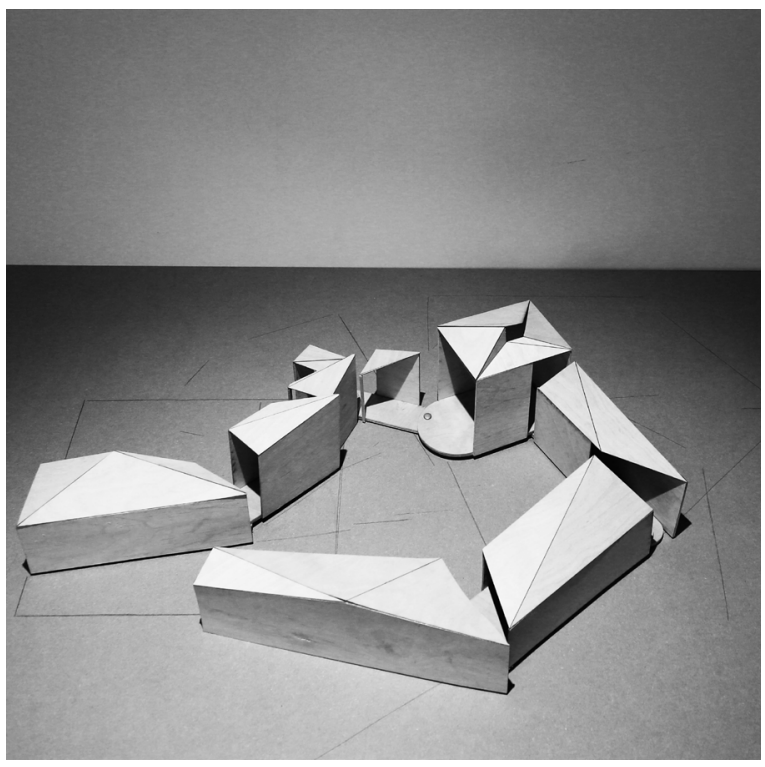

FIGURE 0.1.00 Wood model for Relative Space installation 


\section{JOUR - NEY}

: an act or instance of traveling from one place to another

: a process of changing and developing over a period of time

\section{AR $\cdot$ CHI $\cdot$ TEC $\cdot$ TURE \\ : establishing an order or creating a conceptual structure}

\section{JOUR - NEY - AR - CHI - TEC - TURE \\ : the creation of an order or conceptual structure for a change in time}




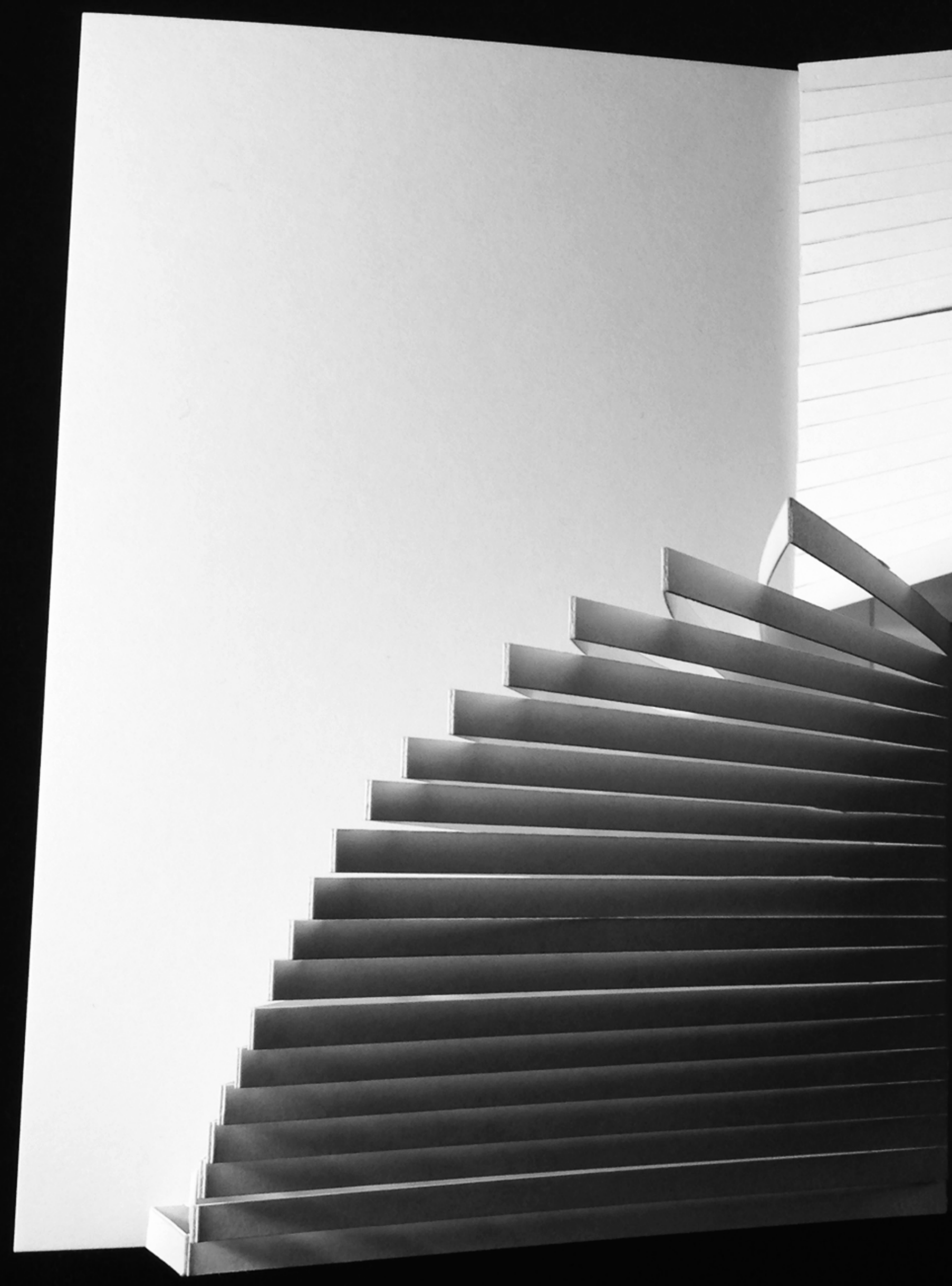


CHAPTER I

JOUR NEY AR CHI TEC TURE

: the creation of an order or conceptual

structure for a change in time 


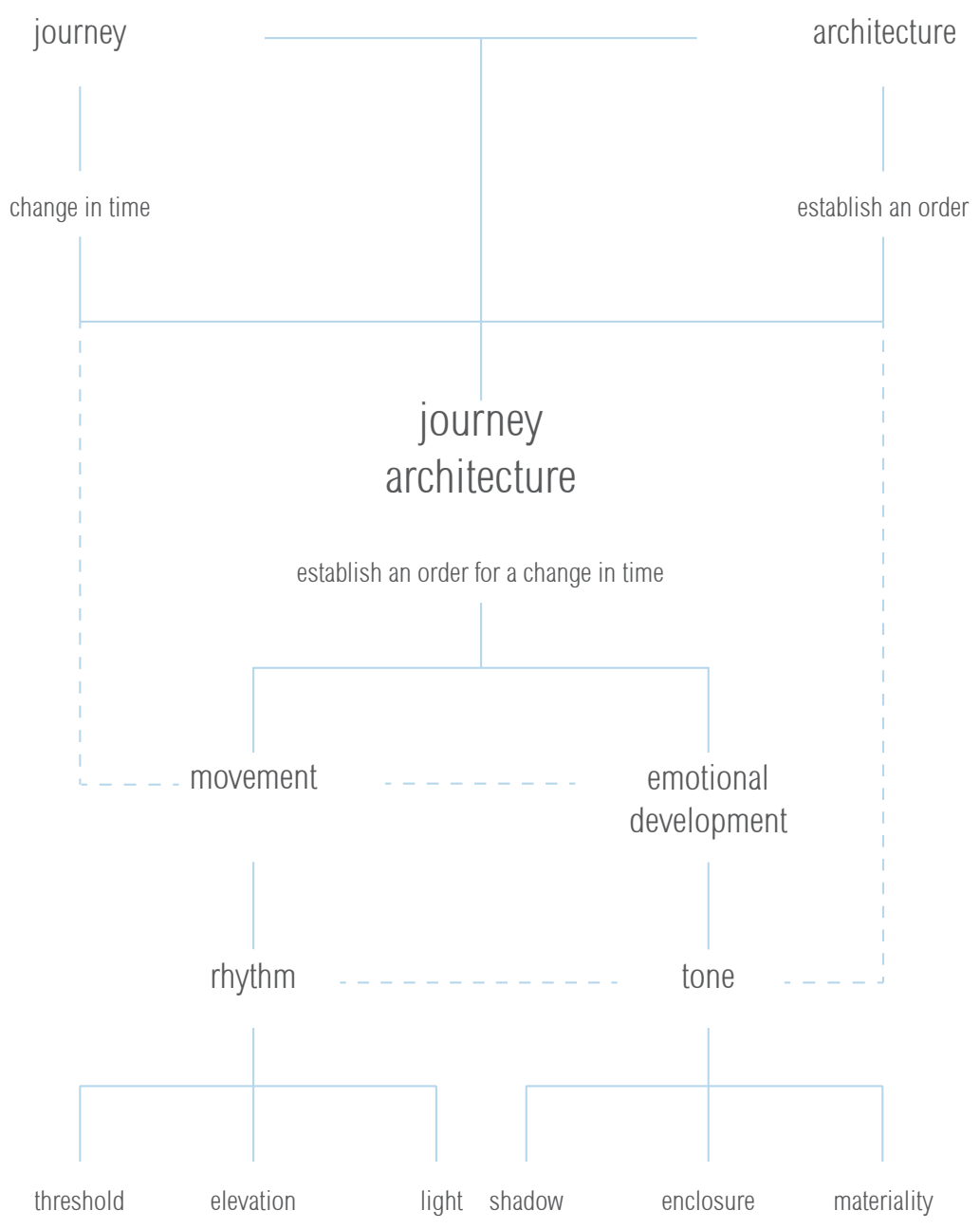

FIGURE 1.0.OB Journey Architecture Definition Diagram 


\subsection{0 \\ DEFINING JOURNEY ARCHITECTURE}

This thesis will establish Journey Architecture as the creation of an order or conceptual structure for a change in time. A journey is defined as a change in time. The term "journey" can define travelling from one place to another or a process of changing and developing over a period of time ("Journey - definition and synonyms," 2015). The former refers to movement or a change in position and the latter refers to growth, a change in emotion. "Architecture" refers to establishing an order or creating a conceptual structure. While a single definition of architecture is widely disputed, Frank Lloyd Wright stated that architecture is "at least the geometric pattern of things, of life, of the human and social world. It is at best that magic framework of reality that we sometimes touch upon when we use the word order". Wright provides the basis for understanding architecture as an order while simultaneously emphasising the importance of human life. Journey Architecture explores perceived change through the interface between architecture, time and the experiencing-body. This change happens over varying time scales, from immediate daylighting and atmospheric spatial conditions to seasonal changes and emotional development over a lifespan. Movement and emotion begin to allow for the discovery of the indefinite possibilities of the human body for transformation and change. Rhythm and tone create an order or conceptual structure for these changes in time - both emotional and physical. Tone can be achieved through materiality, enclosure and light, while rhythm can be achieved through light, threshold spaces and elevation. This thesis utilises the life of great American poet Walt Whitman to put forth these ideas. The life of Walt Whitman presented an entirely unique opportunity to capture a journey in life as he expressed his changing emotions and personal growth at six different periods in his life by reimagining one of his major works, Leaves of Grass. By rebuilding the same work six times throughout his life, I was able to interpret his emotions in each edition through the analysis of his poetry and the writings of several literary critics.

The concept of a journey is commonly explored in documenting a life through exhibitions in museums, films and books. I wrote this thesis to encourage architects to rethink the changes that happen within their architecture, the development and growth of lives over time within the spaces they shape and to reinvest some of that energy into documenting that journey in the architecture. Why is it significant to follow a person's journey through their achievements in art, poetry and humanities? Because that person's life was meaningful, they were successful and we want to be inspired by how they lived. Their journey tells us that even when they suffered, they managed to create something that transcended their physical life in this world. Architecture has the capacity to shape us and represent us but also to outlive us and exhibit our journey long after our life is over. A work of art or poetry provides a momentary glimpse into the emotions of the creator at that moment in their life. To view or read the entire body of one man's work allows us to interpret their emotional development and a part of their life's journey. This thesis utilises Walt Whitman's life journey as interpreted through one of his major works, Leaves of Grass, to develop Journey Architecture. The essential role of this dwelling is to utilise a series of his emotions captured in time to create emotional architecture. The experience of those emotions is subject to each person experiencing the architecture in their own way and open to an infinite number of interpretations. Journey Architecture is not a prescribed path through a space and therefore this thesis should not be read as a prescription on how to develop the journey. This thesis documents the journey to discovering, establishing and defining Journey Architecture. However, "Not I, nor anyone else can travel that road for you. You must travel it by yourself,"(Whitman, 1855). 



\section{1 .0 \\ DEVELOPING THE DEFINITION ThHOUGH DESIGN}

This thesis aims to define Journey Architecture through an iterative process of researching and analysing architectural theories, followed by interpreting them through design explorations and synthesising the ideas into the final design project. The design explorations led to questions about related theories that began to develop my understanding of the main target. To define something requires establishing a comprehensive understanding of the surrounding ideas and theories that start to zero in on the objective. This thesis documents my journey in discovering theories and ideas that surround the concept of Journey Architecture in order to define it.

My thesis research began in search of designing architecture to enhance well-being. The primary concern was to relieve the mental distress of the environment on the occupants. The initial design explorations primarily looked at the emotion and meaning derived from a procession through space. This was achieved through the lived experience, the circulation and movement through and between spaces. Perhaps I was designing Journey Architecture all along and I just did not know it yet. My intuition was telling me how to design but my rationale was telling me it must extend to the greater world via health benefits. At the onset, I could not rationalise why the movement and experience of space was of the utmost importance to the architectural field or how designing with feeling and meaning could shape our lives in ways we cannot articulate. I set out on my journey, just like any literary protagonist, with a path and destination unknown. The architectural thesis abyss presented many twists and turns and moments to refocus. Each idea and theory led me through a process of design exploration and self-reflection that inevitably paved the way from one idea to the next. With no predetermined outcome, this process allowed me to research established concepts relating to journeys and architecture and weave a web of ideas and analysis that would ultimately define Journey Architecture. My interests drifted from mental health issues and began to focus in on the human experience architecture can offer.

Architecture is experienced through movement in space. I endeavoured to achieve movement by guiding the user through space with a narrative or with a sensory experience. The first exploration looked at the sequencing and choreographing of spatial illusions. The notions of temporal movement and revelation embedded in an illusion installation led me to ideas in performance in architecture. Through the use of stop motion film, I explored the theatricality of light and the spatial and temporal experience of a narrative. Similar to literature, theatre, film, music and art, architecture offers a unique medium to support or express a narrative. The purpose of creating a narrative in architecture is the same as any other art form - to excite, inform and connect ideas to achieve a comprehensive understanding and engage an audience. Narratives in architecture are therefore essential to cultural vitality and the organisation of human experience. Narratives in architecture play with notions of theatricality to tell a story with light and darkness and metaphorical forms. With the Music for 18 Musicians installation, I explored movement of space with a narrative, both spatially and visually. This led to a design exploration in theatre design under the Yonge Street and Queen Street subway station. With this site, I was able to utilise dramatic lighting, heavy angular massing and linear progression to create a theatrical narrative that illustrated the

public experience of theatre-going. The ideas from the Lower Queen project whereby spaces were carved 


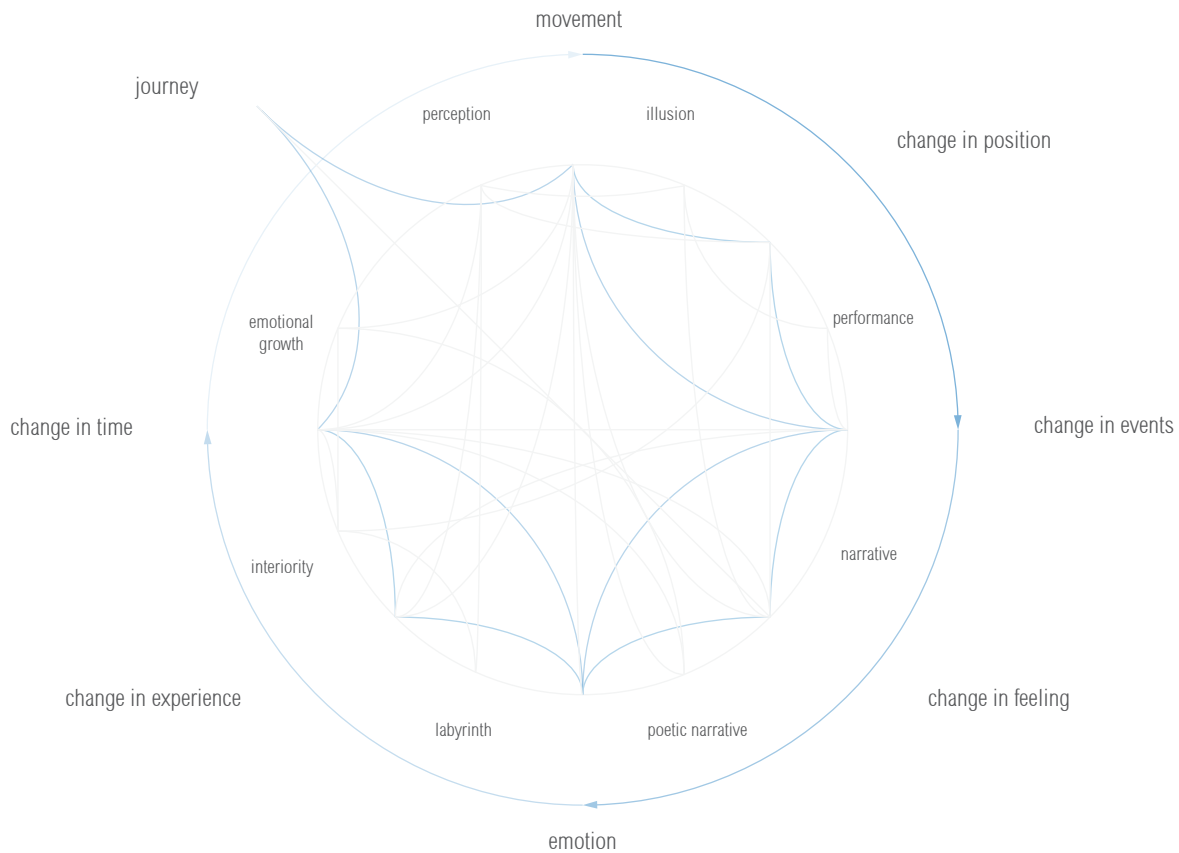

FIGURE I.I.0A Journey Architecture Design Process Diagram

out underground questioned the concept of interiority that was unaffected by the external world. By limiting the interior experience to the interior of the subway tunnel, the experience lacked the play of the interior with the exterior as the space was not affected by exterior views or the change of light filtering in throughout the day. The disorientation realised in this underground theatre complex created a maze-like experience and the linearity of the site restricted the experience to a progression of programmatic spaces.

This was when it became apparent that these design explorations would tell me what is, and what is not, Journey Architecture. Journey Architecture is not an attempt to relieve mental distress and it is not an illustration of a narrative experienced in one specified sequence. Journey Architecture does, however, look at the emotion and meaning of a space as it is interpreted by the individual. Journey Architecture is not about the procession of space but rather the experience of the space in time. This temporal experience captures, guides and encourages movement but does not prescribe it; prescription contradicts the notion of Journey Architecture. These reflections led to the establishment that Journey Architecture requires an individual experience, which could be designed through the use of labyrinthine qualities. For the purpose of this thesis, the definition of labyrinthine qualities can be understood as Umberto Eco's definition something having infinite pathways, interpretations and meanings (Eco, 2014). This concept led to the design and construction of an architectural labyrinth called the Relative Space project. This installation model allowed users to determine the path of the model by moving, twisting and unwinding it. The abstract model was designed to represent the journey of the labyrinth. The journey is about the unique individual experience. It does not prescribe a path, nor is it about a set path from one point to the next, but rather a development of change over time. The changes were seen as each individual moved the model from one position to the next, thereby changing the interior lighting conditions of each space. The interior experience revealed changes of atmosphere through lighting and scale of space.

These design explorations led me to theories on poetry, art, philosophy and architecture, which I then 
analysed to conclude that Journey Architecture is the establishment of an order or conceptual structure for a change in time. A journey concerns growth over time and architecture has the capability to frame it in the moment or reflect on it after the moment has passed. Architecture encompasses a poetic dimension as it narrates through individual interpretations of spatial imagery, emotion and cadence. It causes us to think about things beyond the logic of what is presented before us. Poets create emotion by referring to a specific situation and creating imagery of the situation through the use of metaphors, connotations and sounds. Similar to architecture, poetry presents emotions and ideas that come together in unexpected ways to then be interpreted. The art of poetry is composed of layers of imagery and emotion that unfold temporally and were explored architecturally. I have also explored the temporal nature of perceiving architecture through the lens of art and philosophy. Architecture is experienced in space and time by moving through space to change one's perspective and gain an understanding of the whole. This is crucial because philosophers such as Maurice Merleau-Ponty have concluded that one can never view all sides of an object at one time. Therefore to understand an object, we must complete it in our mind based on memory or experience it in time. Paintings are also experienced in time by the viewer, however, cubist painting looked for ways to transcend time and reveal a variety of perspectives from one simultaneous viewpoint. Journey Architecture borrows the concepts of individual interpretation, temporal experience and perception to assert that architecture can reveal an individual experience in time and space through movement and expression of emotion.

My journey was the search for a narrative and an expression that established and defined Journey Architecture. My thesis temporalised space by exploring the journey of a man's life. I utilised the concepts of a journey as the device to temporalise architecture and spatialise the life of Walt Whitman. My research and interpretation of his poetic self-portrait was explored through architecture. Whitman wrote and rewrote Leaves of Grass six times throughout his life as a reflection of himself, his emotions and values in his life at that moment in time. My thesis project explores both his poetic and life journeys in Leaves of Gras, reinterpreted through architecture. By designing an architectural portrait of Walt Whitman, I will explore the journey of the famous poet through emotional moments in his life. The program will be shaped by present habitation and the site by the memory of a man's journey. This thesis project is not about Whitman but rather, I have utilised his life's work as a reference to discuss Journey. His creation of a self-portrait through poetry provides a narrative that can be framed through words, imagery and architectural space. Architecture, similar to poetry, has an unpredictable way of slowly unfolding emotions, ideas, imagery and structure.

The architecture developed in this thesis begins to develop and establish a journey. It takes a labyrinthine approach to develop the journey of a house that bears witness of growth from youth to maturity. The poetry of Walt Whitman does not describe the biographical narrative, but rather alludes to it through imagery and symbolism that reflects his life. The Dwelling of Walt Whitman proves Gaston Bachelard's statement that "Space can be poetry" (Bachelard, 1994). Walt Whitman thought of poets as time binders of the continuous past present and future (LeMaster \& Kummings, 2011). The Dwelling of Walt Whitman is a poetic representation of the past, providing an emotional experience in the present open to future analyses. The poetry of Walt Whitman is an emotional journey of his life intended to create a work for others to experience and interpret. Similarly, the architecture in the Dwelling of Walt Whitman is a work shaped by his emotional journey intended to be interpreted and experienced by the individual. With poetry, art and architecture, there has been, and always will be, a separation between the intent of the narrative and individual interpretation and this is where the journey finds its beauty. By exploring Journey Architecture, this thesis situates architects in a parallel role whereby the journey is as much about memorialising a life as it is about framing the life and maintaining an open mind for future interpretation. 


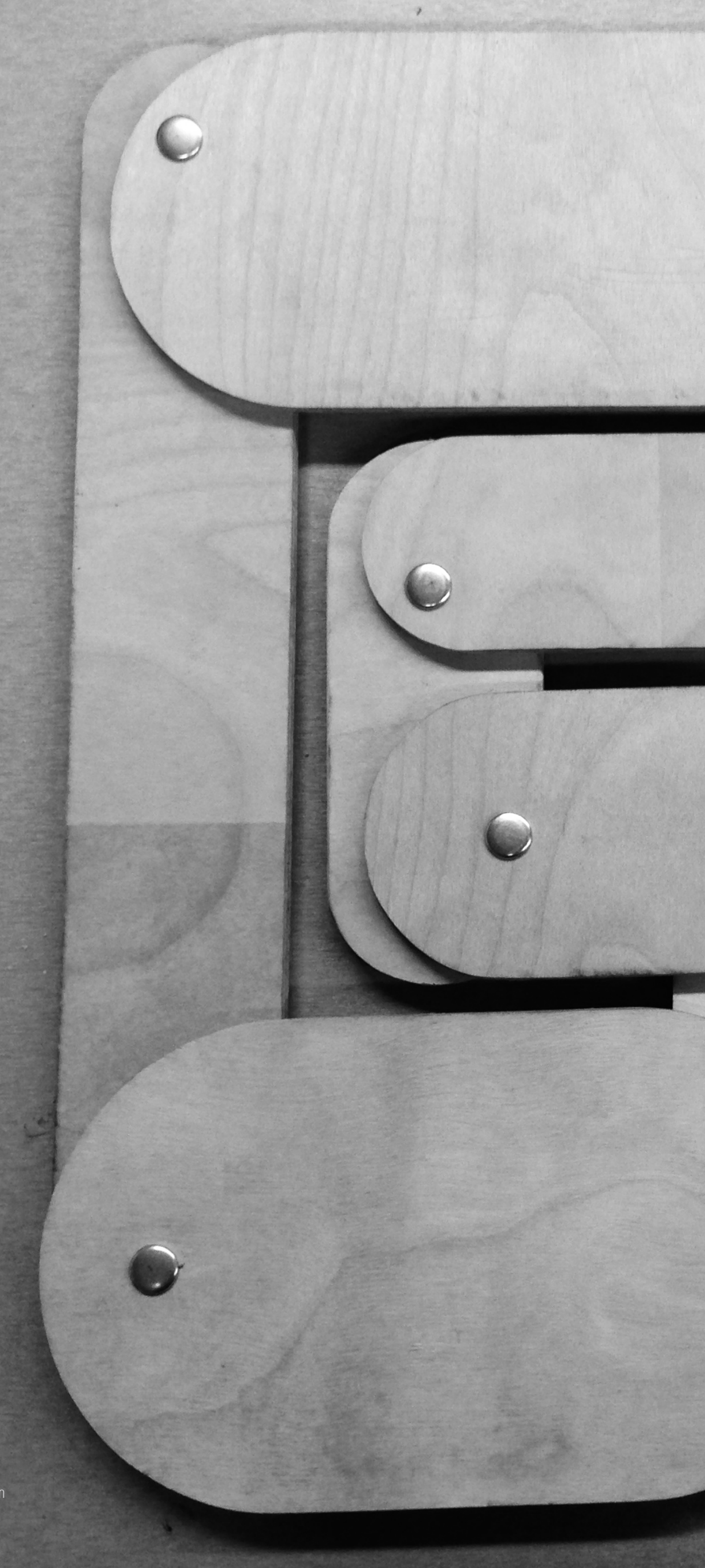





\subsection{0 \\ MOVEMENT}

\section{Defining Movement}

My exploration of movement in architecture began with a study on the variety of definitions associated with the term "movement". For the purpose of this thesis, I will present two seemingly different definitions of the word movement, both retrieved and cross-referenced from Dictionary.com Unabridged and Merriam-Webster.com websites. The first definition refers to the body; a change of position or location ("Movement," n.d.-a) or more specifically the act or process of moving people, your body or things from one position to another ("Movement," n.d.-b). This definition encompasses the meaning of the embedded verb to move and illustrates the act of moving from one point to another. The second definition refers to a narrative; the progress of events in a narrative ("Movement," n.d.-a) capturing the qualities in literature that constantly hold a reader's interest such as a quickly moving plot ("Movement," n.d.-b).

\section{Exploring Movement in Design}

This chapter documents how I began to explore the first definition of movement through physical movement of the body and space. By utilising notions of performance, I was able to design installations that encouraged bodily movement within space. These performance techniques led to explorations in architectural structures that performed through stop motion film to represent their adaptive spaces and theatrical qualities. The second definition of movement was explored through the use of narrative spaces. By utilising the narrative of the musical piece, Music for 18 Musicians by Steve Reich, an installation video was created that demonstrated how architecture can reveal a series of events in a plot whilst still holding the attention of the user. While many of the spaces had elements that were in physical motion, there was striking contrast to those spaces that were stationary but experienced movement by external forces of the sun and wind. The narrative of this musical piece was not like a literary narrative with a climaxing plot but rather the narrative of the layering of music instruments sounding in and out. The narrative itself presented another definition of movement - the rhythmic character or quality of a musical composition ("Movement," n.d.-b) - which I was able to express in the installation.

The initial explorations in movement were illusion installations documented through film. These projects utilised an object to facilitate movement in space. As any object contains varying perspectives as the perceiver circulates around it, the illusion installations used this to their advantage. The temporal revelation as the user circulated built up intrigue and culminated in a privileged perspective that would reveal the plot. The illusions provided new information and different interpretations of the object as one circulated around it. The illusions were able to engage the user in experiencing the whole work through continuously changing perceptions. The performance of the illusion was enacted by the user's circulation stimulated by intrigue and the final moment of discovery. In Phenomenology of Perception, Maurice Merleau-Ponty stated that the perception of an object or space is infinite because it changes with every slight move in location or direction (Merleau-Ponty, 2005). Human perception translates information by utilising stored memories, experiences and emotions. Due to an object's three-dimensions, a person

can never view all sides of an object at one time. Some parts of an object or space are always hidden 
and therefore the individual must complete it in their mind, building the "whole" based on memory and past experience. An architectural project can provide the framework for countless perceptions of the space between individuals based on prior experiences as well as infinite possibilities for the individual to perceive the space based on their location within it. Merleau-Ponty argued that architecture cannot be perceived from a single viewpoint and, therefore, the conventions of plan, section and elevation are subject to the point of view of the architect (Merleau-Ponty, 2005). Architectural drawing conventions neglect Merleau-Ponty's assertion that each individual perception of the same experience is unique. Conventional drawings in architecture limit the chances for unique experiences and interpretations of architecture. This thesis explores a variety of unconventional architectural media to construct and represent a unique journey in architecture. The second explorations in movement were the conceptual designs of a Roulotte Theatre, a temporary street performance theater, which utilized theatrical techniques to represent how the architecture could be altered upon use. Through stop-motion film and live interpretive dance, the concept of a transformable theatre was embodied. These unconventional techniques allowed for the expression of theatrical architecture to be perceived and explored ideas of both physical and narrative movement.

\section{Movement in Architecture}

Architecture is not required to physically move but a design can facilitate movement by offering possible paths to move along or meander. To experience architecture, our bodies must move in order to gain a sense of volume and depth. Steen Eiler Rasmussen, author of Experiencing Architecture, wrote "Architecture itself has no time dimension, no movement, and therefore cannot be rhythmic in the same way as music and dancing are," (Rasmussen, 1964, p.135). I strongly disagree with this statement as Rasmussen is simply adopting one meaning of the terms "time" and "movement". Movement does not need to act in physicality. It can simply pertain to the quality of representing or suggesting motion ("Movement," n.d.-b). It is this definition of movement that applies to architecture. Not only does architecture have the ability to represent and suggest movement from one position to another, but its dimension of time lies in the representation of events and life. Architecture utilises changes in elevation, scales of spaces and lighting to suggest movement within and between spaces. Movement of inhabitants and light are captured and guided by architecture in a temporal sequence. Rasmussen develops this argument into something more insightful as he begins to discuss rhythm. He describes our rhythmic experience of architecture as a product of memory and a process of recreation (Rasmussen, 1964). He asserts that if you are able to feel the rhythm of something static, this is because the perceiver relates it to a similar experience from their past, which involved the same rhythm but in motion. This furthers the idea that memory plays in the experience of movement and rhythm. Architecture can achieve movement by triggering memories of similar rhythms experienced elsewhere. The movement explorations in this chapter reveal how the rhythm of the architecture moving in the stop-motion film the Performing Roulotte Theatre (figure 2.1.2c) is felt by the viewer because of previous experiences of those rhythms in dance. Similarly, the rhythm of the Music for 18 Musicians installation is felt because the viewer has experienced these same rhythms when hearing those musical instruments. 



\subsection{0 MOVEMENT OF THE PERFORMER}

This chapter explores movement through the lens of the inhabitant or user of a space engaging in a performance and through the lens of the architecture or space being the performer. The construction of two illusion installations allowed me to study the performance of a person moving through space. The illusion has predetermined points of discovery and provides a framework for people to perform the journey to discovering the illusion. The creation of two concepts for a theatre allowed me to study the performance of an adaptive architecture of transformation. The program of a transportable theatre space created a unique platform where not only would the theatrical performances be moving, but so would the physical structure.

\section{Illusion Performances}

The illusion itself was not the central idea in figure 2.1.2a and 2.1.2b, but rather the journey the illusion created for the user to experience. If a journey refers to a change in time then the illusionary journey encompasses the changing perception of the illusion as one experiences it. In these two illusion explorations, the user experiences a change in time as they circulate around the illusion to gain new knowledge and arrive at the privileged perspective. In the illusion objects illustrated in these images, movement is achieved through intrigue, curiosity and mystery.

\section{Theatrical Performances}

The live nature of performance as opposed to static matter was discussed in Philip Ursprung's Herzog \& de Meuron: Natural History. The ephemeral art of performance that disappears was compared to the lasting physical art and objects. Swiss architects Jacques Herzog and Pierre de Meuron challenged this by designing the House of Leyman, whereby the invisible performance remained in architecture (Ursprung \& Schneider, 2002. pg.219). The history and memory of the site for the House of Leyman remain due to the symbolic references in the design. In Herzog \& de Meuron, 1978-1988, The Complete Works Gerhard Mack stated that the building symbolises "the lost history" of the site. In the same chapter, Rebecca Schneider responds that "if the building is a vessel citing that history - history is not lost at all, but remains in the gesture of memory that the building performs," (Ursprung \& Schneider, 2002, pg.226).

Jacques Derrida argued that citation, utilised in literary theory to quote or allude to other works, is the core of human communication (Wigley, 1995). In literature, writers may use quotations or footnotes to refer to other works while architecture has the ability to cite other works through metaphors, replication of key elements, forms and symbols. Schneider discussed the role of architecture as a citational practice, bridging past, present and future. The inhabitants of the house are performing a citation of all previous habitual activities of dwelling rather than reinventing these practices. This presents an additional citational practice of architecture, whereby the inhabitants' activities are repeated as a performance of entering, gathering, eating, sleeping, working and cleansing. History reverberates in the house, both in visible matter such as symbolic and literal design features as well as on an invisible level of citational practices and past performances (Ursprung \& Schneider, 2002). People utilise their memories, previous knowledge and feelings to understand the world around them and engage in the performance of life. 


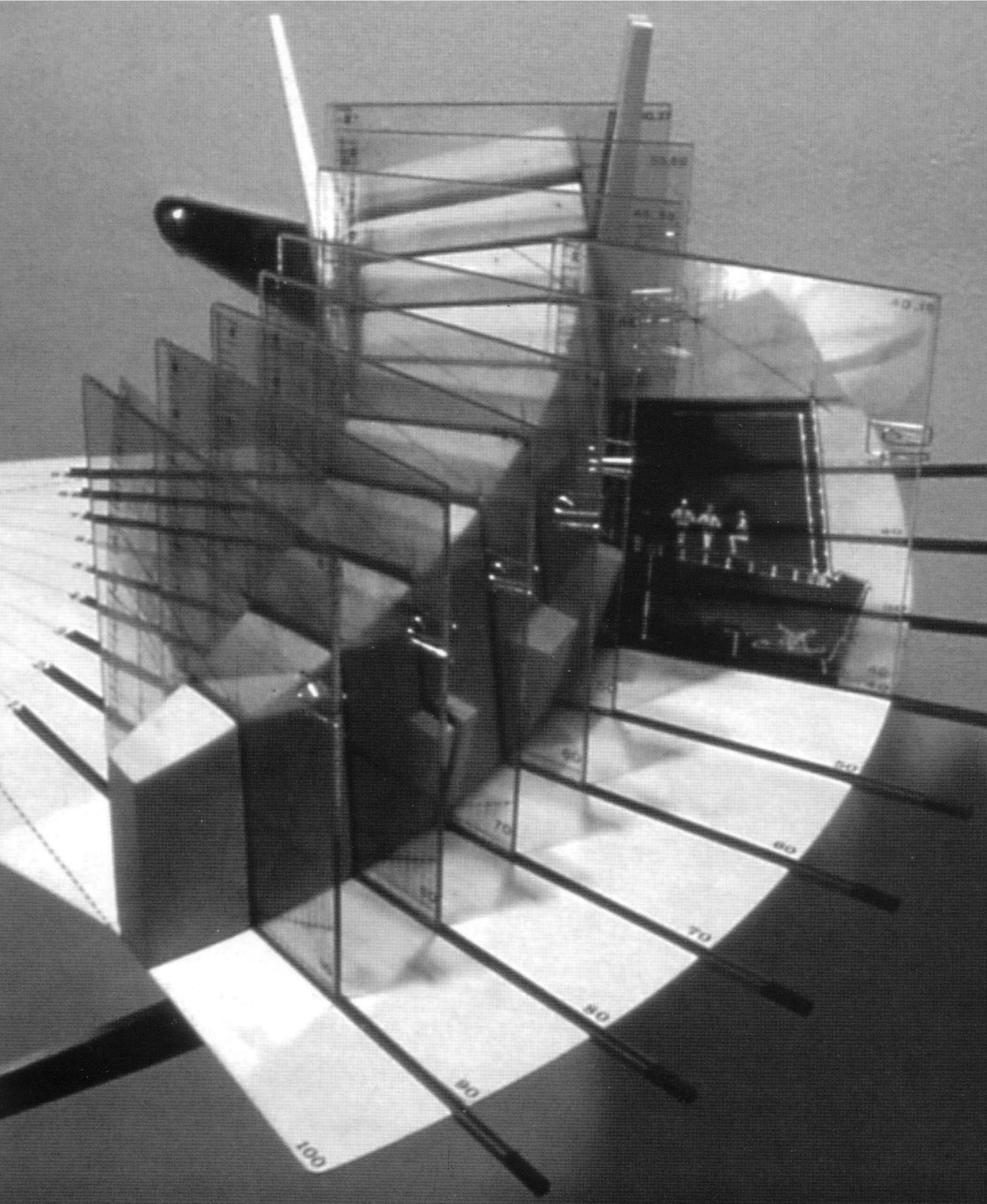




\subsection{1 \\ PRECEDENT ON MOVEMENT OF the PERFORMer}

The Slow House by Diller and Scofidio

The Slow House is an example of the early work of Diller and Scofidio when their projects reflected a simultaneous interest in performance and theatre. This project was of interest to my thesis as it explored how a house could be designed to unfold the everyday habits and activities like a theatrical narrative. The section cuts sliced through the model seen in Figure 2.1.1a illustrate how the changing 'set design' and the constant change in perspective around the tangential building allow for the script to be unfolded in space and time. This vacation home was shaped by the concept of a door that leads to a window, representing the motion of physically entering and optically departing (Diller \& Scofidio, 1994). This exploration in dwelling played with the performances of habitation. While the picture window suggests an invitation of the exterior world to be viewed from the inside, The Slow House utilised it to display the 'living room set' whereby the inhabitants would perform (Diller \& Scofidio, 1994). The design erased the traditional restrictions of private space by transmitting the inside out. The inhabitants are on display through the large picture window acting out the daily performances of habitation for the world to see.

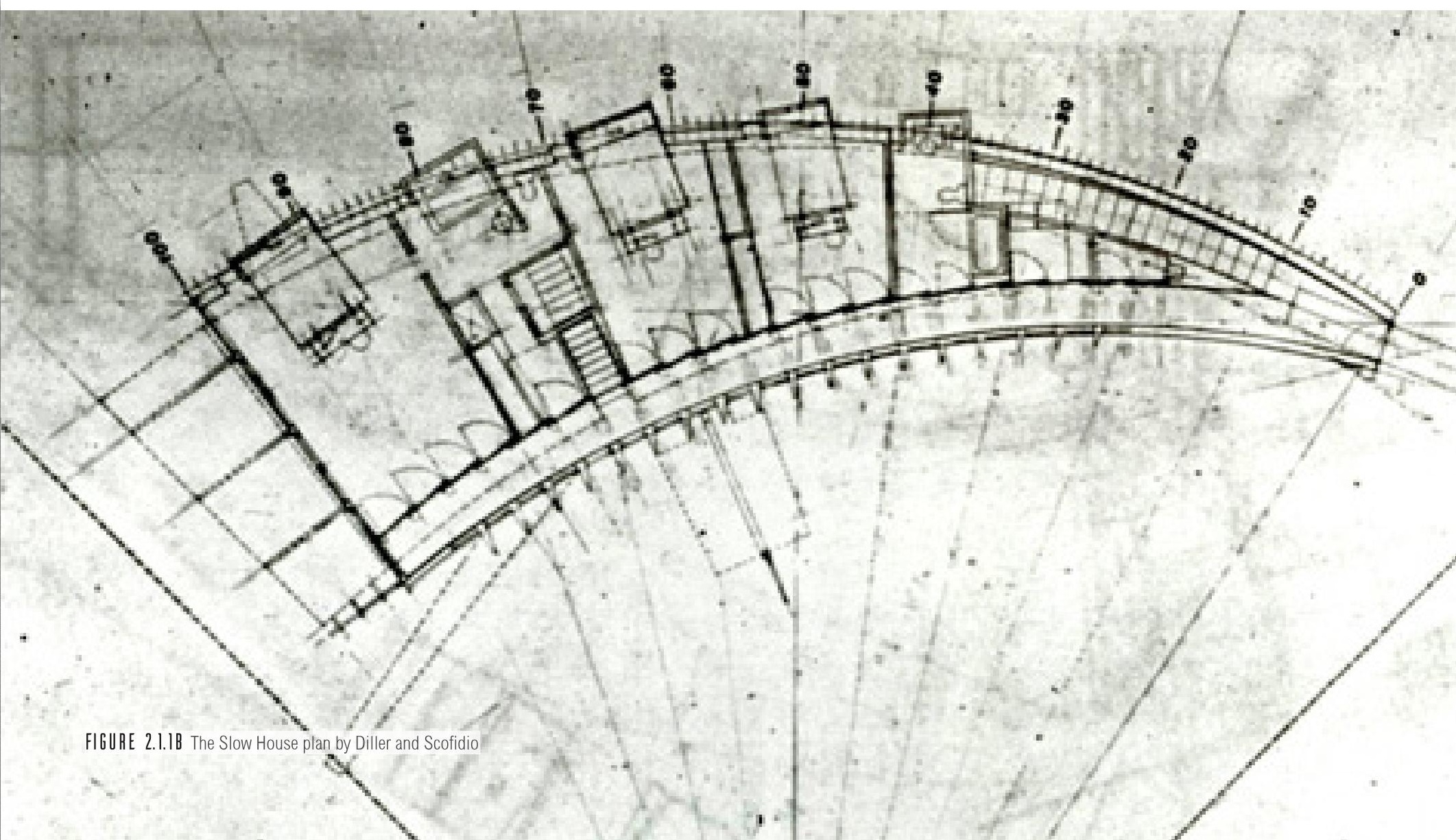




\subsection{2 \\ DESIGN EXPLORATIONS ON MOVEMENT OF THE PERFORMer}

\section{Illusion Series}

The Illusion Series was a collection of two installations created with an illusion object (figures 2.1.2a and 2.1.2b) in order to document reactions, responses and individual experiences to a single object. The etymology of the word "illusion" comes from the Latin word Ludere, which means "to play". This captures the role of the installations - to play and engage with them. In addition, "to play" can mean "to perform". In these installations, the users were performing the act of discovering the illusion. Each person moved at different paces, gained knowledge from different cues but, in the end, was encouraged by the object to circulate and experience the whole installation.

\section{Illusion Exploration 1}

In Illusion Exploration 1, figure 2.1.2a depicts the journey of gaining knowledge as one circulates around the cascading image. The storyboard illustrates the relationship between object and viewer, or artefact and story. At first glance the object was simply a black plane on display in a three-dimensional space. As people approached it there was a sense of curiosity and wonder regarding the ambiguous artefact and its presence. The desire to discover what this artefact was and why it was located there led to the viewer actively engaging in the exploration of the artefact. Each individual would then circulate around the artefact temporally receiving more knowledge about it. The absence of complete information encouraged movement and the final perspective depicting the words "now you know" signalled that there was a revelation of knowledge in the journey of the installation. The illusion enabled a temporal unfolding of information that took the individual from unknowing viewer, because they were unaware of the total object's appearance, to knowing participant once they had discovered the end result.
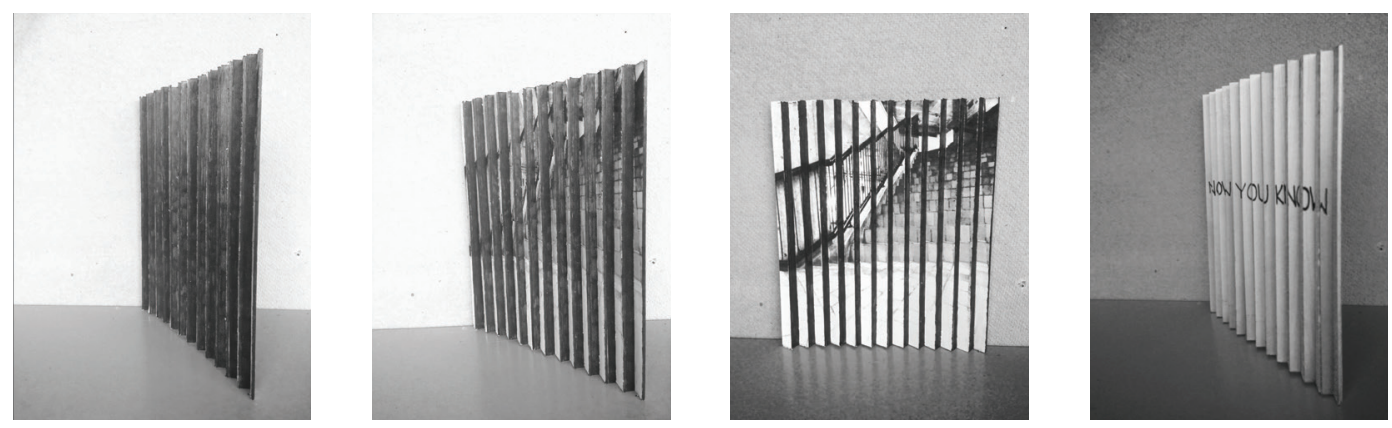

FIGURE 2.1.21 IIlusion Design Exploration 1 
The journey of the illusion is demonstrated as follows:

\begin{tabular}{|c|c|c|c|c|c|c|c|c|}
\hline Intrigue & $\rightarrow$ & Hypothesis & $\rightarrow$ & Transition & $\rightarrow$ & Discovery & $\rightarrow$ & $\begin{array}{c}\text { Knowledge of } \\
\text { Reality }\end{array}$ \\
\hline $\begin{array}{l}\text { A physical or } \\
\text { visual cue is } \\
\text { seen }\end{array}$ & $\rightarrow$ & $\begin{array}{l}\text { First im- } \\
\text { pression on } \\
\text { the Truth or } \\
\text { Reality }\end{array}$ & $\rightarrow$ & $\begin{array}{l}\text { Change in } \\
\text { Perspective } \\
\text { Occurs }\end{array}$ & $\rightarrow$ & $\begin{array}{l}\text { Arrive at the } \\
\text { Privileged } \\
\text { Perspective }\end{array}$ & $\rightarrow$ & $\begin{array}{l}\text { Leave with } \\
\text { Gained } \\
\text { Knowledge }\end{array}$ \\
\hline
\end{tabular}

Illusion Exploration 2

The storyboard in figure 2.1.2b illustrates the journey of circulating around the sculptural hilltop path that becomes a globe at the privileged perspective. As the second exploration in this series, the illusion installation plays with similar notions of the journey. The intent of this project was to create an installation of the Earth's globe. The installation aimed to illustrate the human perspective of the globe that is relatively flat when we are within it but, from a privileged perspective in space, we can perceive the globe in its entirety as a sphere. By utilising a privileged perspective through the camera lens, the viewer perceived the installation as a sphere in digital space. The experience of the installation led viewers from the point of unknowing viewer to moving user in search of an understanding of this as a globe. Upon arrival at the privileged perspective, the structural elements converged to form the geometry of a sphere and the words "now you see" can be read. The viewer was able to transform their understanding of the staggered sculpture to an interpretation of a globe. Once again, knowledge was revealed in time through the user's change in position. This static object enabled a performance of movement and a journey of attaining knowledge.
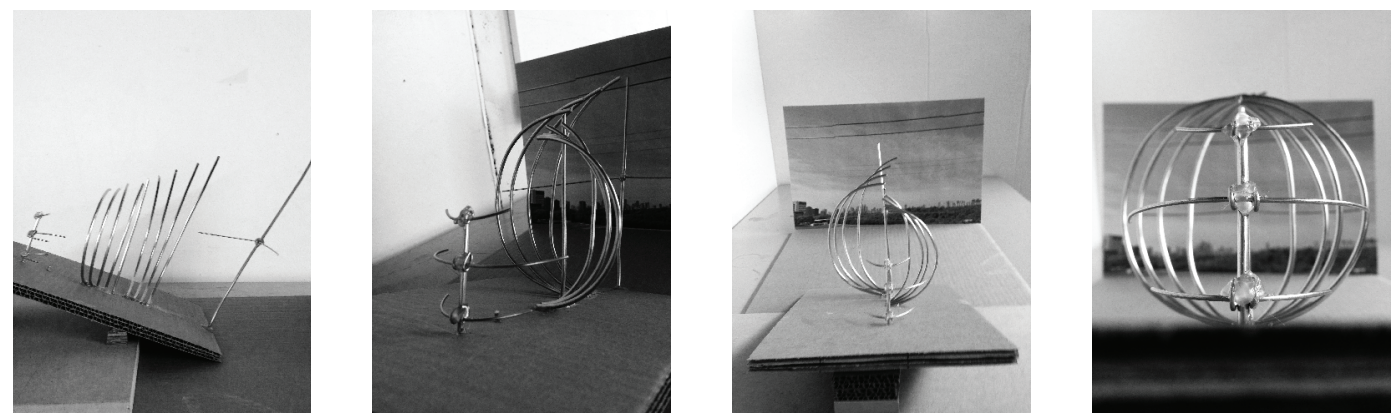

FIGURE 2.1.2B IIlusion Design Exploration 2 
Performing Roulotte Theatre Series

The Performing Roulotte Theatre Series (figures 2.1.2c and 2.1.2d) are explorations of performance in architecture through the design development of a travelling theatre. The roulotte is a French-inspired mobile professional arts venue. It is a self-contained structure that can be transported by trailer to new locations, similar to Gypsy caravans. The roulotte provides a backdrop that supports and extends performances of actors and artists. The architecture occupies public space but, in reality, its engagement with the public audience creates the public space. The design explorations (figures 2.1.2c and 2.1.2d) present the architectural concept of the roulotte as a performer.
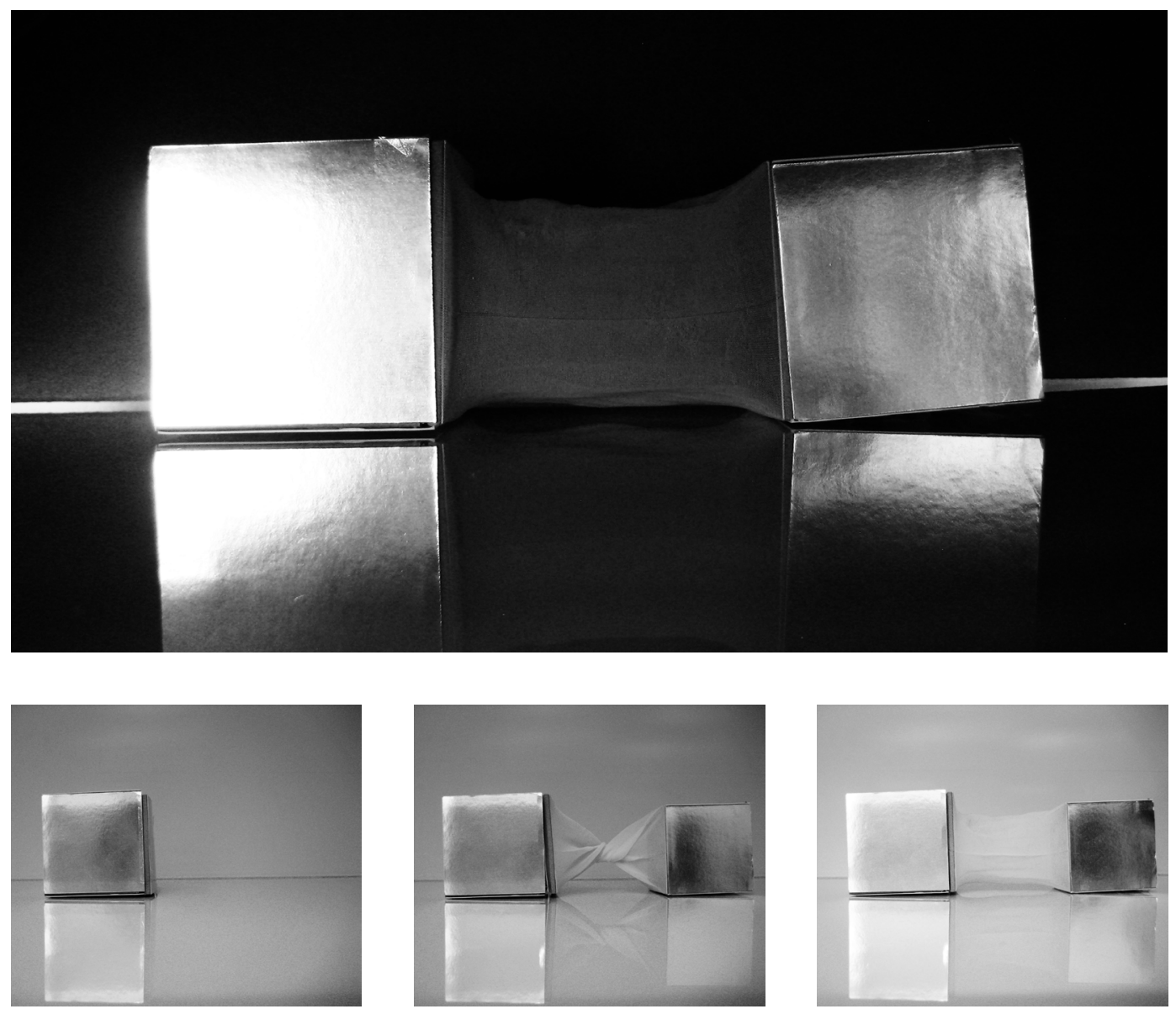

FIGURE 2.I.2C Performing Roulotte stop-motion film storyboard 1 


\section{Storyboard 1}

The Performing Roulotte in figure 2.1.2c is a storyboard of the film created to embody the idea of a performance theatre through the performance of the architecture. Through a stop-motion film of the physical model, this concept was conveyed with moving walls and adaptive textiles. The film cited the 1920's notions of performance with the use of music and rough stop-motion film techniques to portray theatrical movement of the architecture. The illusion of the moving architecture was a personification of the architecture to explore the performance of the inhabitants.

\section{Storyboard 2}

The second iteration of the Performing Roulotte in figure 2.1.2d was a group effort to conceptualise a spatial temporal sequence that explored the performance of the inhabitants. The storyboard documents the live performance that the group enacted to demonstrate the evolutions of the theatre, both formally and functionally. The live-motion media allowed for the representation of the architecture to cite interpretive dance, projections of spectacles and theatrical portrayals of utilising the space. In other words, the architecture is represented by the very media it will house.
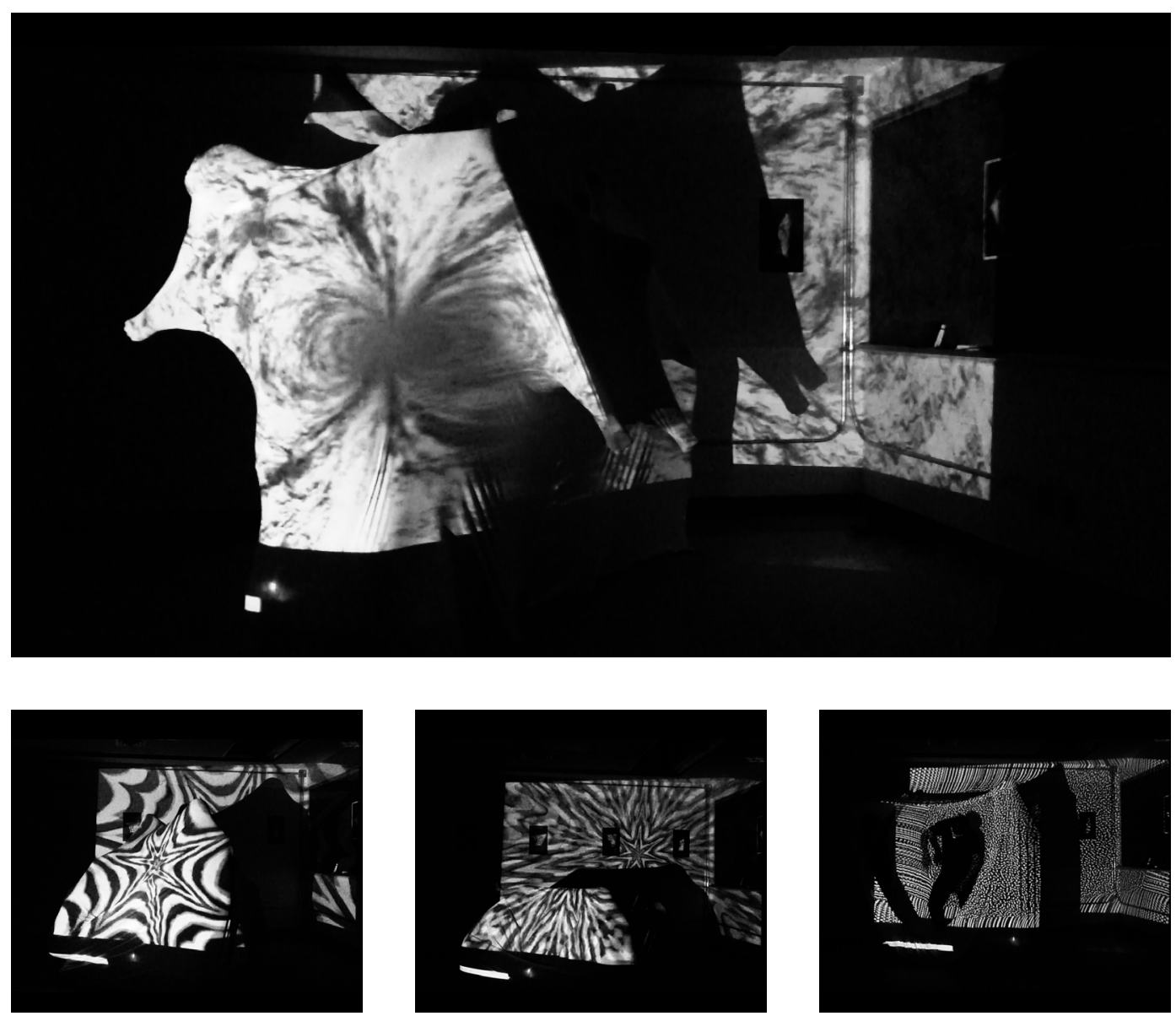

FIGURE 2.1.2D Performing Roulotte live performance storyboard 2 


\subsection{0 \\ MOVEMENT OF THE NARAATIVE}

\section{Defining Narrative}

A narrative is a story or an account of events and experiences in sequence ("Narrative," n.d.). Narrative meaning is derived by establishing a connection between the narrative and the larger context in which it occurs. The meaning established is a relative term as it provides a level of understanding of the world through connections, associations and common cultural knowledge. David Blair and Tom Meyer documented experiments in narrative structure and guiding non-linear narratives in their research paper, Tools for an Interactive Virtual Cinema. They coined the term "Narrative Intelligence" to describe the human ability to order events and derive meaning from them by connecting the events to familiar narratives (Blair \& Meyer, 1997). This begins to define narrative as an interactive relationship. Narrative is not simply told by one and listened by another but rather it is told by one and interpreted by another. This duality presents the complexity of narrative as each listener's interpretation of the narrative may differ. Roland Barthes literary theorist, semiotician and author of Introduction to the Structural Analysis of the Narrative asserted that, "The narratives of the world are without number...the narrative is present at all times, in all places, in all societies; the history of narrative begins with the history of mankind; there does not exist, and never has existed, a people without narratives" (Barthes, 1996).

Humans are natural storytellers. Since the dawn of civilisation, humans have used stories that represent an event or series of events as ways to learn and understand their past and world around them (Abbott, 2002). Bedford argued that stories aided humans in defining their values and beliefs and allowed the listener to project their own thoughts, feelings and memories onto the story and draw connections between the spatial experience and users lives and memories (Bedford, 2001, p.30). In The Cambridge Introduction to Narrative, a narrative is described as "a human phenomenon that is not restricted to literature, film and theatre, but is found in all activities that involve the representation of events in time," (Abbott, 2002, p.xii).

History of Narrative

Narrative theory includes a variety of concepts from literary theory, narratology, performance and film theory. Paul Cobley, Professor of Semiotics and Communications and author of Narrative (The New Critical Idiom) discussed the two theories on the origin of narrative (Macleod, Hanks, \& Hale, 2012). The first theory being an ontogenetic perspective whereby narrative arose as a result of the human ability to use language and the second, a phylogenetic perspective asserting that narrative was a product of cultural evolution (Paul Cobley, 2001). A literary narrative is typically structured with a beginning, middle and end characterised by the introduction, rising action, climax, falling action and conclusion. Paul Ricoeur asserted that time is not solely experienced as a linear sequence of moments because we utilise narrative to build the story of our life and history (McQuillan, 2000). Narrative enables those moments in time to have meaning and emotion and construct our identity. Ricoeur's theory situates narrative identity as a mediator between object or subject of interpretation and the interpreter. Narrative identity encompasses the interpreter and the interpreted because the individual who reads the story is simultaneously the writer (Ricoeur, 1991). According to Ricoeur, narratives are innovative and based on 
common views. This enables the story to be relatable and understandable while inserting originality to stimulate the imagination. Literary critic Fredric Jameson asserted that narrative is fundamental for our understanding of the world; it is the way the human mind develops reason and belief (Macleod et al., 2012). A poetic narrative takes on a more labyrinthine approach. It utilises words and metaphors to layer imagery and create or recreate an experience or story. It is interpretable as the words do not dictate an exact description.

\section{Defining Narrative Architecture}

In addition to literature, theatre, film, music and art, architecture offers another medium to support or express a narrative. Architecture has the ability to support narratives of the city or immerse the occupant into an isolated narrative. Architecture and literature can similarly be seen as a medium to convey a narrative between architect and user or author and reader. Architecture as a narrative encompasses a spatial experience from meaning and guidance to sensory experience. By participating in the spatiality and materiality, users activate the space and engage in the choreography of the space. By utilising light, shadow, scale of space and material palettes, buildings can compose the movement of its users. Narrative sequencing, movement and progression through space develop a rich experience of architecture. Narrative architecture "draw[s] the user into a complex psychological configuration" (Coates, 2012, p.80), incorporating metaphors and the dimension of time.

Narrative gives meaning to architectural space through a sensory experience of spatial depth and views, volume and rhythm, form, colour, light, materials and sound (Macleod et al., 2012). Narrative environments are in fact performative as they encourage corporeal engagement and subjective interpretation. A spatial narrative appeals to the user's mind provoking bodily participation and spatial exploration. Narrative architecture provides emotion, personal connection and purpose. Upon entry, users can understand the space in one way and exit having gained new experiences and knowledge. It provides the purpose to circulate, move or meander through a guided or unguided path towards discovery of a story or a metaphor. I will explore the methods and techniques used to narrate architecture and the impacts it can have on visitors. Narrative can be utilised to gain knowledge, excite, entertain, reference common cultural knowledge and organise human experience. Gianni Pettena, Italian architect and contributor in the Radical Architecture movement of the 1970's stated "I prefer my architecture to tell stories. It is meant to be food for the brain, and not an instrument for practical function," (Coates, 2012, p.139).

Narrative choreographs the movement between spaces by a chronological order or logical arrangement of ideas. Architect and Modern critic, Adolf Loos, wrote about this concept, "The Journey of the Gaze", in his design of the Moller House whereby circulation connected rooms both physically and visually. A series of openings in the walls framed the views from one space to the next enhancing the theatricality of gazing through the house. This idea is also referenced by modern architect Le Corbusier in his concept of "The Architectural Promenade", which he exemplifies in the Villa Savoye that utilised circulation as a guiding principle and focused on the sequence of movement through space (Samuel, 2010). Placing visual cues along an architectural promenade allows access into the brain's memory through the process of logical sequencing. 
Christian Norberg-Shulz, architect and author of Intentions in Architecture, discussed the human need to draw connections and relationships to the environment (Norberg-Schulz, 1971, p.9). This can be understood in conjunction with the spirit of place or genius loci that expresses the constant need to identify oneself with their environment. To recreate the experience of a place, narratives can connect memories of a place in a specific time through smells, atmospheres and sounds. Through studies such as the Method of Loci, it is evident that a spatial narrative can make these elements memorable by connecting objects with places or abstractions with visual references. The Method of Loci links feelings to places through the recollection of familiar memories.

History of Narrative in Architecture

Bernard Tschumi defined two theories, in his work Architecture and Disjunction, based on Georg Wilhelm Friedrich Hegel's declaration that architecture is an "artistic supplement" added to the building. Tschumi's first theory was that architecture is a language that represents something other than itself. This positions architecture as a representational medium that symbolises meanings outside of architecture. The second theory is that the architectural object is a language and architecture itself is the continuous manipulation of the grammar and composition. This positions architecture as an independent entity that communicates by referring to other architectural forms, functions and symbols (Tschumi, 1996, p.36). Both theories position architecture as a mode for communicating and the need for there to be meaning extended beyond the simple building. Tschumi, however, was not the first to write about architecture as a medium for communication.

Charles Jencks wrote extensively on the death of modern architecture for its alienating qualities to which people could not relate in The Language of Post-Modern Architecture. The univalent form and shallow meaning of modernism prevented architecture from being used as a language or medium to express ideas of metaphor and symbolism. Postmodern architecture established references that linked the present to the past, elite to popular cultures and amalgamated new techniques with historical forms. Postmodern architecture was meant to represent something; it had a linguistic nature of metaphors, icons, symbols, syntax and semantics. Many early postmodern architects looked at the role of communication in architecture as a critique to the modern prescription. According to Heinrich Klotz, author of The History of Postmodern Architecture, the objective of postmodern architecture was to create an architecture of "narrative contents," (Klotz, 1988, p. 128). Architecture contained a narrative potential beyond its practical function whereby places could convey a message or an idea (Klotz, 1988). Jencks defined an essential feature of postmodernism, which was the stylistic pluralism that no single style was authorised 
by the movement. Art critic and curator, Achille Bonito Oliva, picked up on the diversity of postmodern style as essential to providing a vocabulary to validate an architectural narrative. Oliva stated that styles should change to contribute to the significance and meaning of the narrative. In opposition to the abstract modern forms that represented nothing beyond the pure form, stylistic pluralism was essential to visually articulate the narrative content. Robert Venturi furthered this ideology in his gentle manifesto Complexity and Contradiction in Architecture. He critiqued modernism for its simplicity with his celebrated statement, "less is a bore," in response to modern architect Mies Van der Rohe who stated "less is more" (Klotz, 1988, p.142). Venturi's pluralistic view was that "A valid architecture evokes many levels of meaning and combinations of focus: its space and its elements become readable and workable in several ways at once" (Klotz, 1988, p. 143). Venturi celebrated the variation of individual interpretations of architecture and believed they added to the experiential qualities. The literary references and pluralistic styles were some of the defining features of early postmodern architecture that aimed to counter modernism through narrative.

Deconstructivism was an act of criticism that utilised narrative text as a critical device. The origins of deconstructivist architecture come from the literary movement of deconstruction, a form of semiotic analysis. Literary deconstruction is a method of interpreting meaning through opposition, contradiction, absence and conflict. The role of a deconstructivist reading is to highlight the contradictions and conflicts within a seemingly unified concept. Deconstruction is a strategy of questioning and an approach for critical thinking that establishes meaning through collaborating concepts and reversing logical constructs. French philosopher Jacques Derrida wrote about literary deconstruction and the need to dig below the surface and take apart the text to understand its value. Mark Wigley denoted that Derrida understood architecture "... as a representation of deconstruction, the material representation of an abstract idea" (Wigley, 1995). The architectural movement became further popularised in 1988 following the Deconstructivist Architecture exhibition at the Modern Museum of Art, curated by Mark Wigley and Philip Johnson launching careers for unknown architects at that time: Frank Gehry, Daniel Libeskind, Rem Koolhaas, Peter Eisenman, Zaha Hadid, Coop Himmelblau and Bernard Tschumi. Wigley described the projects in the show as a continuation of "...the experimentation with structure initiated by the Russian Constructivists, but the goal of perfection of the 1920s is subverted. The traditional virtues of harmony, unity and clarity are displaced by disharmony, fracturing and mystery," (Wigley \& Johnson, 1988). The distorted and dislocated geometries symbolises fragmentation in society and a break from overly simplistic modern approaches (Tabb \& Deviren, 2014). Of the leaders in the deconstructivist movement, Daniel Libeskind continues to work within the realm of narrative architecture. 

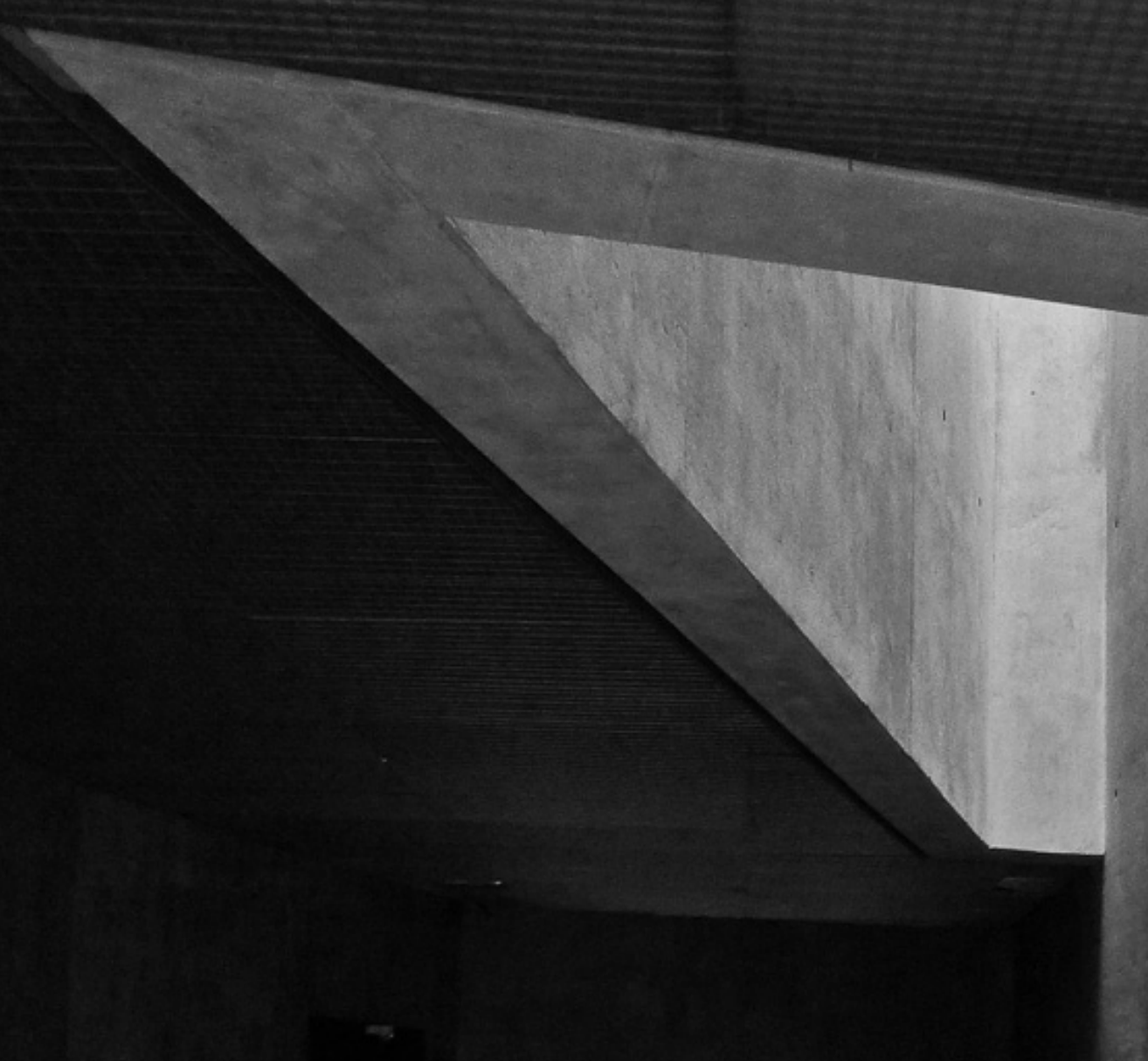

FIGURE 2.2.11 Jewish Museum by Daniel Libeskind 


\subsection{1 \\ PRECEDENT ON MOVEMENT OF THE NARAMTIVE}

Daniel Libeskind's Addition to the Jewish Museum in Berlin was a competition-winning design in 1988 and exemplifies narrative architecture. The concept utilised architecture as an expressive device to represent and emulate the emotional journey of the Jews before, during and after the Holocaust. The addition to the museum utilised this narrative to create promenades, galleries, empty spaces and dead ends that convey the emotion of the Holocaust rather than the factual events. While moving and transitioning through the spaces visitors feel a sense of absence, emptiness and loss of hope. The design of great empty spaces, uniform in materiality, devoid of windows symbolise the dark moments pierced by a sliver of light that represents the hope of survival. The zigzagging form of the plan and the solid tall concrete walls were designed to confuse, disorient and overwhelm the visitor. The design goes as far as leading stairways to solid blank walls, forcing the visitor to retreat in search of another route.

The human experience of the tragic history is translated into an architectural composition. Libeskind utilised movement to narrate the story as one can only begin to understand as one explores and inevitably gets lost. The overwhelming confusion, dark emotions and disorientation are maintained in the spatial experience while glimpses of hope flash through openings high above sight level. Three underground paths have different narratives that unfold as the visitor circulates through. The first leads to a dead end culminating at the Holocaust Tower. This represents an end for the lives taken in the Holocaust. The second leads out of the building into the Garden of Exile and Emigration representing the exit from Germany for the lives forced to relocate. The third path leads to the stair of continuity and more exhibition spaces to represent the enduring history. The narrative recounts history through the lens and emotion of people, rather than events, and conducts a spatial experience. The use of movement and emotion to shape the architecture was a key component of studying this precedent. Upon discovering this project I thought it would be a good example of Journey Architecture due to its narrative content. However, upon further examination I discovered it was not Journey Architecture because of its prescription of how one should interpret the spaces. The project is intended to be experienced and understood in a definitive way to recount the history and, therefore, whilst it is a powerful narrative architecture, it is not an example of Journey Architecture.

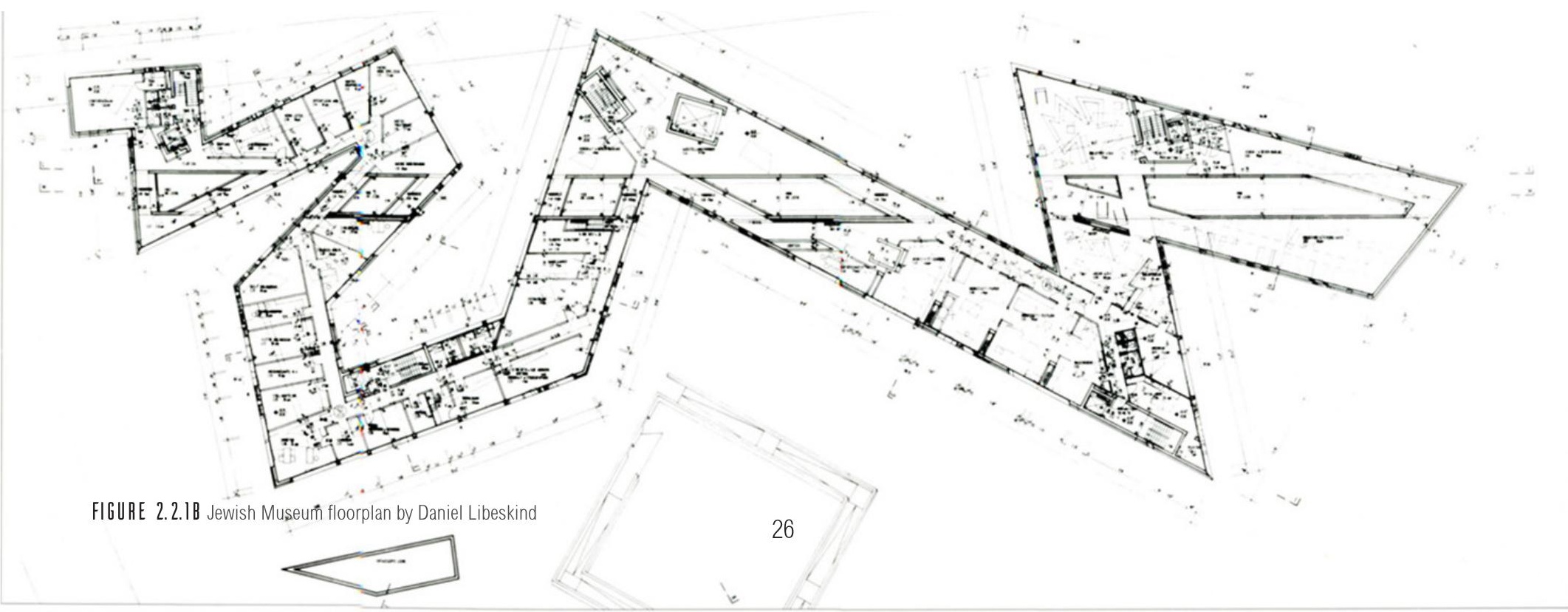




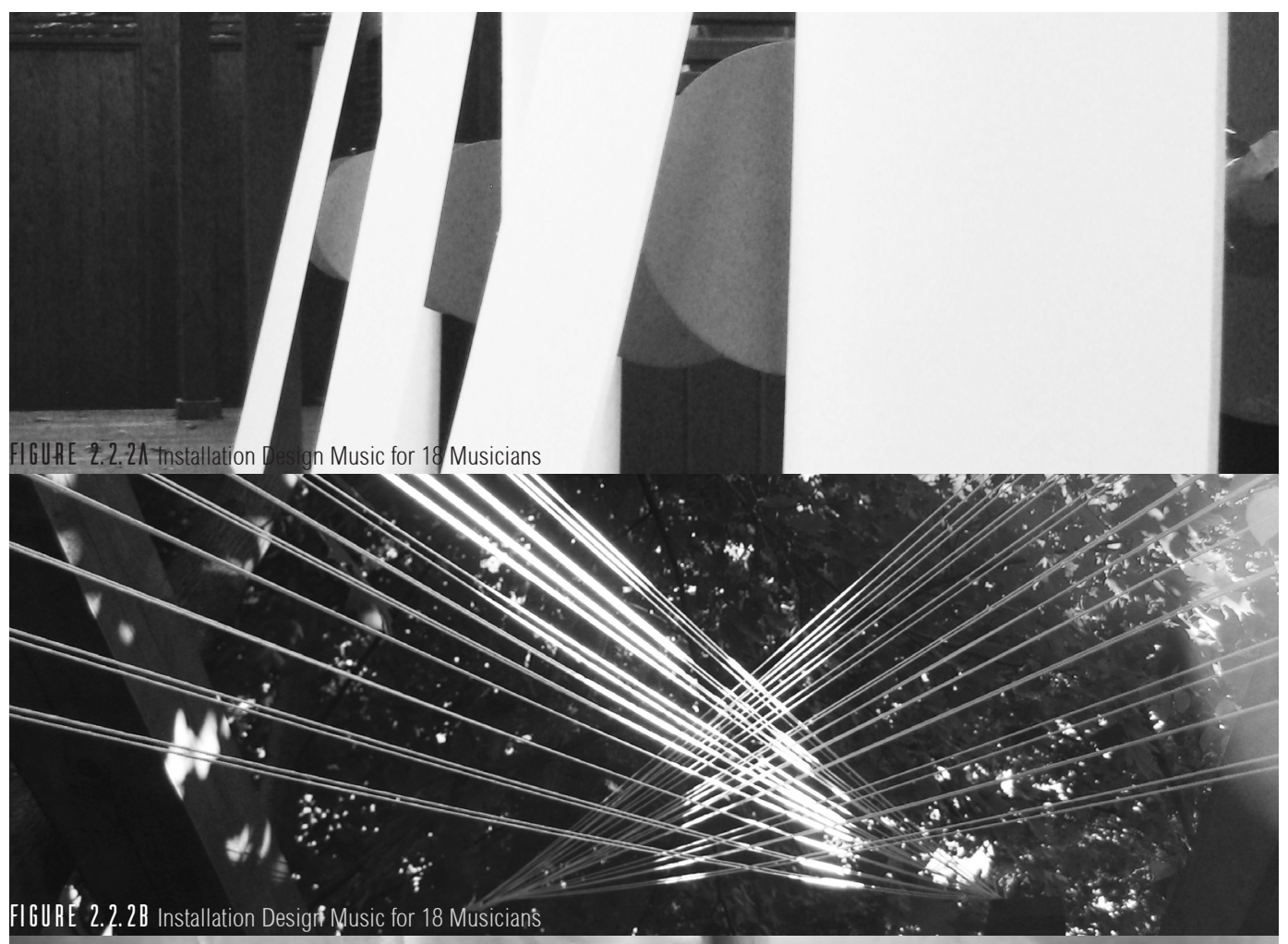

FIGURE 2.2.2C Installation Design Music for 18 Musicians

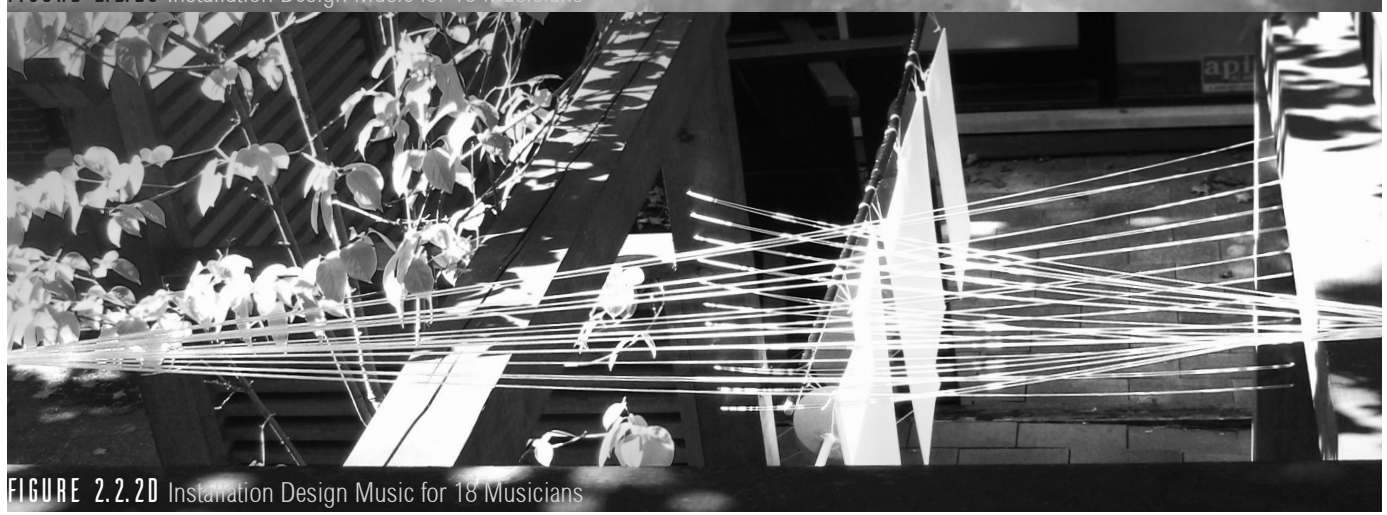




\section{2 .2 \\ deSIgN EXPLohations on MOVEMENT of the NahantIVE}

Installation Film

The Installation Film: Music for 18 Musicians (figures 2.2.2a, 2.2.2b, 2.2.2c and 2.2.2d) began with the exploration of narratives in literature, film, painting, photography and music. The desire to narrate a musical composition through spatial experiences was driven by the music being the only art form studied that does not have a given visual or verbal description of space. The sounds merely act as spatial reflections and can provide listeners with a narrative through emotion, intensity and musical composition.

Steve Reich's Music for 18 Musicians is a contemporary classical piece that was chosen for this exploration in space. The instrumental structure of the music provides a complex narrative that balances the harmony from 18 individual musicians playing a variety of instruments. Much of the narrative lies between the rhythmic measurement of the human breath for the clarinets and singers at a slow pace while intertwining with quick pulses of the mallet and string instruments. The intensity of the piece comes from this parallel feeling of slow and fast movement. The piece is structured with a narrative arc whereby the music moves from light to dark and back to light again. 


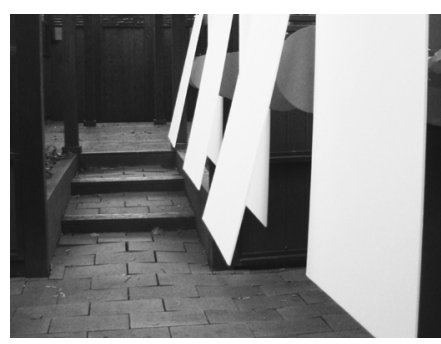

FIGURE 2.2.2E

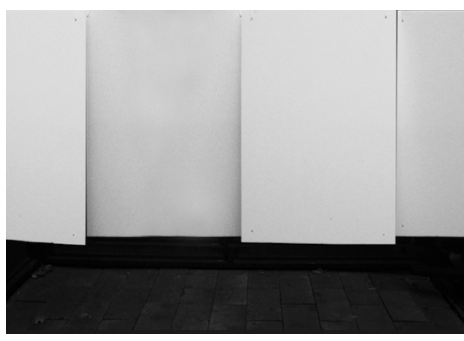

FIGURE 2.2.2F

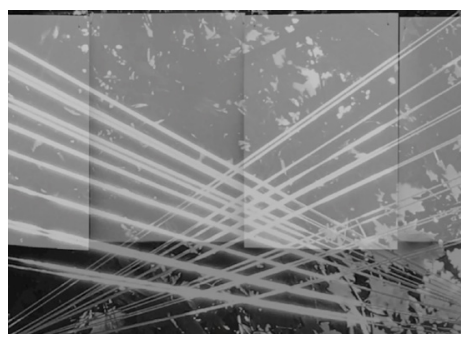

FIGURE 2.2.26

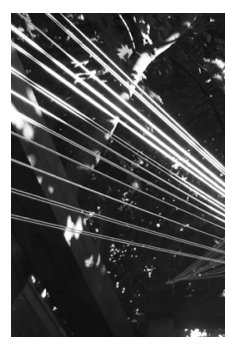

FIGURE 2.2.2H

FIGURES 2.2.2E-2.2.2K Installation Design Music for 18 Musicians

Installation Film: Design Concept

The 1:1 scale installation was realised and documented in film and photography. It explores the introduction section to Music for 18 Musicians called Pulses. The music and sounds can be understood as spatial reflections, as well as the structuring of the chords within each section. ABCDCBA as noted in the initial concept diagram (figure 2.2.2e) is a reflection of itself which repeats the same notes in reverse sequence. The spatial experience designed intends to immerse the visitor into the space to focus in on one instrument at a time. Figures 2.2.2e and 2.2.2f illustrate that the first space focuses on the piano

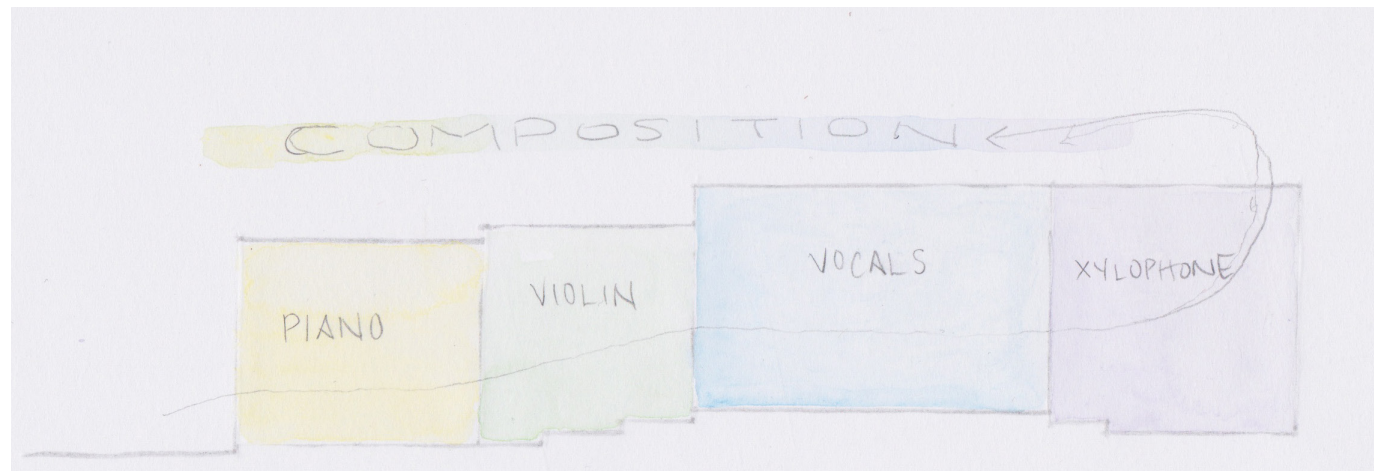

FIGURE 2.2.2L Initial Spatial Narrative Diagram for Music for 18 Musicians Installation

FIGURE 2.2.2M Initial Visual Narrative Diagram for Music for 18 Musicians Installation 


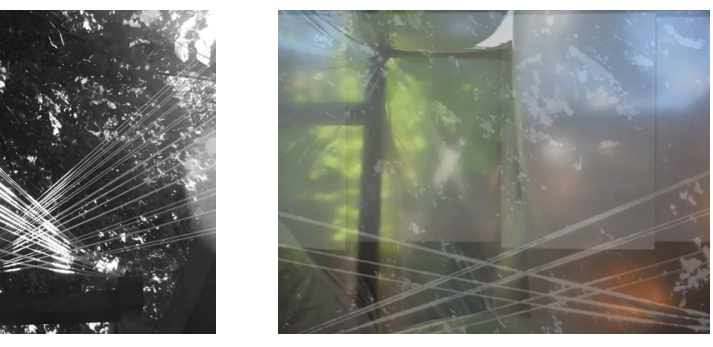

FIGURE 2.2.21

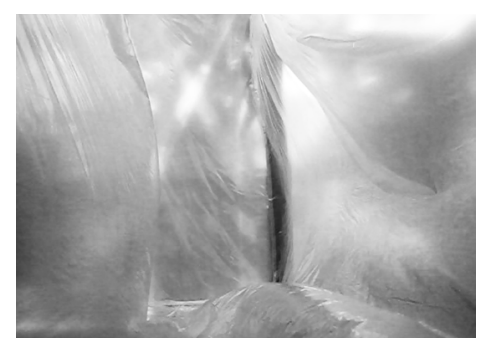

FIGURE 2.2.2J

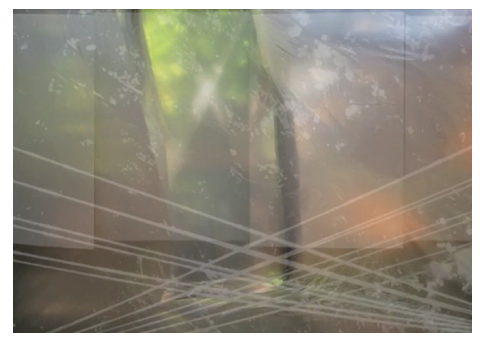

FIGURE 2.2.2K

pulses, the second space on the violin notes, the third space on the soft vocals and the final space provides a view that reflects back on the journey experienced. This reflection illustrates to the visitor that these individual experiences, spaces and sounds are in fact one total composition. After listening to this musical composition one can retain certain rhythms. However, after immersing oneself into this spatial experience, the intention is that visitors will be able to preserve the memory of the rhythms, harmonies, chord structuring and the wide variety of instruments playing simultaneously.

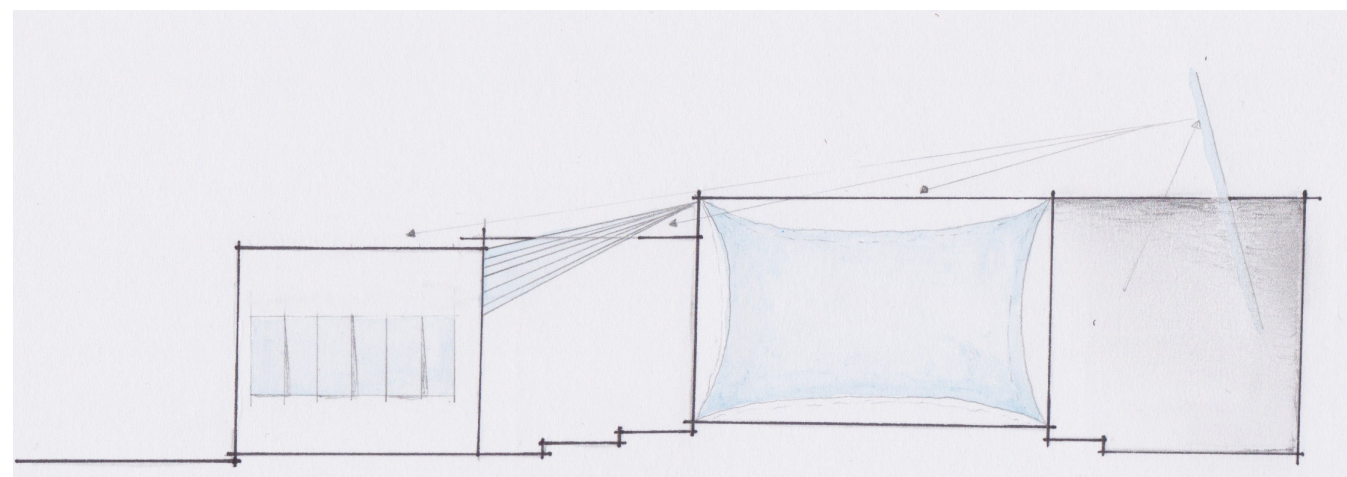

FIGURE 2.2.2N Developed Spatial Narrative Diagram for Music for 18 Musicians Installation

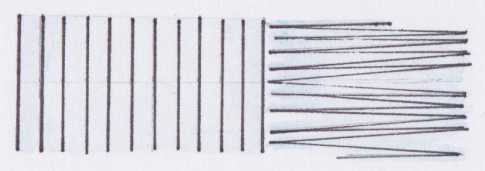

FIGURE 2.2.20 Developed Visual Narrative Diagram for Music for 18 Musicians Installation 



\subsection{0 \\ SIGNIFICANCE OF MOVEMENT IN JOURNEY ARChITECTURE}

Chapter 2 explored the notions of movement in architecture through an iterative process of gathering ideas, precedents and design explorations. The concept of movement was discussed at the beginning of the chapter as a change in position led to explorations in performance. Subsequently the definition of movement as a progress of events in a plot led to explorations in narrative. Performative movement invited the user to interact physically provoking intellectual engagement while narrative movement invited the user to engage intellectually causing physical interaction.

In the essay Narrative Space: The Book of Lies by Paola Zellner, she expresses a need for narrative to be utilised as a conceptual device rather than an idea to be illustrated in architecture (Macleod et al., 2012). This chapter waivered back and forth between actively representing a literal narrative and discovering and unfolding an inherent narrative retrospectively. In order to utilise performance and narrative to establish Journey Architecture, a narrative was engaged in the development of the design in addition to the experience of the design.

Zellner reiterated Tschumi's discussion on our inability to simultaneously perceive or conceive space. She further states that narratives allow for us to be consciously aware during sensory experiences (Macleod et al., 2012). Steven Holl in Questions of Perception quoted Franz Brentano's distinction between outer perception that engages with the senses and inner perception that engages with the mind. Holl asserted that design should "heighten phenomenal experience by simultaneously expressing meaning," (Macleod et al., 2012). The role of architecture is to provide a conceptual structure for our experiences, by designing them to reference and challenge our intellectual and sensorial understanding of the world.

Movement is the device in which we can perceive architecture in time and it allows for a temporal revelation of knowledge and experience. The design explorations in this chapter contain qualities of physical movement rather than representing or suggesting motion. Media such as painting and poetry do not rely on physical motion to achieve movement ("Movement," n.d.-b). In the succeeding chapters, I will explore methods in architecture whereby movement can be achieved emotionally, intellectually, representationally and metaphorically.

In his book The Sense of Space, David Morris referred to Maurice Merleau-Ponty's theory on the relationship between body and world, whereby bodily movement affects the space we are in and, in turn, a space is affected by our bodily movement. Morris stated that "the body moves by growing, grows by moving. Space grows. We grow into space," (Morris, 2004 p. 158). Therefore, the movement explorations in this chapter required many definitions and prescriptions. Moving forward, I required an approach that allowed the architecture to affect the experience of the user as well as the user to affect the experience of the architecture. When individuals shape the experience of architecture, it is enabled by a poetic experience that provokes emotion, thought and imagination. Individual journeys can be achieved when linear narratives and prescribed movement is removed. 



\subsection{0}

\section{EMOTION}

According to Merriam-Webster.com, "emotion" is a conscious mental reaction subjectively experienced as a strong feeling usually directed toward a specific object and typically accompanied by physiological and behavioural changes in the body ("Emotion," n.d.-a). Similar to the previous chapter that discussed movement as a change in time, this chapter will illustrate emotion as a change in time. While movement was defined as a change in position or location, the term "emotion" refers to a change in psychological state accompanied by physiological changes ("Emotion," n.d.-b). The evolution in this thesis project from explorations in movement to explorations in emotion references the etymology of the word "emotion". The word "emotion" stems from the Latin word emovēre - to displace - and from movēre - to move. The history of the term "movement" or the verb "move" (c.1300) meant "to affect with emotion" and it was not until the 14th Century that it meant "to prompt or impel toward some action," ("Move," n.d.). To move someone is still commonly understood as an act of evoking strong feelings of emotion ("Move," n.d.). The linguistic history links together the concepts of movement and emotion explored in this thesis.

Maurice Merleau-Ponty states that objects are "...a system of properties, which present themselves to our various senses and which are united by an act of intellectual synthesis," (Merleau-Ponty,1995, p.88). This intellectual connection between our senses and the physical world is continuously being reinterpreted to develop our understanding of the environment, culture and overall sense of being. Merleau-Ponty states that human emotions are deeply connected to the physical world by senses and memories (Merleau-Ponty, 2005). Memories are moments in an individual's life recorded as frames or images that can be recalled upon when the individual requires them to assist in understanding the world. A collage of these memories forms the basis of who we are as individuals. The image or frame stored from an experience is unique to that of another person who also shared the same experience. Henri Bergson in Matter and Memory (Bergson, 2007) states that memories reside in the intangible realm of the brain, however, they are formed by the tangible realm. He believes that it was the role of the physical world to enable "past experiences in the brain," (Bergson, 2007,p.72).

Memories bridge the gap between architecture that inspires movement and architecture that stimulates emotion. In the book Atlas of Emotion by Giuliana Bruno, the concepts of motion and emotion are united (Bruno, 2007, p.263). Bruno asserts that we understand and perceive the world through our senses and the movement of our bodies. Movement allows us to recognise the world through present engagement and recollection of past experiences. Bruno suggests that movement in space recalls memories that reestablish those emotions or nerve connections within the brain. Architecture can only be experienced by moving through it and that experience recalls past memories and emotions. Israel Rosenfield challenges two main theories about how the brain functions in The Invention of Memory. The first theory posits 
the brain's capacity to permanently store fixed memories that can be recalled later and the second theory, titled "Localization", suggests that certain brain activities occur in specific areas of our brains (Rosenfield, 1988). Rosenfield suggests that Gerald Edelman's theory of Neural Darwinism disproves both of these theories. According to "Neural Darwinism", memories are not fixed but rather in a state of constant renewal and recreation in response to stimuli. A stimulus is linked to an emotion that activates past connections of nerve networks in the brain. These nerve networks are constantly in flux based on the experience. Rosenfield's theory suggests that the mind cannot function with fixed memory storage because the survival of memories depends on the continuous interaction of past experiences with present environment. Only the nerve networks that are constantly being recalled upon are strengthened through repetition and, as a result, survive. For this reason, this theory is called Neural Darwinism. This theory calls upon architecture and the built environment to take advantage of the fluid state of human memory.

In Questions of Perception: Phenomenology in Architecture by Perez-Gomez, Holl and Pallasmaa, the notion of past memories affecting one's experience in architecture is reiterated. They define "Bodily Identification" as a term to reference an individual's encounter with architecture. It infers that the architecture is not complete until the individual views, interprets and experiences the work (PerezGomez, Holl and Pallasmaa, 2003). Merleau-Ponty stated that this body and world relationship allows us to understand a sense of depth, dimensionality, flow, movement, form, colour and tactility (Macleod et al., 2012). Absence and uncertainty provokes user engagement and stimulates the imagination (Macleod et al., 2012). The interaction with the architecture or with another person within the work is referred to as "Projective Identification". The experience of a work of architecture is enhanced, further developed and understood by our projections of past experiences onto it.

Julio Bermudez interpreted the writing of Merleau-Ponty and taught students to design with emotions and experiences. He positioned architecture as the union between perceiver, perceived and co-operative act of unfolding phenomena (Bermudez, 2007). Looking at phenomena and experience (or emotions and actions, in the case of this thesis project) rather than function and form helps to subconsciously promote architecture with experiential qualities. A simple shift in terminology begins to emphasise emotion and action within the space rather than the function. Journey Architecture exercises Bermudez's interpretation of architecture by designing spaces that play with the movement of the perceiver, the emotion that is perceived and the temporal unfolding of these experiences. Journey Architecture seeks to connect the physical space with the change in emotion over time. It is crucial in the design of Journey Architecture to ensure that a space evokes a sensual experience and triggers memories. Journey Architecture layers the emotional experience in present time with the metaphorical experience that triggers past memories. 


\subsection{0 \\ EMOTION OF THE LABYAINTH}

Umberto Eco defines three concepts of the labyrinth in his work, From the Tree to the Labyrinth. The Classic Labyrinth of Cnossos has one path into the centre and one path out; it is unicursal (Eco, 2014, pg.52). The legend presents this labyrinth as a singular path, whereby Theseus unravelled a thread as he entered to reorient himself on his way out. If this classic labyrinth was unfolded there would be one linear path without the confusion of dead ends. The second type, the Mannerist Labyrinth, is a model for trial and error. It presents crossroads with multiple choices of where to circulate, however some of these paths lead to dead ends. Only one path leads through to the end and, therefore, if it were unravelled it would resemble a tree (Eco, 2014, pg.52). The path from start to finish resembles the structure of the tree trunk branching smaller dead-end paths off of it. The third type of labyrinth, defined by Eco, is the Network Labyrinth whereby any point may connect to any other point creating infinite possibilities. This network cannot be unfolded as there is no distinction between interior path and exterior path. There is no centre, exit or dead end because new connections are constantly emerging. Eco challenges the analogy of knowledge as a tree for it presented a closed system of finite branches and proposed knowledge as a labyrinth with infinite pathways, interpretations and meanings (Eco, 2014).

Bernard Tschumi explains the notions of the pyramid and the labyrinth in his book Architecture and Disjunction. He references George Bataille's explanation of the two spaces of conception and perception as the pyramid and the labyrinth. The pyramid represents conscious knowledge and the labyrinth carries no substantive meaning itself other than to provide the unconscious experience and route to the pyramid. The labyrinth contains false turns and twists in hope of reaching the unreachable pyramid of knowledge. The concept of the labyrinth captures the notions of a journey seeking the achievement of knowledge. The labyrinth is a metaphor for sensual and perceived architecture that is unconsciously subjective to memories and prior experiences. The pyramid is the rational conscious that interprets architecture as an abstract object. Architecture has the ability to be both pyramid and labyrinth as it is both conceptual and perceptual, thus the paradox that Tschumi illustrates (Tschumi, 1996, pg.50). Therefore "...the solution of the paradox is the imaginary blending of the architecture rule and the experience of pleasure," (Tschumi, 1996, p.51). The conceived knowledge of the pyramid and the perceived experience of the labyrinth are unified in Journey Architecture as the architecture is conceived with the conscious narrative and experienced with the unconscious sensual experience of the interior. A poetic architecture has the ability to utilise notions of performance and narrative to inform it consciously while allowing the user to interpret it unconsciously through a labyrinthine experience. Journey Architecture seeks to blend the knowledge of the architectural movement with the experience of the architectural emotion; thus allowing the architecture to be both conceived and perceived.

Tschumi states that one may participate in the labyrinth but one can never see it as a whole. One's perception of the labyrinth is fragmented as it reveals parts of itself. Tschumi argues that the labyrinth is a symbol for the history of space, a space unfolds in time and, therefore, a total revelation of the labyrinth is historically impossible. The temporal unfolding of the labyrinth ensures one can never see or experience the whole because that would require transcending time and space. The nature of the labyrinth is that 


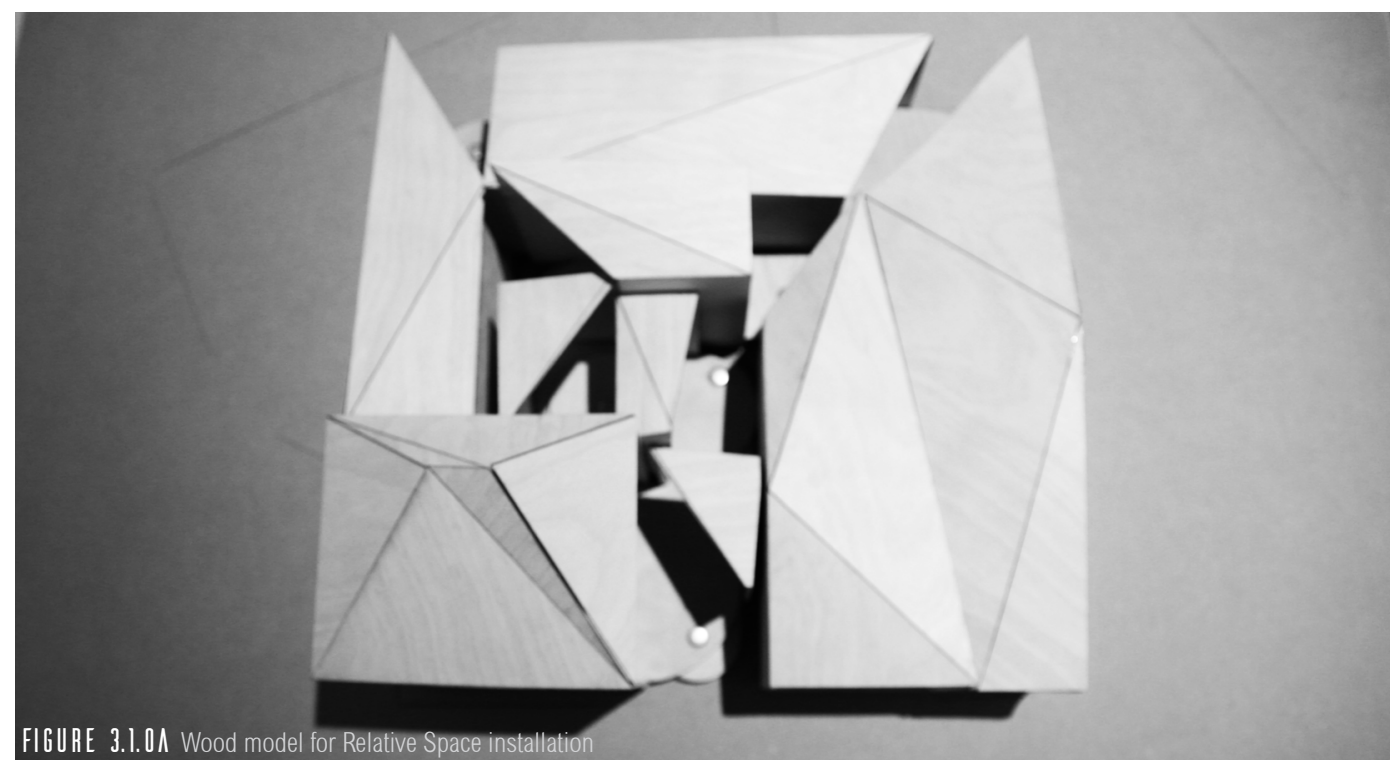

it cannot be dominated; it only entertains dreams of achieving the imaginary pyramid (Tschumi, 1996, p.49). What we do as architects is present people with a space or idea and, through active engagement, individual readings can emerge. There is a dependent relationship between the architect, the user and the architecture; one which reveals the other and brings it to life. The architectural labyrinth is always present but it is not activated until the user discovers it, engages with it and interprets it. Knowledge is gained through experiencing the architecture as one moves and allows it to unfold and reveal itself.

Historically, architecture provided a conceptual structure and order for people based on societal ways of life. However, architecture has disassociated itself from the narrative potentials of ordering the life it intends to facilitate. Architectural theorist Alberto Perez-Gomez states that "modern aesthetics... have failed to grasp the fundamental thrust of architecture as poetic representation of significant human action," (Macleod et al., 2012). Hermann Kern, author of Through the Labyrinths, suggests the inherent metaphor of the inner path of the labyrinth arriving to the central point and the outward path departing from that point represents the path from life to death to rebirth (Kern, 2000). In the essay "Narrative Transformations and the Architectural Artefact" by Stephen Wischer, the labyrinth is presented as a symbol of path and boundary (Macleod et al., 2012). The nature of the labyrinth is constantly in flux, provoking a sense of familiarity and orientation juxtaposed with ambiguity and disorientation. The Myth of Daedalus by Alberto Perez-Gomez depicts the design of the labyrinth that draws influence from culture and context with originality and innovation. This follows a method of Mimesis, whereby the situations are relatable with room for individual interpretation (Macleod et al., 2012). A journey through space can never be absolute. The Relative Space project explored these notions of individual experience based on how one interacted with the installation. This is an important factor to consider when designing Journey Architecture as every occupant and every visitor will experience the space differently. They may draw different associations and understand the world from different perspectives. The moving model allowed each individual to unwind the spaces and create different formations and interior conditions, thereby creating their own individual journey. The ambiguity and familiarity present the labyrinth as a poetic framework for an emotional narrative. 

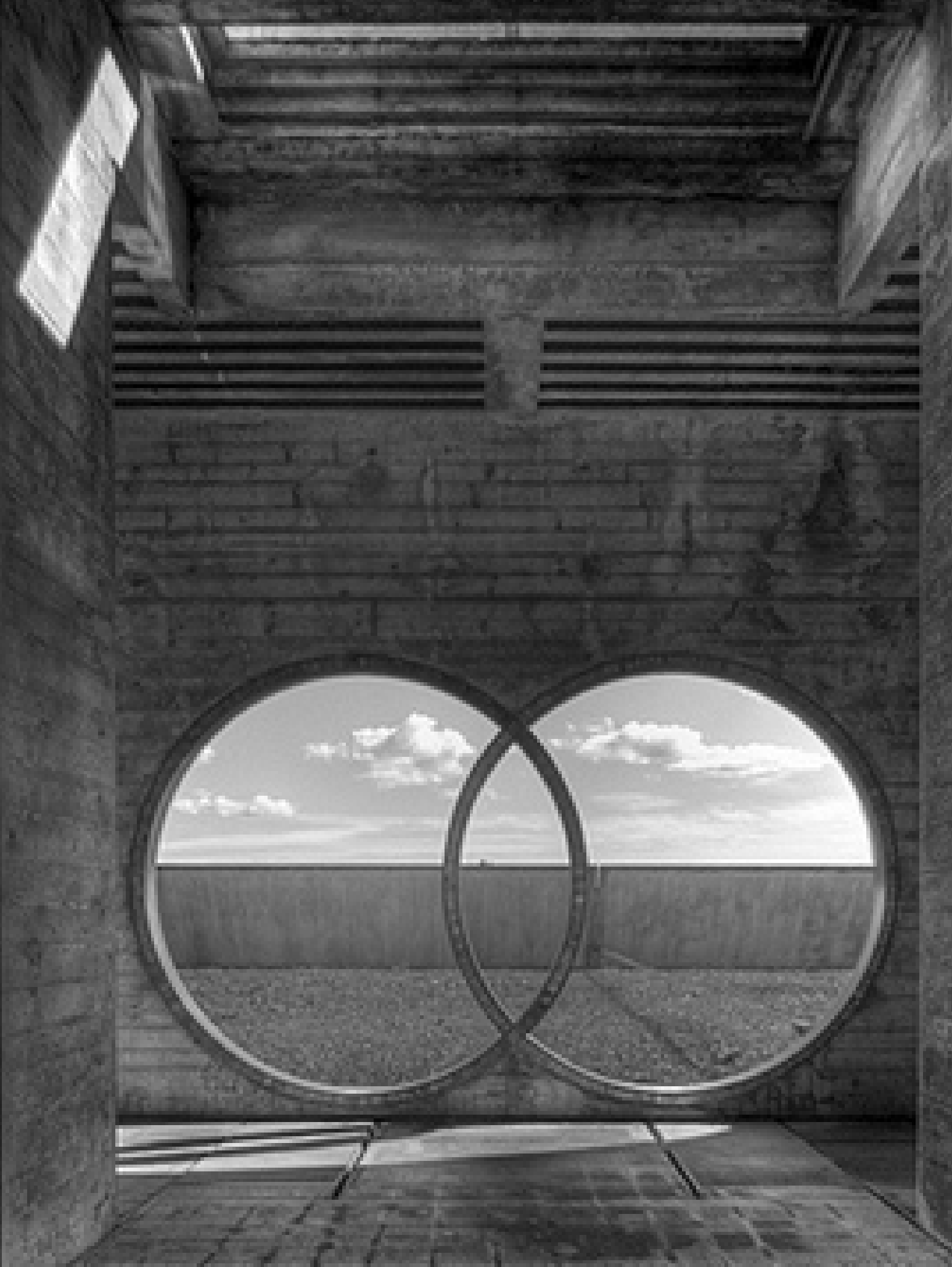

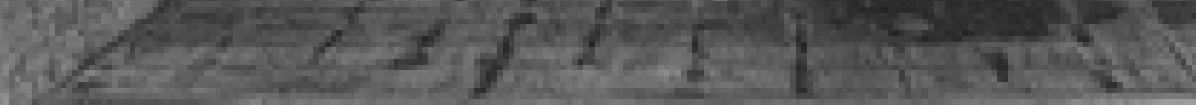




\subsection{1 \\ phecedent on the emOtION OF the Labyanth}

\section{Brion Cemetery by Carlo Scarpa}

Carlo Scarpa's design for the Brion family cemetery in San Vito d'Altivole, Italy showcases the architect's ability to design an emotional narrative architecture with labyrinthine qualities. The design's structure is based on the narrative of following the passage from life to death, however visitors are invited to stray from the path, meander and construct their own experience of the space. Scarpa designed the Brion tomb to act primarily as a public garden for the adjacent cemetery of San Vito designed as a necropolis, the Greek term for city of the dead (Stern, 1994). The public entry appears like a classical civic expression for the town cemetery while the funerary entry defines the beginning of a soulful journey in Catholicism from life to purgatory to heaven. The spatial organisation of the project transitions from spaces of private meditative thought symbolic of life and public social interaction symbolic of society (Stern, 1994). The L-shaped plan guides visitors in a linear sequence following the mortuary rituals of separation, transition and incorporation (Stern, 1994). Movement is orchestrated through the shifting of stairs and the framing of views. The use of heavy concrete, intricate details, water and iconography create a theatrical experience unfolding memories and emotions. Scarpa expresses philosophical ideas through imagery and symbolism broadly understood by collective human experience. His use of light, enclosure, movement and threshold spaces create a sensory experience symbolic of the notions of life and death. The Brion Cemetery exemplifies many qualities of Journey Architecture through its poetic narrative of life to death and the use of ritual to frame the spatial organisation while maintaining a free circulation plan for visitors to meander freely. The design captures the changes from the dweller's human life to afterlife while framing the visitor's atmospheric changes throughout the day.

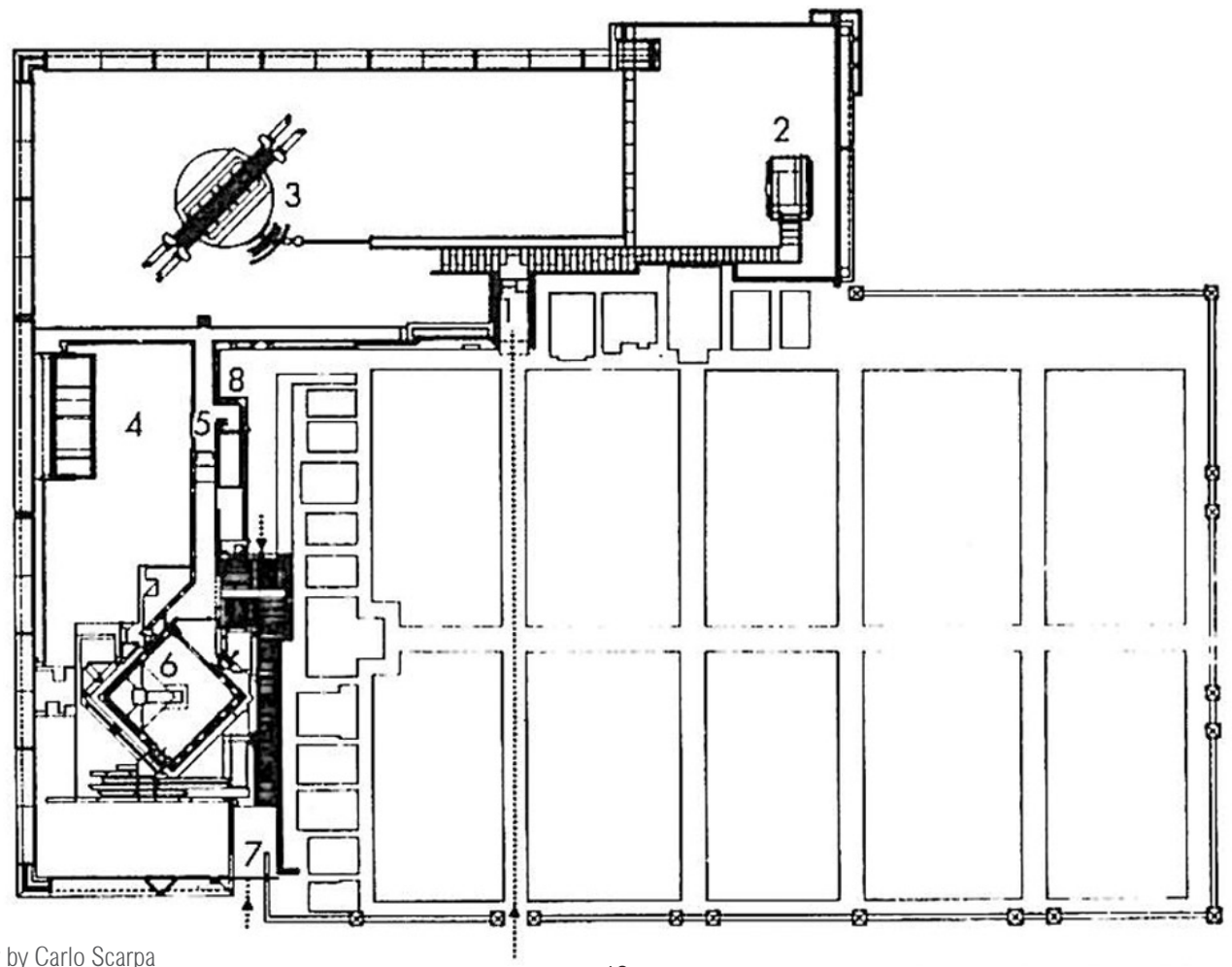

FIGURE 3.1.1B Brion Cemetery by Carlo Scarpa 

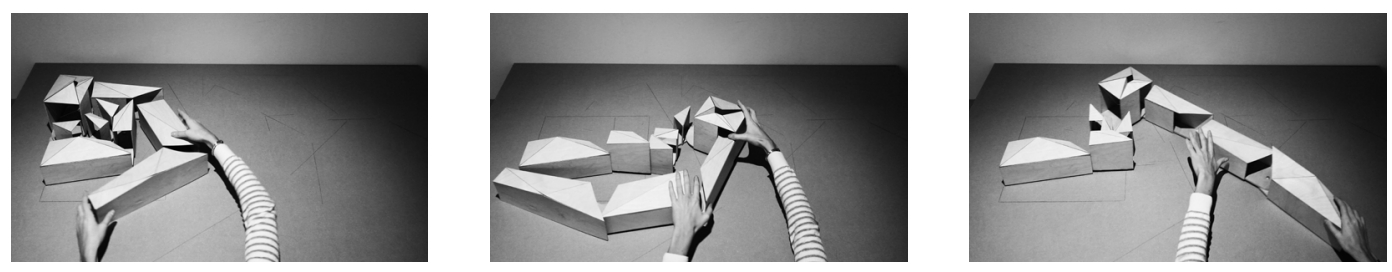

FIGURE 3.1.2A Wood model for Relative Space installation - Journey A
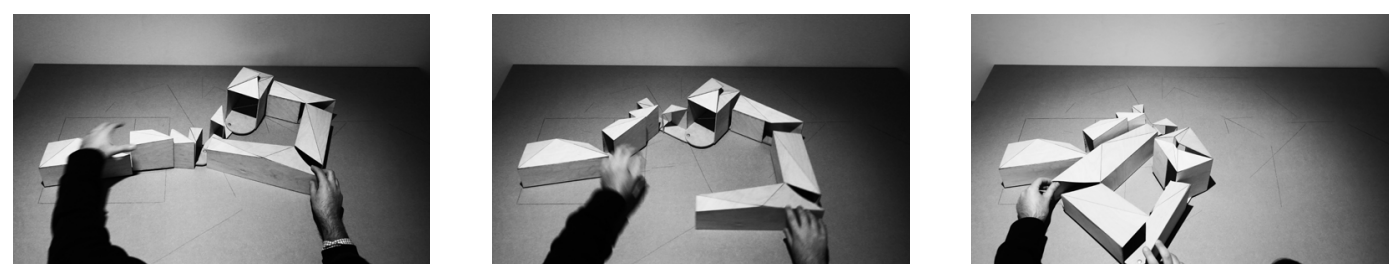

FIGURE 3.1.2B Wood model for Relative Space installation - Journey B
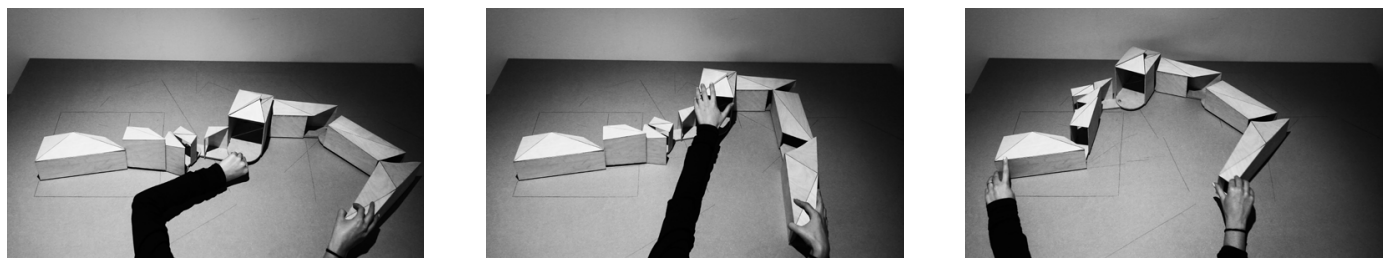

FIGURE 3.I.2C Wood model for Relative Space installation - Journey C

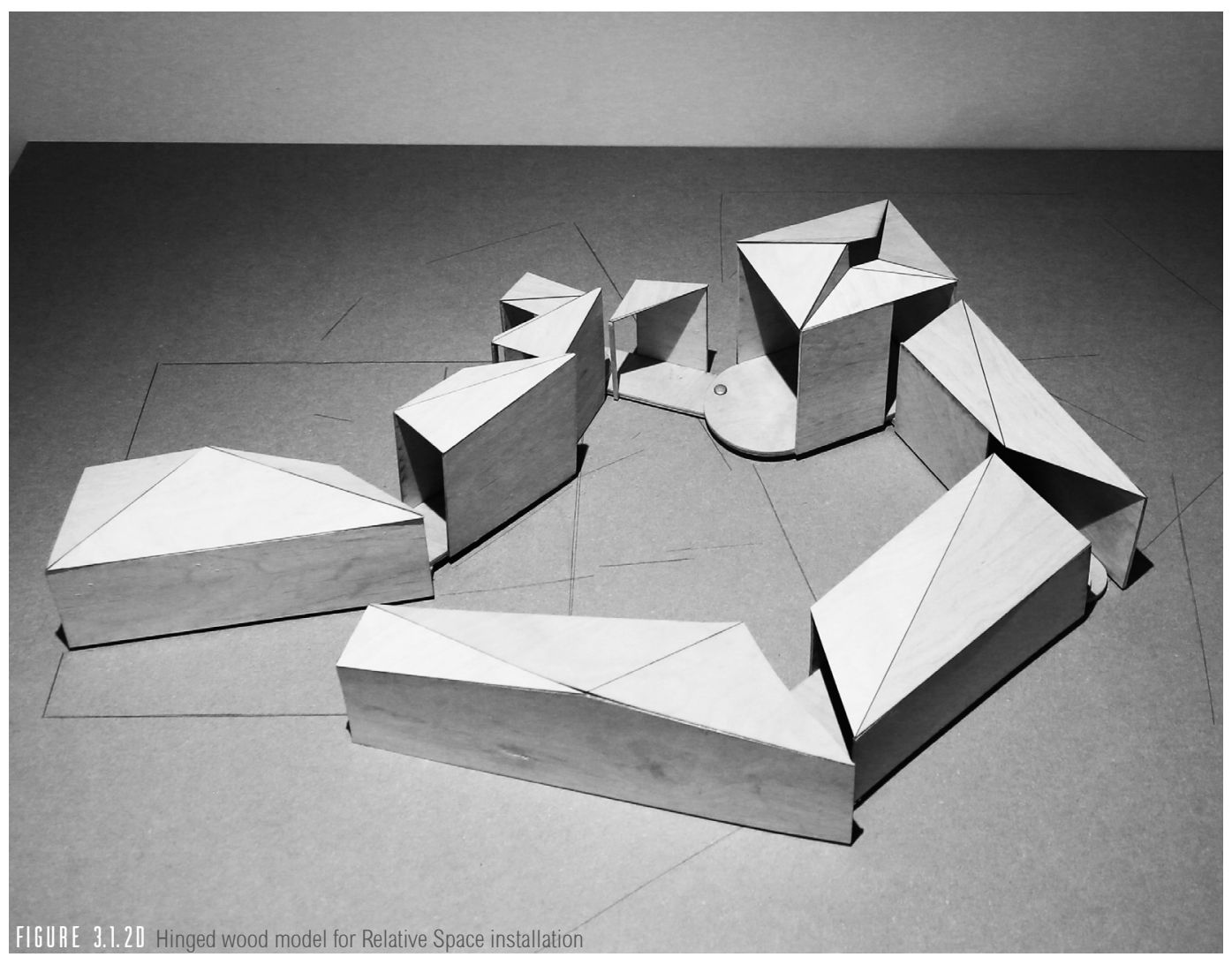




\title{
3.1.2

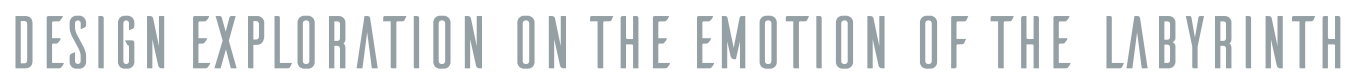

\author{
Relative vs. Absolute
}

A journey through space can never be absolute. This is an important factor to consider when designing Journey Architecture as every occupant and every visitor will experience the space differently. Oftentimes journeys in architecture are designed as a prescribed path that one must follow or have a desired outcome that the designer wishes all visitors to experience. Every experience of space is relative to the person as they arrive with their own memories, prior experiences and knowledge. They may draw different associations and understand the world from different perspectives.

\section{Installation Model}

The installation model entitled Relative Space depicted in figure 3.1.2d, represents the idea that a journey through space is never absolute. The architectural model was designed as an interactive installation in the Ryerson Architecture building for individuals to engage with (figures 3.1.2a, 3.1.2b and 3.1.2c). The Relative Space project explored the notions of individual experience based on how one interacts with the installation. The moving model allowed each individual to unwind the spaces and create different formations and interior conditions. The model is a series of events or spaces that build upon each other to form a whole. The forms are derived from a literary narrative structure that invites the visitor in to a fixed entry and allows the flexibility to move the spaces around and experience them differently. The representation is similar to Freytag's pyramid of dramatic structure. It begins with the exposition or point of arrival, a series of events build towards the point of greatest interest known as the rising action, the climax is the turning point in the narrative, the falling action is where the conflict begins to unravel and the denouement brings the narrative to an end. The form is symbolic to the labyrinth as it deals with ideas of progression through space on a journey and the unravelling of the labyrinth pays homage to the retracing of the string through the path of the labyrinth. The journey through the formal square space can be unravelled into a linear path similar to a three dimensional experiential section. The path is not always linear in form but it is always linear in time. 


$$
\text { ¿1" }
$$




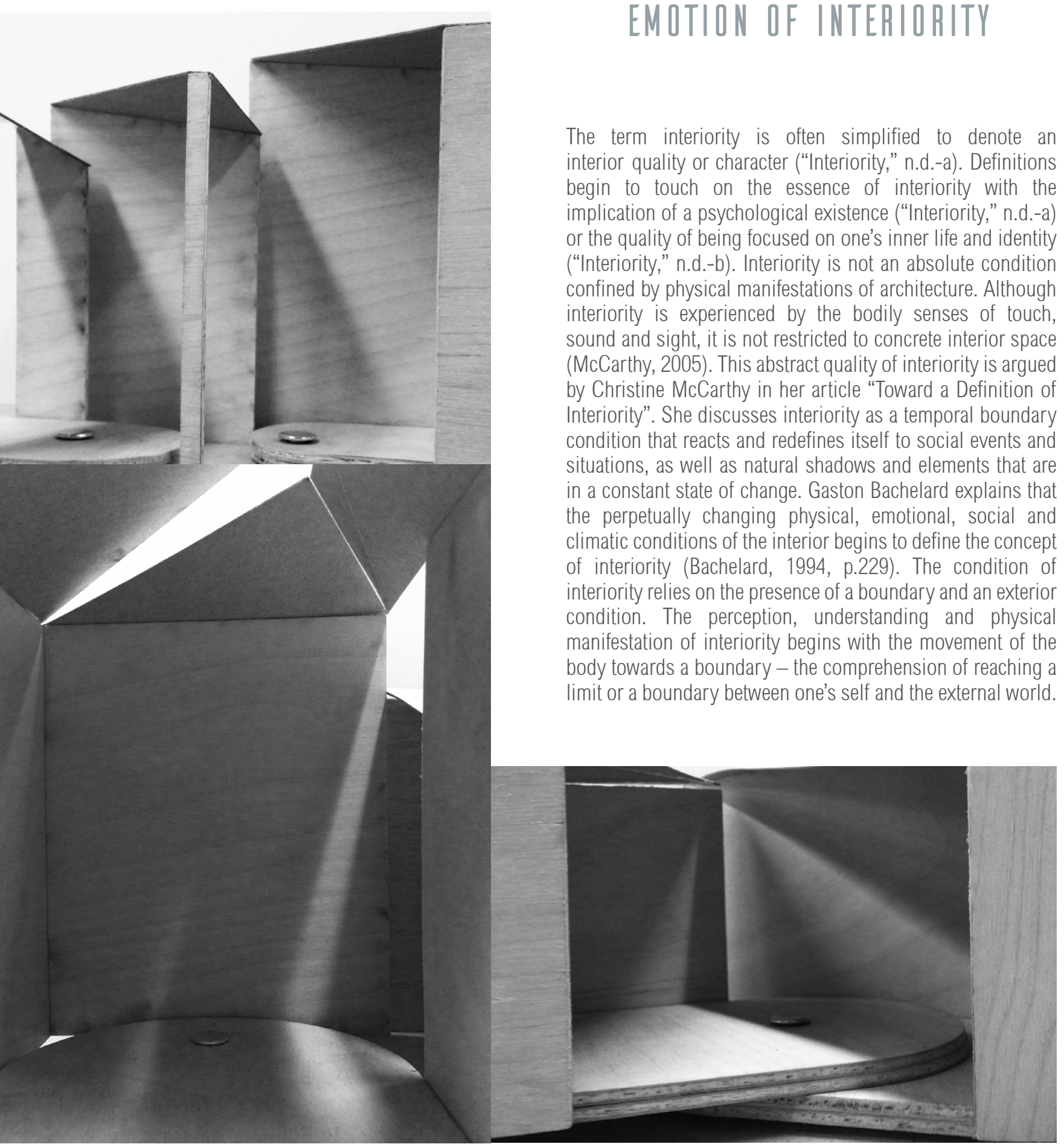

\subsection{0}

\section{EMOTION OF INTERIORITY}

The term interiority is often simplified to denote an interior quality or character ("Interiority," n.d.-a). Definitions begin to touch on the essence of interiority with the implication of a psychological existence ("Interiority," n.d.-a) or the quality of being focused on one's inner life and identity ("Interiority," n.d.-b). Interiority is not an absolute condition confined by physical manifestations of architecture. Although interiority is experienced by the bodily senses of touch, sound and sight, it is not restricted to concrete interior space (McCarthy, 2005). This abstract quality of interiority is argued by Christine McCarthy in her article "Toward a Definition of Interiority". She discusses interiority as a temporal boundary condition that reacts and redefines itself to social events and situations, as well as natural shadows and elements that are in a constant state of change. Gaston Bachelard explains that social and concept an exterior condition. The perception, understanding and physical manifestation of interiority begins with the movement of the body towards a boundary - the comprehension of reaching a limit or a boundary between one's self and the external world. 

Interiority requires an act of entering, the conscious act or thought of crossing a boundary and achieving a sense of enclosure (McCarthy, 2005). Interiority captures movement as the indeterminate boundary acts as a point of transition and marks a change of state. It has a presence and redefines the boundary as a starting point (Heidegger, 1971, p. 154). The concept of interiority is comprised of a level of concave geometry regulating the interactions between outside and inside. A sense of interiority is felt when the boundaries function "to enclose rather than direct space," (Venturi, 1966/1977, p. 70). The space must have boundaries and provide protection, shelter and containment. These levels of control and limitation allow for habitation and differentiate interiority from that which is exterior. The creation of an enclosure enables one to control the conditions of the interior such as daylighting, noise and heat, which cannot be controlled on the exterior. Therefore, McCarthy asserts that interiority is "an explicit manipulation of an environment to achieve and construct a desired space," (McCarthy, 2005). The capability to control the interior space by filtering or obstructing the exterior conditions indicates interiority's relative dependence on the presence of exteriority. The presence of interiority relies on the separation and the controlled penetration of the exterior.

The temporal nature of interiority presents itself as the boundaries, performances and daylighting change. The sun rising and setting casts varying shadows into the enclosure defines the change of a day or season while shedding light on the reality of the contained space. Interiority is produced by familiarity and enclosure as one gains a sense of security (McCarthy, 2005). Predictability ensures known comforts and that inhabitants engage in the space with certain behaviours. The unknown may leave one vulnerable and desiring of interiority. Oftentimes materials utilised on the interior would otherwise be at risk from the exterior and their usage reiterates that the boundary is providing protection and safety.

As previously mentioned, McCarthy asserts that space is constructed by performance and inhabitation as much as spatial boundaries (McCarthy, 2005). Interior space is produced by physically constructed boundaries whereas interiority can be achieved by behaviours, human patterns of activity and emotions. The emotions associated with interiority are subjective to the individual and are in a constant state of change. When an interior space changes from a place of protection to a place of entrapment, the enclosure may begin to feel more extreme and impenetrable. Although interiority houses the emotions of protection and security, they are not consistent or logical to the nature of its physicality. An individual's memory will alter his or her emotional connection with interiority and consequently every experience with interiority will be relative. This was discovered in the design exploration documented in chapter 3.1.2 entitled Relative Space. The installation model was constructed to demonstrate and amplify the changes in the quality of the interiors as each individual engaged with it. The upcoming design exploration in chapter 3.2.2 amplifies the notions of interiority through extreme boundaries of enclosure. The selection of an underground site provides a canvas to focus entirely on the quality of the interior space. This project looked to utilise interiority as the foundation in which to shape the building. The scale and choreography of light in the interior spaces informed the design of the Lower Queen underground theatre complex. The architecture was shaped by the emotional narrative and human activity of the interior space. I would later discover that a true experience of interiority requires the presence of exteriority, which is limited and nearly unattainable underground. 


\subsection{1 \\ PRECEDENT ON THE EMOTION OF INTERIORITY}

The Therme Vals by Peter Zumthor

Peter Zumthor's thermal baths in Graubünden Switzerland exemplify the concept of "A bath born of the mountains just as a hot spring is born of the mountains," (Copans, Part I, 2007). The project focuses on the primary experience of bathing, cleansing and relaxing in water. The sensory experience plays with water surrounding the body at various temperatures and in different settings. The sensory experience of the water is amplified by the physical contact with the stone, the play of light and shadow and the use of colour in conjunction with associated temperatures. Blue tones signify the cold baths while red tones signify the hot baths.

Zumthor wanted to design architecture that was equally physical and geometric as it was a sensuous experience. In Being in Time, Heidegger discussed abstract space and concrete place asserting that abstract experience cannot exist without physical context (Heidegger, 1962). Zumthor blended ephemeral and physical approaches by utilising the body; engaging the senses of sight, touch and feel. He focused on the biological and emotional effects of the concretised architecture of the baths.

Although the layout had to adhere to the standard form of a thermal bath, Zumthor took a labyrinthine approach to this layout. The geometric blocks are joined by glazed joints that generate a light washed wall. The light washed walls are located strategically to guide individuals through the baths without forcing a route (Copans, Part III, 2007). The guiding light approach allows visitors to explore and create their own experience. The light and shadow create movement as people are naturally drawn to light and away from shadow. In addition, the design plays with the speed of movement with cooler water temperatures and locates moments to pause with warmer temperatures. Zumthor utilises these concepts to guide visitors through the baths in a sensory labyrinth, exemplifying unrestricted meandering and individual experience.

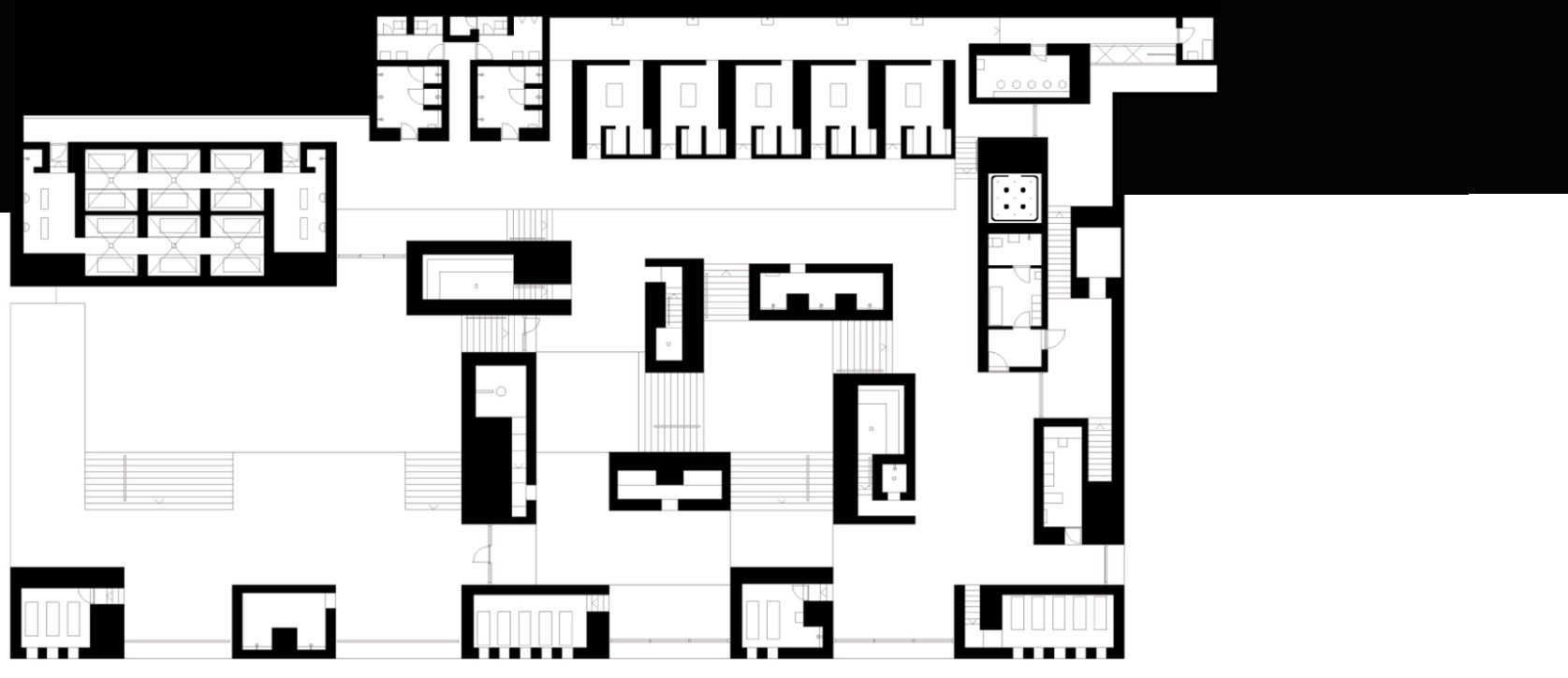




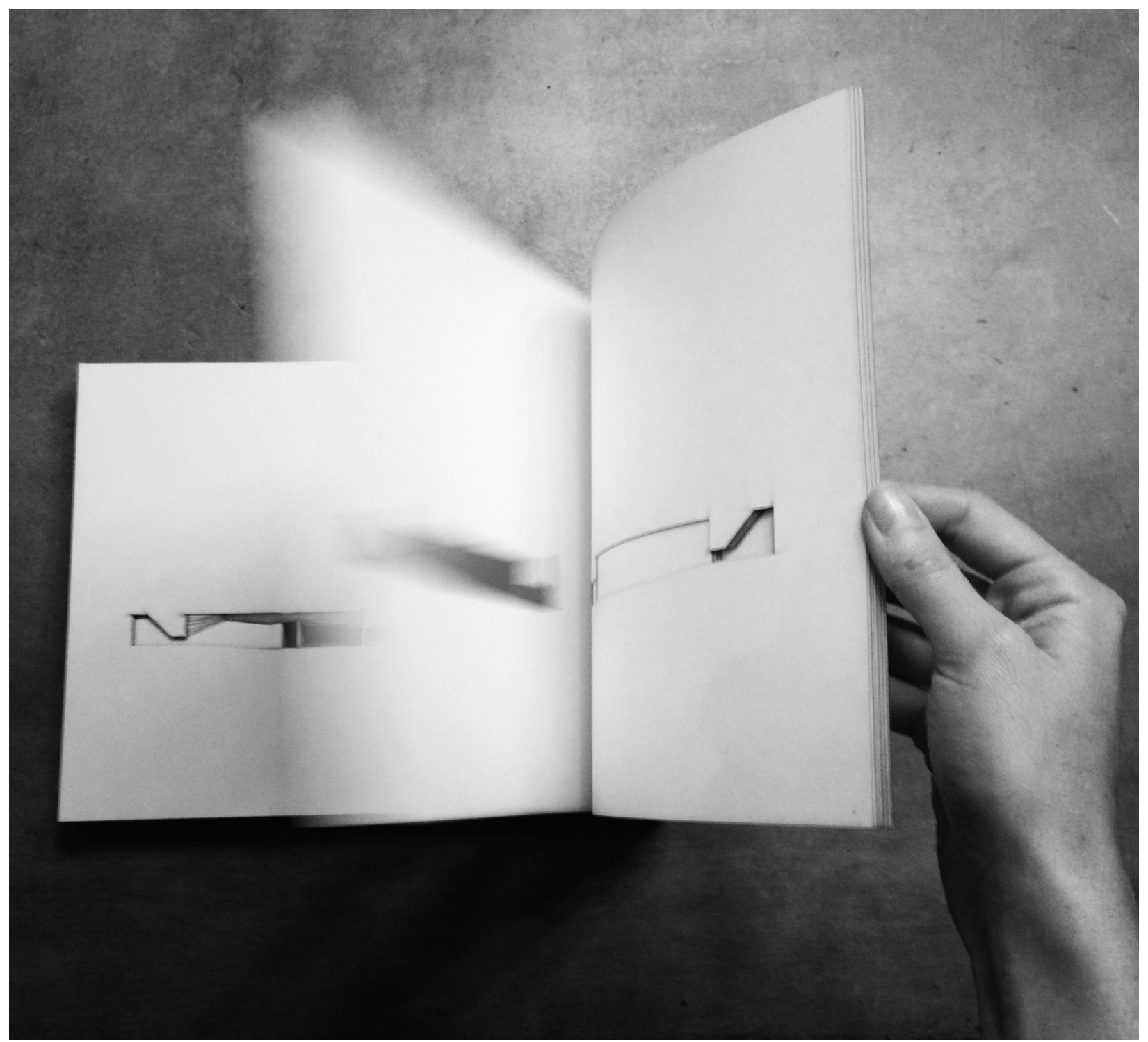

FIGURE 3.2.21 Sectional Paper Book Model for Lower Queen project

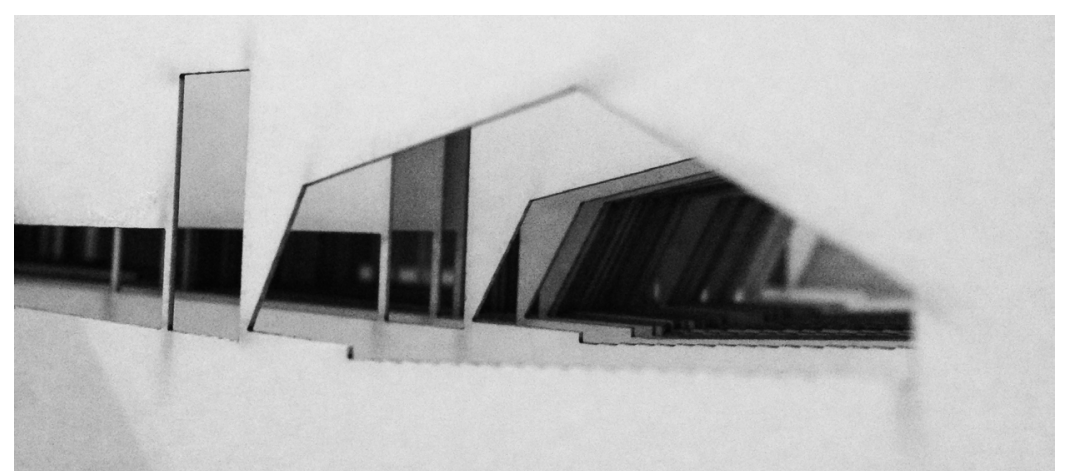

FIGURE 3.2.2B Sectional Paper Book Model for Lower Queen project

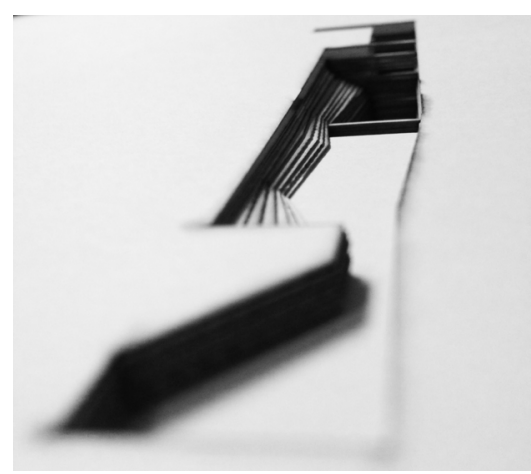

FIGURE 3.2.2C Sectional Paper Book Model 


\subsection{2 \\ DESIGN EXPLORATION ON THE EMOTION OF INTERIORITY}

\section{Designing Underground}

Peter Zumthor states that, "Architecture is not about form, it is about many other things ... the light and the use, and the structure, and the shadow, the smell and so on. I think form is the easiest to control, it can be done at the end". By exploring a design underground, it eliminates the formal expression and focuses the design on being shaped by the light and use. In order to focus on the experience of architecture and remove the object of "nature", I chose to submerge the experience underground so the total form could not be perceived as an object and the experience would resonate in the meaning and emotion created along the architectural journey. The object of the building cannot be removed from architecture just as the body cannot be removed from the art of dance. When American modern dancer Martha Graham draped her body in fabric for a dance performance, the art became about the movement. The exploration illustrated in figure 3.2.2d searches for a method to design architecture around the emotion of the interiority rather than the form.

\section{Design Exploration}

At 46 feet beneath the Queen Street TTC subway station lays a piece of Toronto's past. Below this commuter transit hub is a vacant space of what could have been the station for the east-west streetcar-subway line. This line was never realised and the underground station was abandoned in favour of building a subway line across Bloor Street. The station was put in place to bring passengers up to the Simpson's department store to compete with the neighbouring Eaton's department store. Although these retailers are no longer in existence, Lower Queen is currently surrounded on three sides by historic sites. To the Southwest was the historic Simpson's department store building (now the Hudson's Bay Store), to the Northwest was the Jamieson Building (now expanded into the Eaton's Centre) and to the Northeast was the former 1912 bank building where the façade still remains enclosing the Bank of Montreal and offices. This site had the potential to maintain a critical piece of the neighbourhood's collective memory and would allow expansion and redesign to an unused space while focusing on the experience through it. The site offered options of varying distances from the exterior and the ability to submerge the building in the city provided opportunities to connect and disconnect from the city. There was an opportunity to take visitors from the

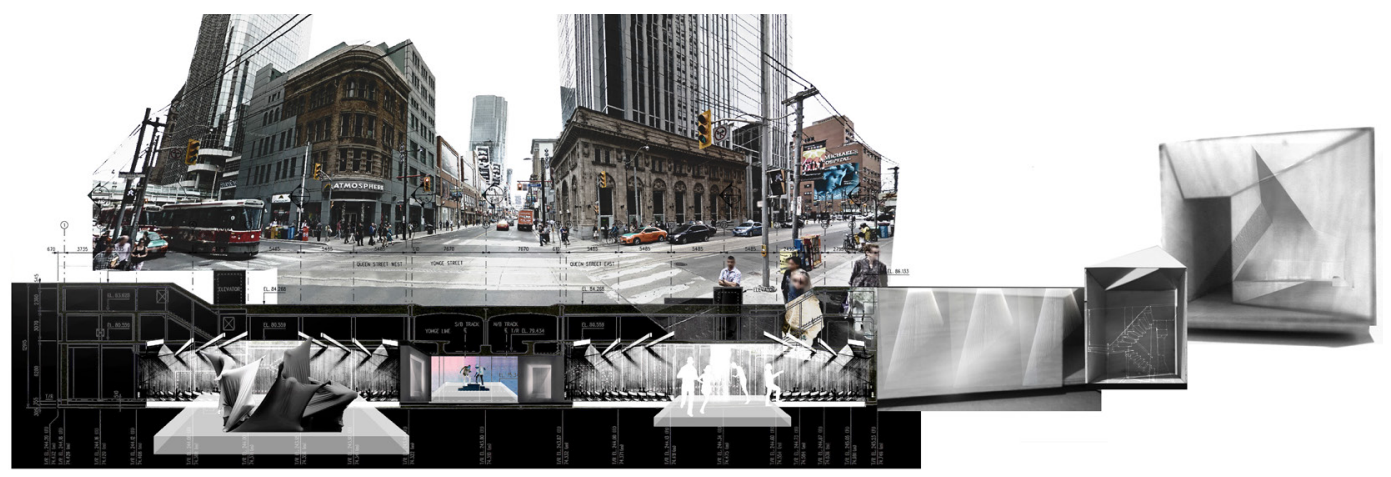

FIGURE 3.2.2D Experiential Section Drawing for Lower Queen project 


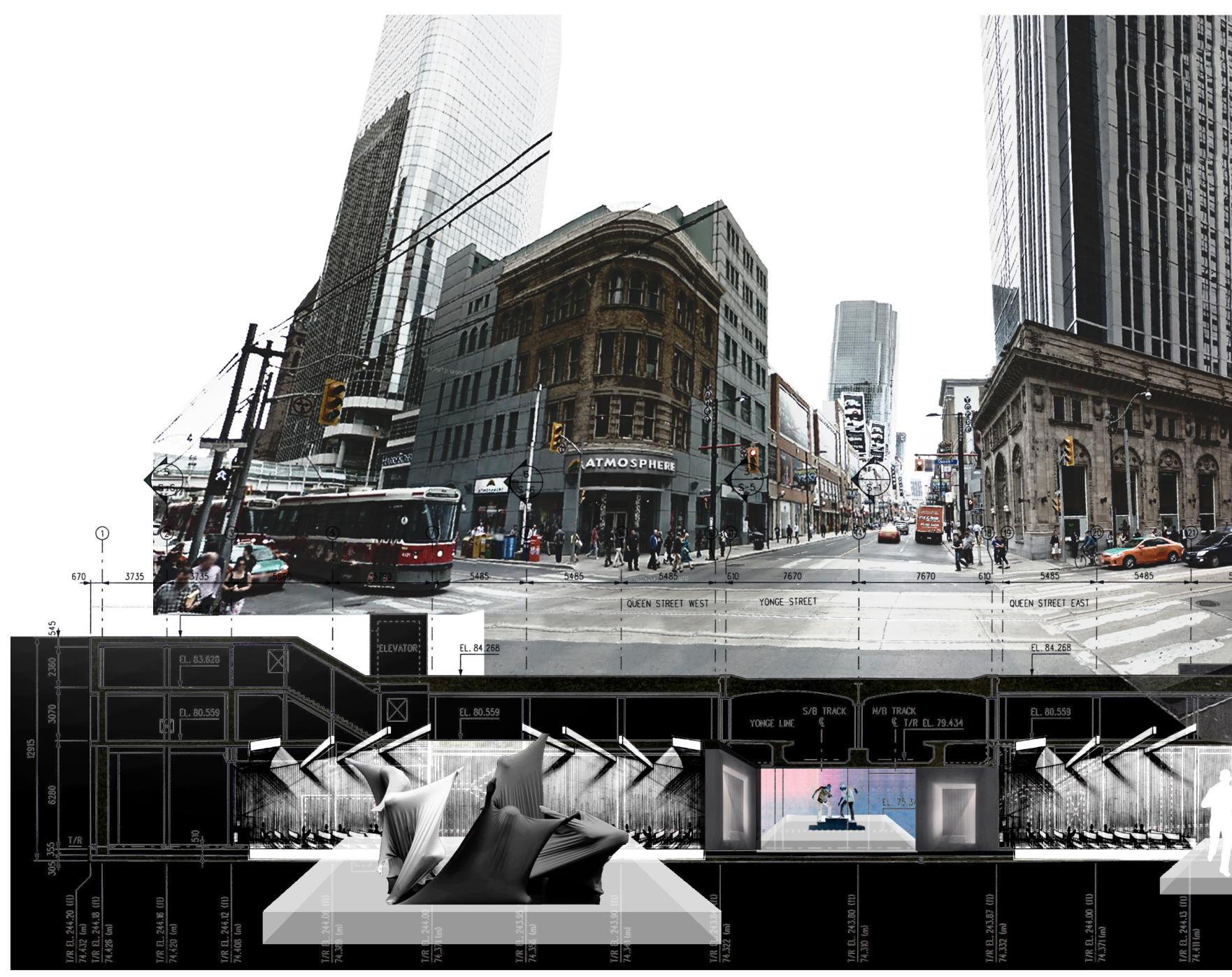

FIGURE 3.2.2D Experiential Section Drawing for Lower Queen project 
Samantha Martin-McAuliffe and Nathalie Weadick's essay titled "The Thick Present" states:

"like a poem or symphony, a building can yield a new interpretation each time we encounter or experience it. This is so even if we revisit the site at the same time of day or the same time of year. Our judgments of it change. We bring different emotions, memories and revelations to a place each time we explore it anew. The architecture changes, too. It ages, acquires a patina, accumulates furnishings and people. As such, the values and meanings expressed by the physicality of architecture are themselves likely to shift and change," (Macleod et al., 2012, p.279). 


\subsection{0 \\ SIGNIFICANCE OF EMOTION IN JOURNEY ARCHITECTURE}

This chapter explores the concept of emotion in architecture through theory and design iteration. Architecture has the capability to guide occupant emotion by creating a spatial experience that affects where they move, how they move and what they remember. The emotion felt within a space impacts the occupant's perception of the space and vice versa. The meander of the labyrinth and the atmosphere of the interiors can serve to trigger certain emotions. Through lighting, materiality and scale of space the emotional narrative can connect with the occupants both physically and intellectually. When discussing emotion in architecture one cannot ignore the inherent poetics involved in creating that feeling. Poetry and architecture are as equally concerned with the literal and metaphorical as the sensual and experiential (Antoniades, 1992, p.111). Metaphor, juxtaposition, rhythm, tone and personification are just a few examples of poetic devices that may drive architectural design. This thesis seeks to have architecture directly take on a personality by exploring the emotional narrative of one man's life. When architecture takes on a personality it triggers an emotional response because it connects with the user. The poetic use of rhythm and tone similarly elicit emotions as they activate relative memories and past experiences. Our understanding of the world is composed of present experience with past recollection. For architecture to create meaning, it must tap into the memories by presenting itself as something implicitly relatable but explicitly original. This allows for the user to determine their own meaning and interpretation relative to their past experiences.

The physical world affords sensory experiences and movement of the body, both of which recall memories allowing us to relive those emotions. Architecture that encourages individual experiences for the senses and the movement of the body can therefore provide an emotional experience for the user or inhabitant. This chapter explores the concept of the labyrinth as a poetic means to encourage distinct bodily movement and the concept of interiority to arouse the senses. While the labyrinth provides an open-ended conceptual structure for interpretation and experience, the concept of interiority limits the experience to the confines of a conceptual boundary. Interiority maps the complexities of habitation emphasising the life in which it encloses (McCarthy, 2005).

The concept of the pyramid and the labyrinth illustrate the limitations of the journey. In order to experience the labyrinth one can never achieve the pyramid. It is rather a mere symbol of the end of the labyrinth. To achieve the pyramid one would need to transcend space and time because one can never see or know the labyrinth in its entirety. Just as the labyrinth requires us to experience it in real time and space so does the journey of life. If one reaches the end of their journey in life, they cannot simultaneously know they have reached the end for this would also require transcending time and space. One can only embark on their journey of life knowing what lies before them in the present and can experience it based on their understanding of the past. 



\section{CHAPTER 4 \\ DWELL ING}

: a building or place of shelter to live in

: to be motionless for a certain interval

: to live or continue in a given condition or state 


\subsection{0 \\ DWELLING}

\section{Defining Dwelling}

A dwelling can be defined as a building or place of shelter to live in ("Dwelling," n.d.). This thesis has explored the ideas of change in time pertaining to Journey Architecture. What does it mean to dwell? To dwell in fact contrasts the journey as it means to live or continue in a given condition or state ("Dwelling," n.d.). The act of dwelling is in fact motionless ("Dwelling," n.d.) but this thesis will utilise it as a device to establish motion. The movement here will encompass physical movement and development of emotion. These changes are what shape the lives of the inhabitants and, far too often, the architecture does not reflect that. Consequently, the final design project for this thesis developed into that of a dwelling. Utilising an emotional journey, this project will seek to emphasise the identity of the dweller instead of being self-referential architecture. In contrast with interiority, which does not define interior space but rather the psychological feeling of enclosure, the dwelling does not define the psychological notion of a home but instead the physical shelter of a house.

\section{This is no house, who touched this touches a life}

- Shawna Seligman 


\section{Dwelling vs. Home}

The difference of dwelling and home is the individualisation and personalisation of a dwelling reflecting patterns and stages of life, memories and emotional experiences. Gaston Bachelard in his book Poetics of Space illustrates the oneiric house, the house of the mind and dreams (Bachelard, 1994). This archetypal house requires an attic as a universal symbol of place to store and revisit enjoyable memories as well as a mandatory cellar as a universal symbol for a hiding place to for unwanted memories (Bachelard, 1994). Bachelard presents the need for dwellings to house the mind bringing it closer to life than architectural artefact. This final thesis project intends to bring forth the concepts of the oneiric house, interpreted from the writing of Bachelard, which bridge the gap between dwelling and home.

Juhani Pallasmaa wrote in depth about the notions of personal life in a house forming the basis of a home.

"Home is a collection and concretisation of personal images of protection and intimacy that help us recognise and remember who we are.... Home is a staging of personal memory. It functions as a two-way mediator - personal space expresses the personality to the outside world, but, equally important, it strengthens the dweller's self-image and concretises his world order," (Pallasmaa, 1994).

Pallasmaa articulates that the home is not an object but rather a structure of integrated memories, emotions and time. In Pallasmaa's essay "The Geometry of Feeling", he discusses the ability for inhabited space to have an emotional impact through action and interaction not simply visual imagery and symbolisation (Pallasmaa, 1996b). Pallasmaa states that the foundation for emotional experiences in architecture is based in actions, not objects. He states that "The approaching of the house, not the facade, the act of entering, not the door; the act of looking out of the window, not the window itself; or the act of gathering around rather than the hearth or the table as such seem to trigger our strongest emotions," (Pallasmaa, 1996b). The following design project developed in response to the writing of Pallasmaa by shaping the dwelling as a journey of personal memories and emotions formed by the actions of dwelling, entering, gathering, resting, nourishing, contemplating and cleansing. 


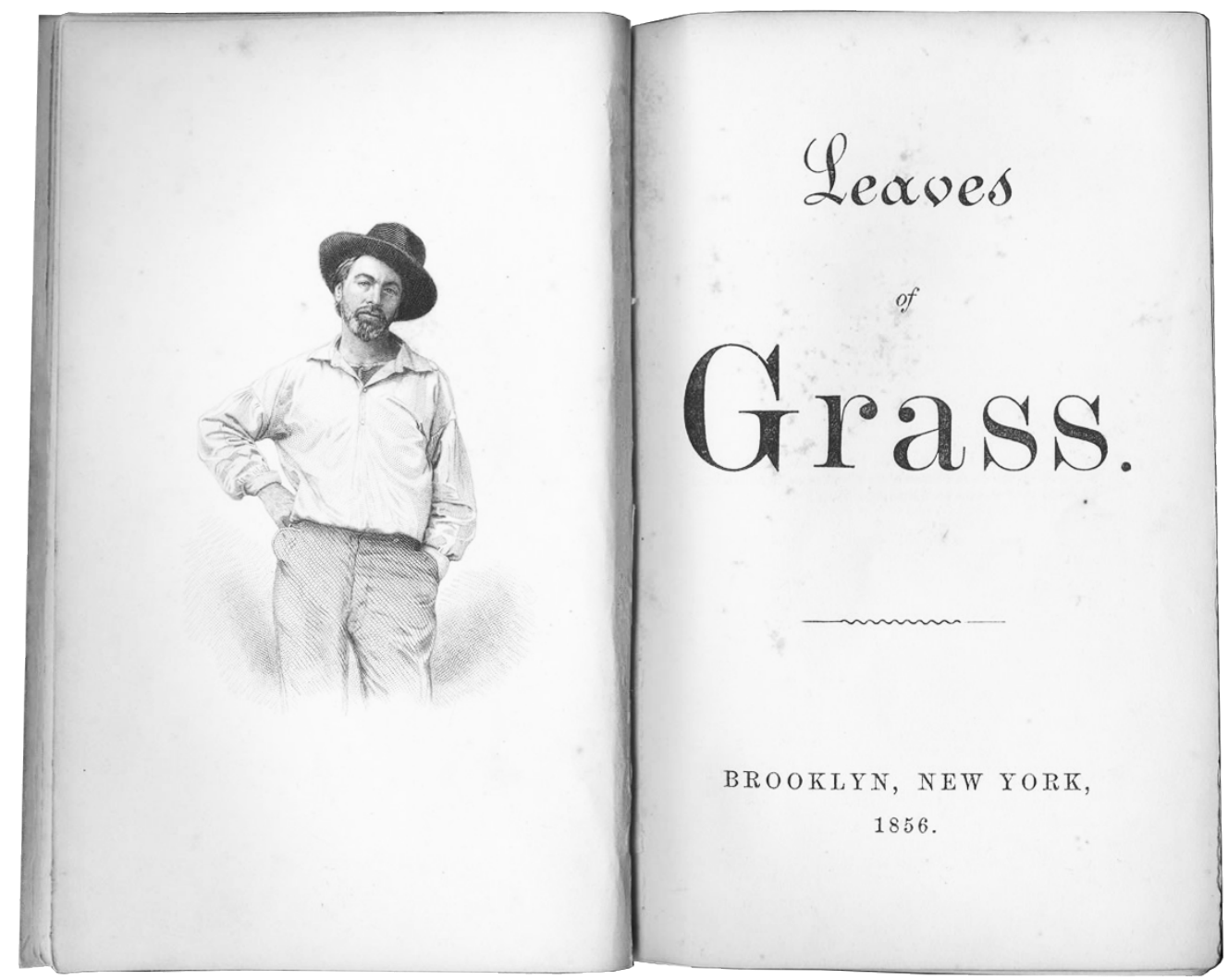

FIGURE 4.1.01 Leaves of Grass 1856 Edition Frontispiece and Title Page

This is no book, who touched this touches a man

- Walt Whitman 


\subsection{0 \\ WALT WHITMAN AS A REFERENCE POINT}

Leaves of Grass

Leaves of Grass, a collection of poems written by Walt Whitman, was republished six times throughout his lifetime. Each major edition of Leaves of Grass can be interpreted by the individual to understand Walt Whitman's emotion at that time in his life. This major work is a self-portrait of a man captured in six moments of his life. Walt personified his poetry as a "living form" and a human personality, saying "Who touches this [book] touches a man," (LeMaster \& Kummings, 2011, p.372). His personification of his poetry as an autobiography takes the reader on a journey through his life, conveying his emotional development and growth over time. Through the poet's use of specific devices such as connotation, sound and rhythm he is able to express emotion within the work. As one interprets each consecutive edition, the tone and rhythm change, revealing emotional growth and development in his life journey.

\section{From Poetry to Architecture}

My thesis project utilises Walt Whitman as presented in Leaves of Grass as a device to explore the creation of a structure and order for emotional development over time. The dwelling has a long temporal understanding that relates to a lifespan - from birth, to death and maturation in between. The creation of spaces and threshold spaces allow one to transition from one emotion to another in time as one moves through the dwelling. Atmospherically and metaphorically, the dwelling conveys the emotions that I interpreted from Whitman's poetry. I utilise various literary critics and the Routledge Encyclopedia of Walt Whitman to examine each edition and determine what Whitman's emotions were. From this I was able to construct an interpretation of the emotional journey through the work and design an architecture of this journey.

The human experience and personal journey is more complex than denotative statements can describe and, thus, poets search for methods to utilise language and poetic devices to capture the complexity of the experience. Similarly, architecture can utilise spatial devices and design principles to present the journey for individual interpretation. This dwelling is not a house but a device utilised to establish a Journey Architecture. It utilises architecture to frame a temporal moment. The temporal moments of Whitman's journey are signified by each edition of Leaves of Grass. This thesis project looks to temporalise architecture by spatialising Walt Whitman. The frame of time is a lifespan and therefore journey is the device to temporalise space. Walt Whitman acted as a point of reference to explore the multi-layered journey in an architectural realm. One can begin to understand the notions of journey in time and space through the creation of devices that create an event and emotion through slow revelation and subjective interpretability. 


\subsection{0 \\ DWELLING OF WALT WHITMAN}

As German philosopher Martin Heidegger said in Being and Time, "it can be inferred that the concern of architecture is to construct things that will allow dwelling, that is, that will allow for the relationship of person as a part of nature to become "unfolded" (Heidegger, 1962)." The design for a Dwelling of Walt Whitman utilised the journey of his life as a device to explore a journey in architecture. His life's journey is captured in his six editions of the major work Leaves of Grass. Each edition impresses a different emotion, rhythm and image upon the reader that I interpreted and used to shape the design.

Professor Clare Cooper Marcus, authority on the social and psychological implications of design, states that the "house interior and its contents mirror our inner psychological self," (Marcus, 1995) and the "'home-self' relationship is a life long journey," (Marcus, 1995). Gaston Bachelard is also interested in the significance of dwelling in the Poetics of Space. He writes, "Life begins well, it begins enclosed, protected, all warm in the bosom of the house," (Bachelard, 1969). Furthermore, "The house we were born in is physically inscribed in us. It is a group of organic habits..." (Bachelard, 1969). Perhaps most interestingly, Bachelard believes that "room and house are psychological diagrams that guide writers and poets in their analysis of intimacy," (Bachelard, 1969, p.38).

The six editions of Leaves of Grass are composed of imagery, structuring, cadence and a slow unfolding of the unexpected. Although the poetry alludes to the emotions and events of Whitman's life, it is open to interpretation. The general consensus posits that the primary intention of Leaves of Grass was to put the inspiring life of a poet into a sequence of poems. Each edition frames a moment in time during whereby Whitman experienced, felt and understood his life and the world around him in a new light. His journey invites interpretation and individual understanding of the development of poetry over a lifespan.

The dwelling of Walt Whitman is situated by the peak of Jayne's Hill in West Hills Suffolk County, New York. This place was a favourite of Walt Whitman as it is nearby his childhood home. Three winding trails lead up to the peak of the hill where a memorial rock to Whitman resides. The trails allow visitors to walk in the footsteps of Walt Whitman and see some of the views that he writes about in his poetry. This site was chosen as the dwelling not for Whitman but rather of him, and thus placing it by his memorial was desirable.

Walt Whitman's poems do not describe the event; they are the event. "This is no book, who touches this touches a man," (Whitman, 1855) and so too the architecture should not illustrate emotion but rather be the emotion. From the first edition, Whitman develops an overall presence, which leads to feeling confident in the second edition. The third edition sheds light on Whitman's intimacy and human relationships, which contrasts with the fourth edition that is heavily influenced by politics and national affairs leaving him in a state of grief. The hardship later on develops into pride and a patriotic outlook on life. In the final edition, Whitman is left feeling spiritual and aware of the end of his life. 


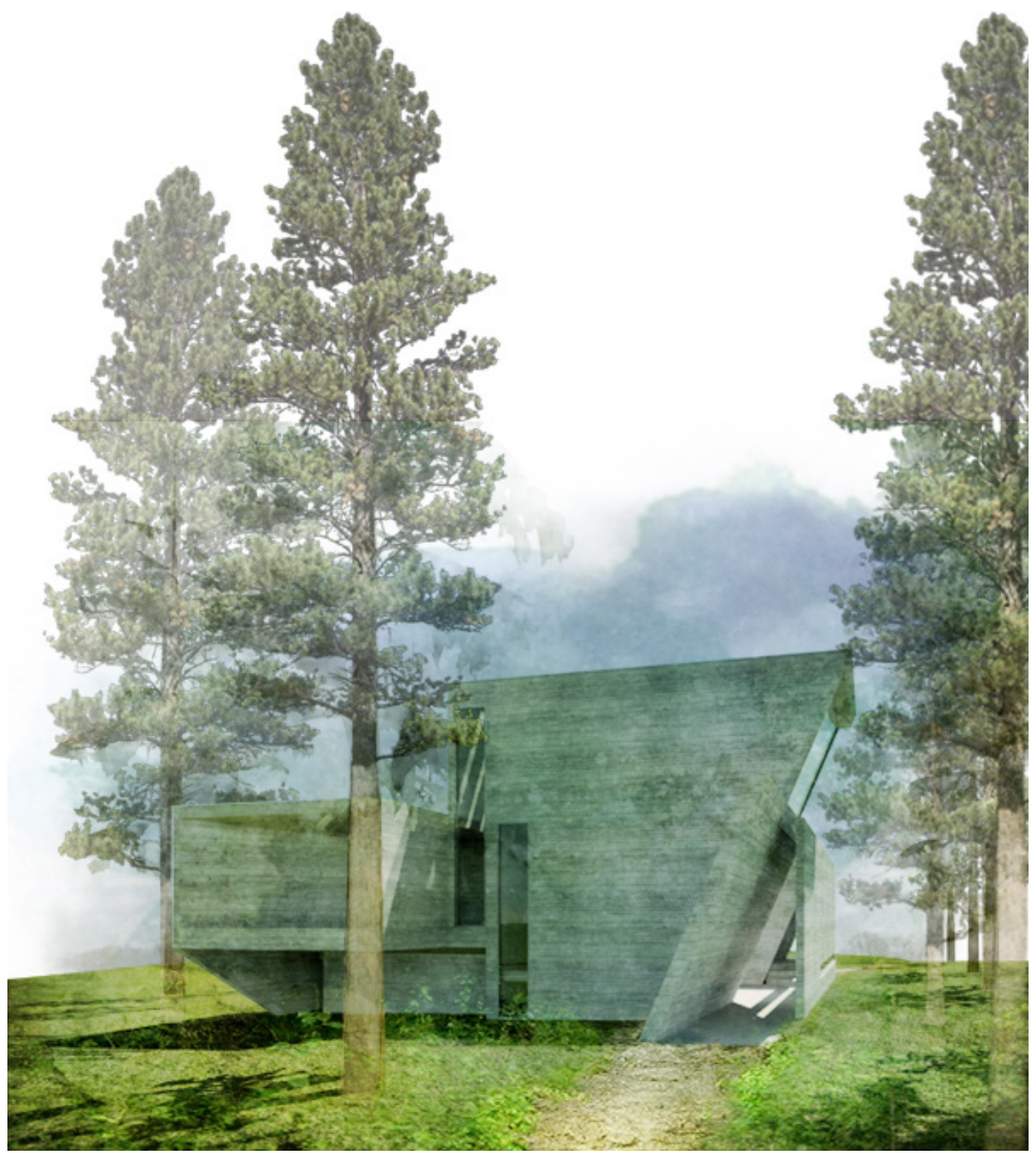

FIGURE 4.2.0^ North West Exterior Rendering of the Dwelling of Walt Whitman project

In each instance, I explore a space within the dwelling that best expresses and evokes the themes and moods of that edition. Through a study of the editions and habitual activities of the dwelling I arrived at a series of abstract spaces that evoked these major ideas. These abstract notions of space lacked materiality, site and connectivity between the spaces and therefore needed to be further developed. I established the individual spaces into an architectural project much like the individual editions of Leaves of Grass into a body of work that could carry the emotional journey of Walt Whitman's life. 


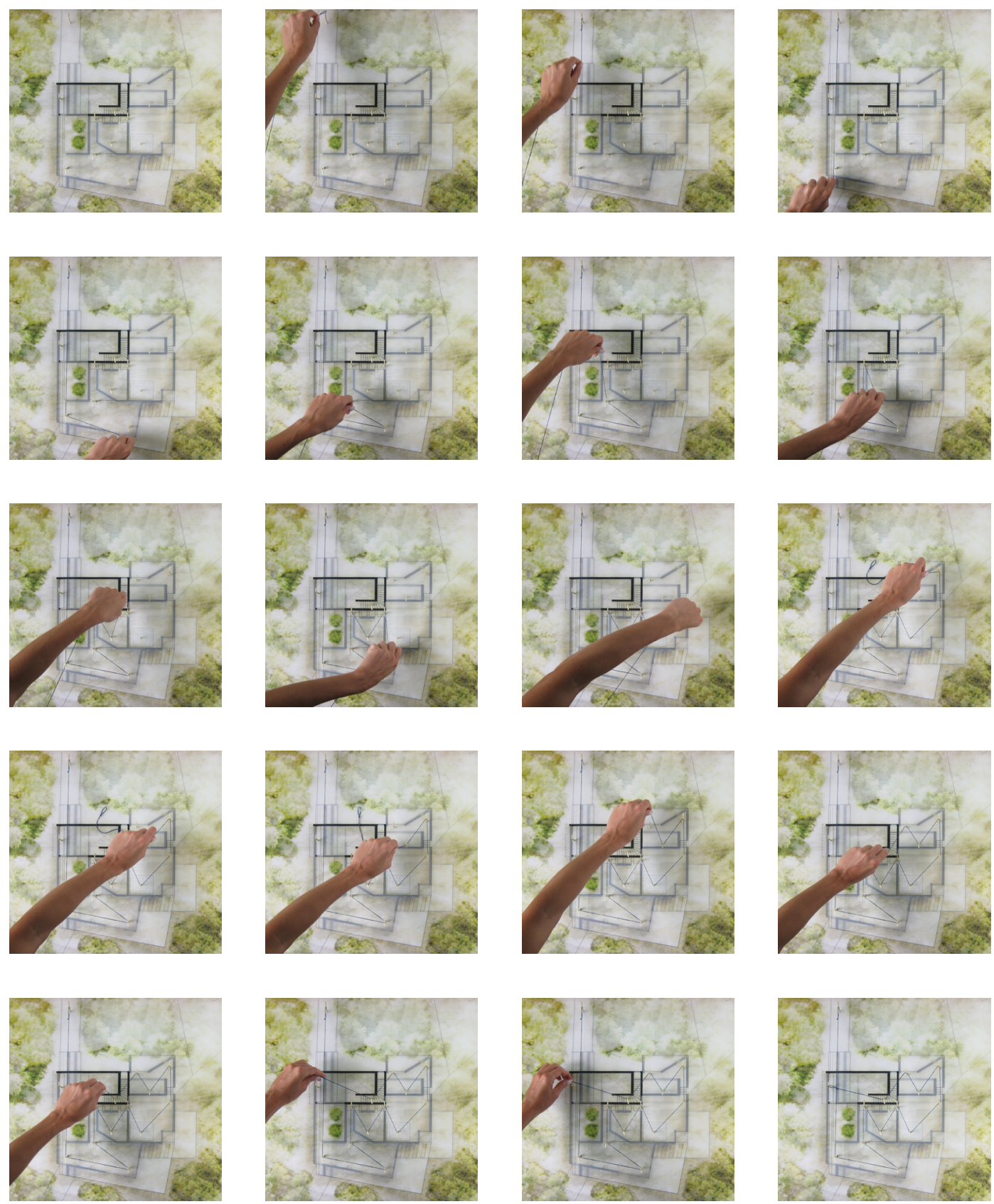

FIGURE 5.O.OB Creating the Journey Path through the Dwelling of Walt Whitman project 


\subsection{0 \\ BHYTHM OF THE DWELLING}

\section{Defining Rhythm}

The etymology of the term "rhythm" dates back to the mid-16th century from the French rhythme, or via Latin from Greek rhuthmos, which relates to rhein - "to flow". The root of rhythm in flow alludes to its definition as a regular, repeated pattern of sounds or movements, pattern of events, changes or activities ("Rhythm," n.d.). Claude Perrault notes that the word rhithmus refers to the parts of a movement that share the same proportion (Pelletier, 2006). He delineated 'eurhythmy' as the measured proportions of notes and steps as utilised in dance and music. Rhythm is the alternation of elements or movements over time and can bring order to chaos. Aristotle recognised four types of motion: coming to be and passing away, alteration, growth and diminution and locomotion. This led to theories on motion as an overarching concept of "change" as change represented the meaning of life itself in constant motion. According to Grant Hildebrand, rhythm can also refer to a progression of hierarchical order (Hildebrand, 1999).

The floor plan illustrated in figure 5.0.0a illustrates the rhythm of the layout and the movement of the spaces. The dwelling was designed to move in a specific rhythm following the emotional journey of Walt Whitman's life, however, it is up to the inhabitant to make their own journey and trace their own path.

\section{Threshold}

Rhythm is experienced through the meandering movement between spaces captured in the threshold. The threshold is the point or level at which something begins or changes. It enhances the emotional impact by hinting or blocking the view upon arrival as well as the scale, temperature and visibility within the threshold. The liminal or in-between space begins to develop the next emotion ensuring time and space never stop, but merely change pace. Ethnographer Arnold Van Gennep and anthropologist Victor Turner discussed "Liminality" as an in-between condition that must be dramatic enough to mark that a transition has occurred.

\section{Elevation}

Change in elevation is defined as rising to a higher or lower position. This changes the rhythm of movement within a space or between spaces. Whether a slow meandering stepping creating an undulating landscape or a steep and direct staircase, different speeds of movement are provoked. The direction of elevation change, such as ascending or descending, can symbolise different emotions.

Light

Light in the spaces of the dwelling acts as an ordering principle for rhythm. The visual patterns reflected on the surfaces suggest directionality and cadence of movement. 


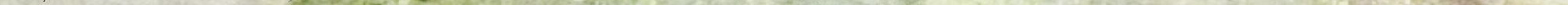




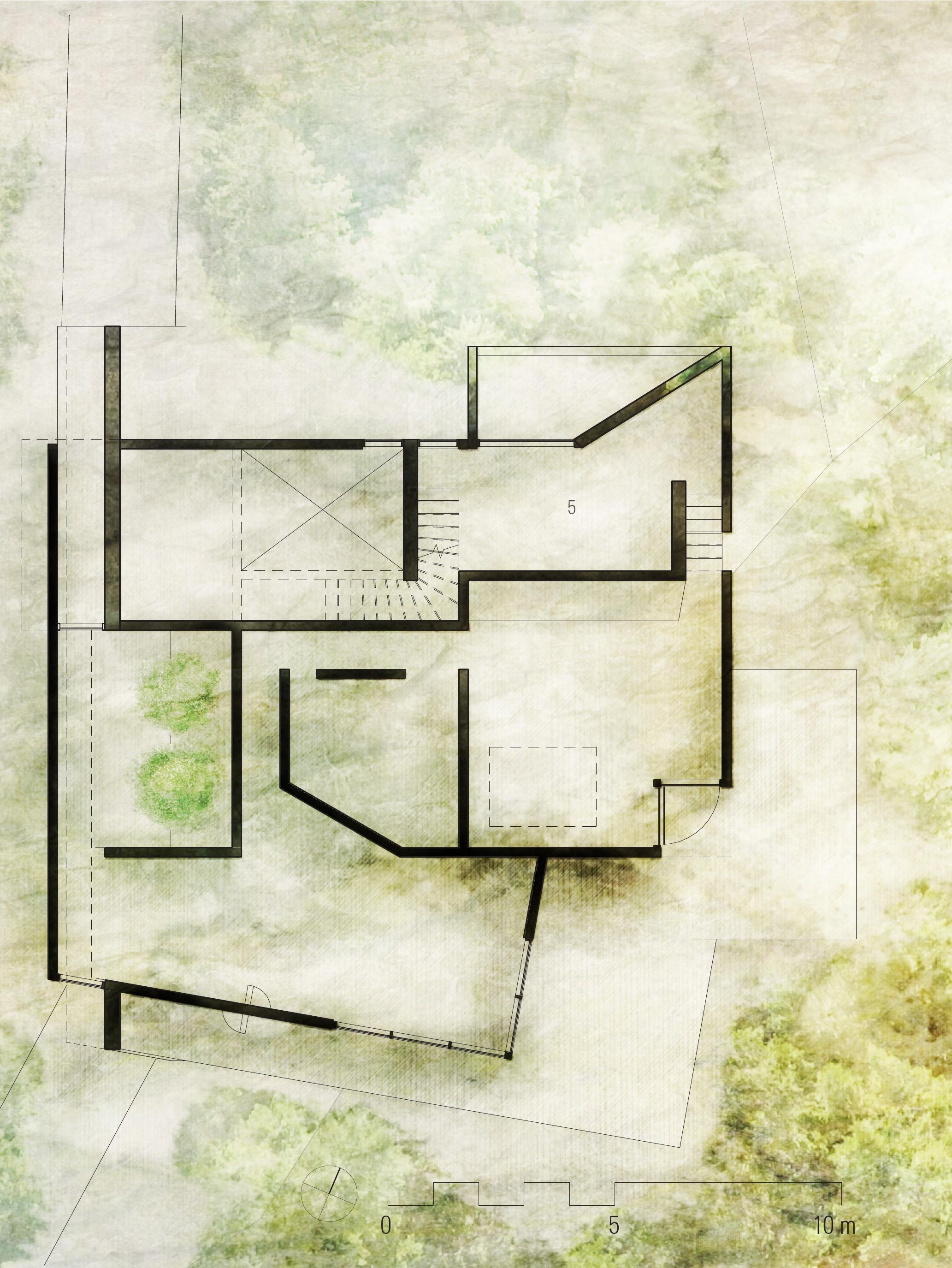




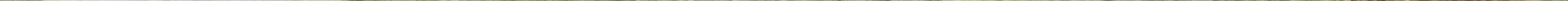




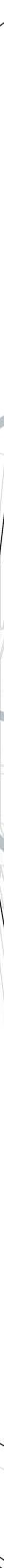

A threshold is "the point or level at which something begins or changes," ("Threshold," n.d.). Thresholds encompass the point of entering or beginning as well as the end or boundary ("Threshold," n.d.). Architect and theatre designer, Pippa Nissen, described the importance of exits and entrances in theatre performances as they symbolise beginnings and endings, frame the narrative, suggest circulation and mark transition (Macleod et al., 2012). Doorways, entrances and exits are not the sole means of threshold conditions. The thresholds may be pathways, corridors or stairs which determine the rhythm of movement between spaces. The importance of guiding, choreographing and designing a rhythm of movement lies in the threshold conditions. Threshold spaces can help to emphasize the feeling of the connected spaces with contrasting scales or lighting. For example, a threshold may be a narrow dark corridor that leads to a brightly lit large space. This juxtaposition and transition from one extreme to another amplifies the emotional impact of the space. The boundaries of interiority or any edge condition between two different states may be considered a threshold condition (McCarthy, 2005). The threshold creates a transition or barrier between two spaces; it creates spatial definition and mediates one's ability to perceive or not perceive where it leads.

Cubism

The Cubist movement looked for ways to represent all facets of an object simultaneously. In a Cubist 



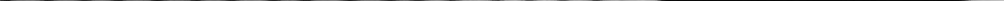




\subsection{0 \\ BHYTHM OF THE ELEVATION}

\section{Defining Elevation}

Elevation is the height or vertical distance between two points ("Elevation," n.d.). The rhythm of movement physically changes as the architecture guides inhabitants up and down to higher or lower elevations. The inhabitants' pace can change through slight stepping to a space at another elevation or a complete stepping to another storey. The elevation changes may inhibit or completely impede the view of the approaching space above or rather provide a full view down into the space.

\section{Ascending and Descending}

In Juhani Pallasmaa's essay, "Stairways of the mind", he presents the metaphorical implications of ascending and descending. He states that rising stairs culminate in heaven whereas descending stairs lead down to the underworld (Pallasmaa, 2000). The symbol of ascending to a higher spiritual place is seen in the temples of ancient cultures; the terraced temples of ancient Greece created a sense of elevating to the heavens. Alternatively, ascending stairs mark the exit from the social realm into the private realm (Pallasmaa, 2000) as we understand in the dwelling. The dwelling of Walt Whitman utilises this notion of ascending stairs to exit from the gathering space into the private resting space as well as exiting from the nourishing space into both the resting space and contemplating spaces. These changes in elevation between spaces signify the changes from public to private space in the dwelling. Ascending stairs may also indicate the final journey to reveal a secret (Pallasmaa, 2000). This concept was utilised in the approach to the cleansing space. The cleansing space in the dwelling symbolises the final edition of Leaves of Grass and consequently the final chapter in his journey of life. As one approaches the cleansing space, they must ascend the stair not knowing what lies ahead until they have reached the top. The cleansing space utilises this rise in elevation to obstruct the view until the point of arrival where the end is revealed. Pallasmaa discusses the psychological difference between ascending and descending movements through photography (Pallasmaa, 2000). One can note that a photograph of a stair taken from below vanishes into an unknown and unseen place above, maintaining privacy from below. An image of a stair descending reveals a larger extent of the space below. The descent expresses a self-presentation, signifying the entry from the private realm into the public realm. The Dwelling of Walt Whitman utilises the descending rhythm to transition the individual to the group by descending down into communal spaces.

Stairs

The architectural element of the stair encounters the body most directly as we measure its dimensions during ascent and descent (Pallasmaa, 2000). The rhythm of the stairs mirrors the beating of the heart and the breath of the lungs as one goes up and down. Pallasmaa states that "steep stairs address the heart, whereas gentle stairs echo the rhythm of our lungs," (Pallasmaa, 2000, p.10). Oftentimes the act of ascending stairs is viewed as an equivalent to descending. The experience of ascending a stair and descending a stair is in fact very different and should be treated as such when utilising it as a threshold between spaces in a dwelling. The Dwelling of Walt Whitman utilises the metaphorical references of ascending and descending into a space as well as the symbolic notions of transitioning between private and public space. Pallasmaa's concern with modern architecture's lack of mytho-poetic experience results in his presentation of the staircase as a vertical labyrinth (Pallasmaa, 2000). The staircase can provide orientation or disorientation as well as encouraging the rhythm of movement. The dwelling utilises varied degrees of elevating to produce a diverse range of rhythmic movement to support the habitual activities and emotional narrative. 


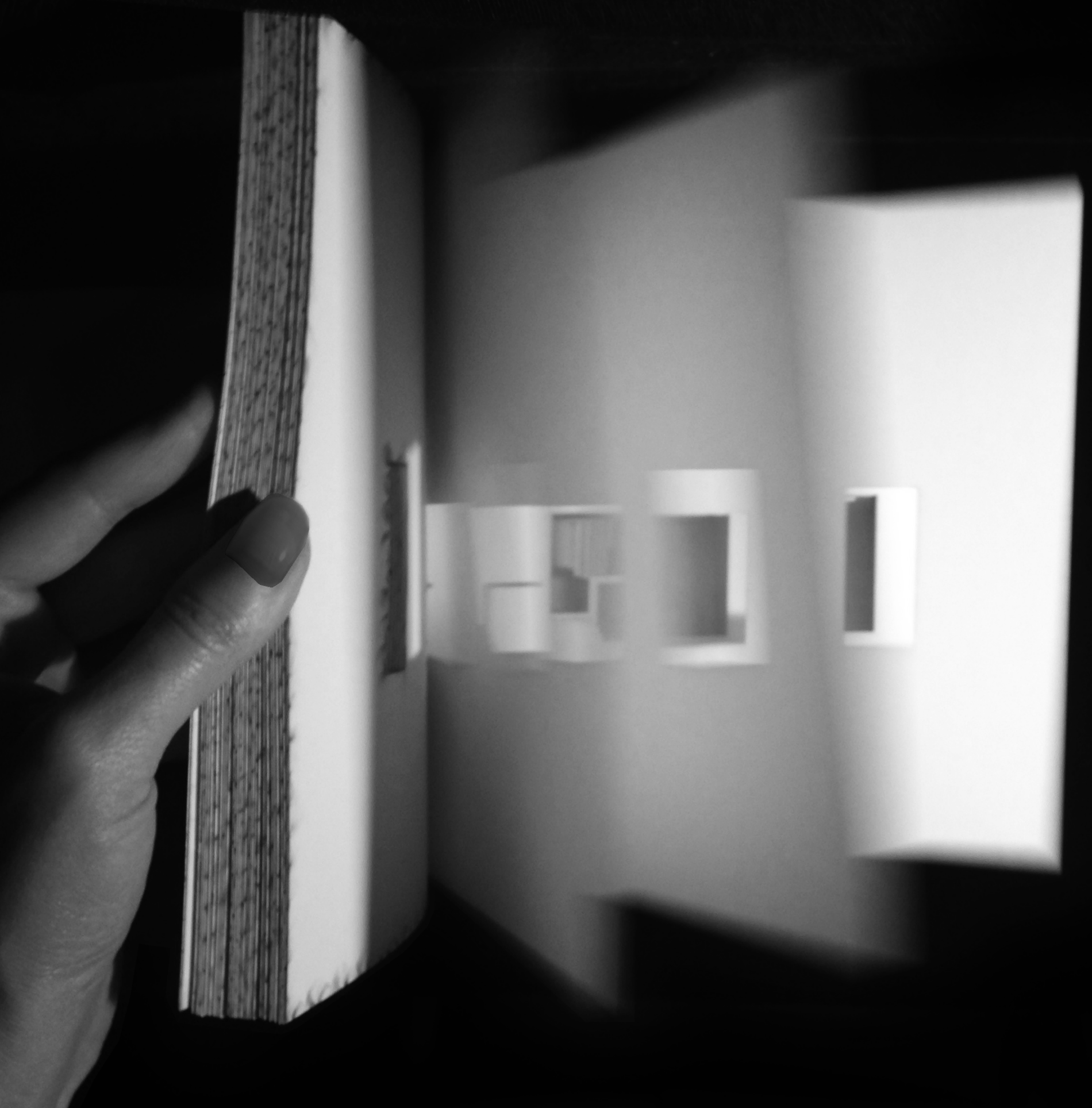

FlGURE 5.3.0A Sectional Paper Book Model for the Dwelling of Walt Whitman project 


\subsection{0 \\ RHYTHM OF THE LIGHT}

\section{Defining Light}

Light is "the sensation aroused by stimulation of the visual receptor," ("Light," n.d.-a) and refers to the source that makes things visible ("Light," n.d.-b). The verb "lighting" begins to explain the rhythmic qualities as it infers "to guide or conduct with a light," ("Light," n.d.-b). Light does not only reveal physical objects and space but can also imply a discovery or revelation of knowledge ("Light," n.d.-b). The rhythm of the light in this thesis serves to guide the inhabitants and reveal successive spaces by moving through.

\section{Daylight Patterns}

The daylight patterns in the Dwelling of Walt Whitman were achieved through a global lighting system that represents the precise way the sun would penetrate the spaces on this site. Just as The Therme Vals by Peter Zumthor utilised light washed walls to guide visitors from one bath to the next, the Dwelling of Walt Whitman utilises light patterns to suggest a path of movement from one space to the next. The thick concrete mass is punctured with floor level openings, large curtain walls, windows and sky lights to bring daylight in and provide a guide to meander. The guiding lights merely suggest a path of movement while maintaining a free flow of movement within the spaces. The role of light is to draw the inhabitant away from the shadow into the brighter spaces as demonstrated by Zumthor. However upon reaching the core of the dwelling this role is reversed and the inhabitant can retreat to the dark shadow of the interior. This is maintained as a role reversal following Juhani Pallasma's theory on the role of shadow for intimacy.

The presence of light inhabiting the space places you in contact with nature, both in place and time. Steven Holl states that "Time and perception in architecture intertwine with light and space of architecture within a certain duration," (Macleod et al., 2012). Light is a device to identify one's place in space and time through built form. The light is formed and controlled by the materials, heavy and light, translucent and opaque. The forms are moulded by light, which is in a constant state of change throughout the day and from season to season. The light provides insight into the time by the shadows it casts. From abundant direct light to its absence in shadows, the light penetration enables a sense of continuously changing illumination and directionality. 



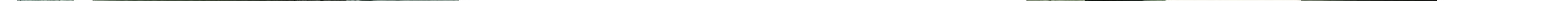



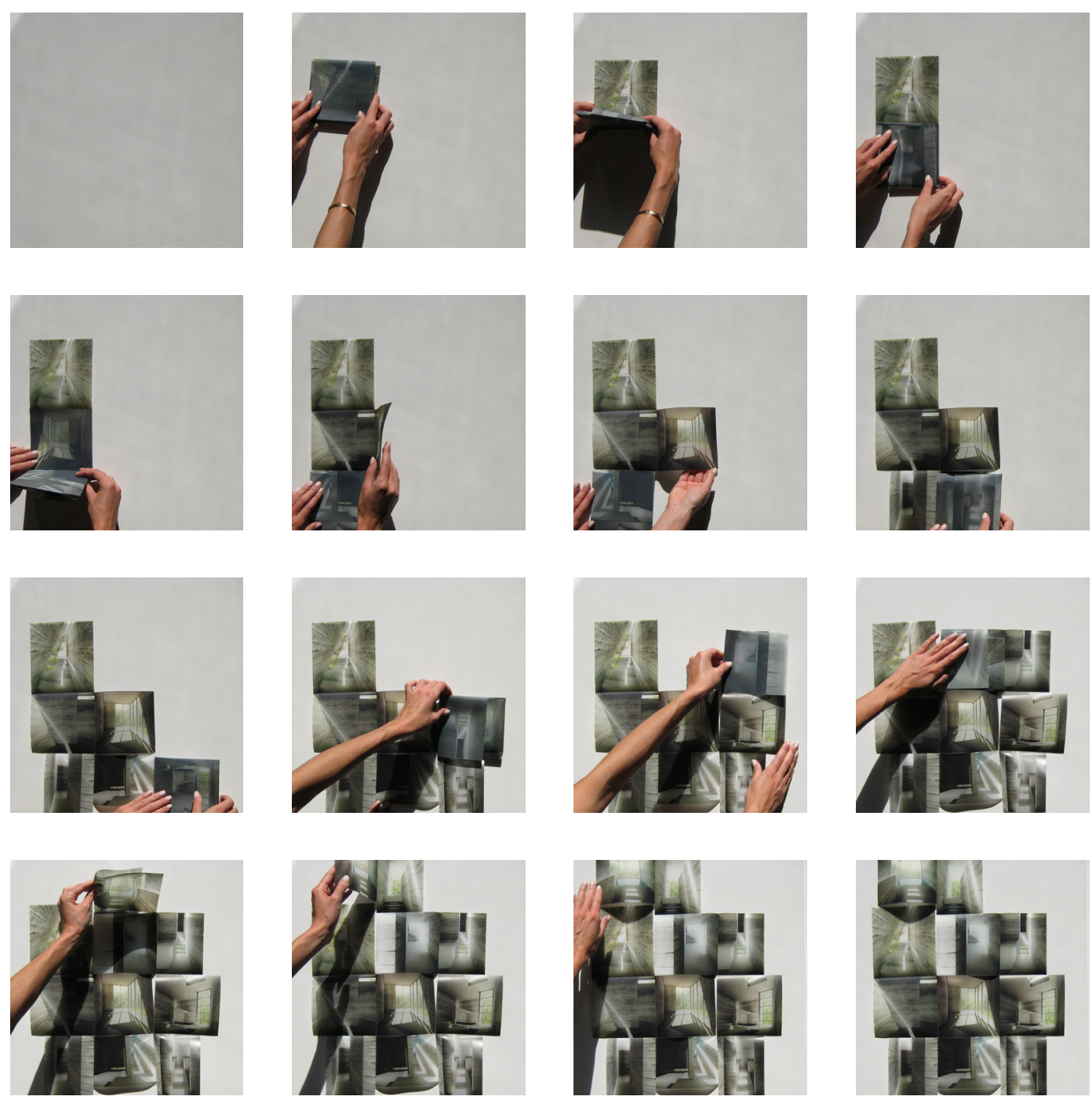

FIGURE 6.0.OB Revealing the Interior Rendered Foldout Drawing of the Dwelling of Walt Whitman project 


\subsection{0 \\ TONE OF THE DWELLING}

Shadow

Light and shadow are crucial elements to creating tone in architecture. The tone of the dwelling was achieved, in part, through the use of openings, windows and skylights that allow natural daylight to penetrate into the space. Juhani Pallasmaa emphasises the importance of shadow and says that "During overpowering emotional experiences, we tend to close off the distancing sense of vision; we close the eyes when dreaming, listening to music, or caressing our beloved ones. Deep shadows and darkness are essential, because they dim the sharpness of vision, make depth and distance ambiguous, and invite unconscious peripheral vision and tactile fantasy." The play of light and shadow reveal and conceal a space, which sets a mood for one's awareness in space. The levels from dark to light can also represent the levels of emotion on a spectrum.

\section{Enclosure}

I achieved tone with "enclosure", meaning "to close in". Atmospherically, the proximity to the body evokes feeling and the scale of space heightens emotion. Enclosure can connect or disconnect us from nature and place. Architect Tadao Ando said architecture allows us to "feel the presence of nature while screening from it". The scale of the enclosure can excite, evoke fear or intimately embrace you while the gestures of the enclosure can invite you in with open arms or provide privacy within. As you enter the dwelling atop Jayne's Hill in West Hills New York, the building invites you in as it protrudes to the hiking trail and begins to enclose you. The long procession brings awareness to this enclosure and you feel a visual and physical presence.

\section{Materiality}

Tone can also be achieved through materiality. The extensive use of concrete provides a datum to measure change and growth. From textured to smooth, heavy to light and cool to warm, the materiality is utilised as an ordering principle. It relates to the site by actually absorbing the site, absorbing more or less heat when exposed to the sun in certain areas. Peter Zumthor explains that "You feel a certain way in a glass or concrete ... It has an effect on your skin ... Wood doesn't steal energy from your body the way glass and concrete steal heat. When it's hot, a wood house feels cooler than a concrete one, and when it's cold, the other way around." The concrete does not only change the tone of the space through temperature changes but it absorbs subtle colour changes in the concrete from the ambient light penetrating the space. Materials chosen in the design are utilised for their suggestive weight, transparency, unity and texture. The colours and temperature created by the reflection of light in the space can recall memories and feelings that impact one's experience in the space. 


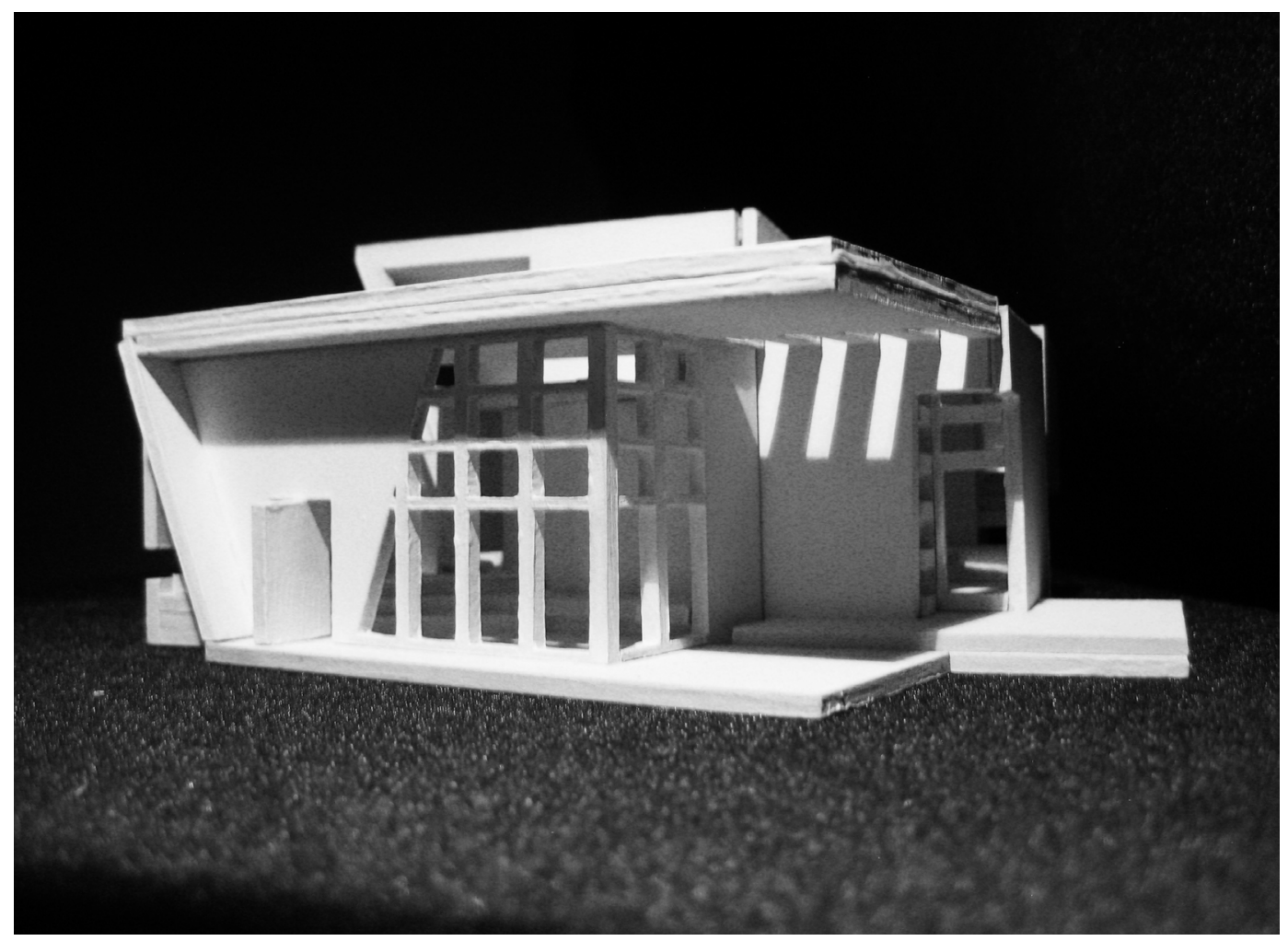

FIGURE 6.I.0A Hinged Wood Model for the Dwelling of Walt Whitman project

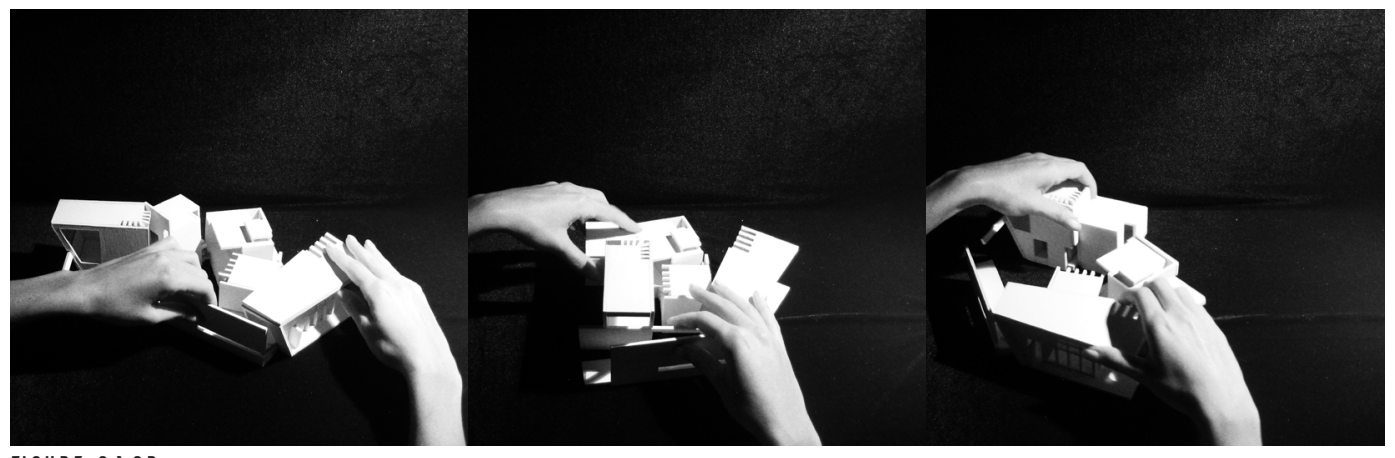

FIGURE 6.I.OB Hinged Wood Model for the Dwelling of Walt Whitman project - Journey A

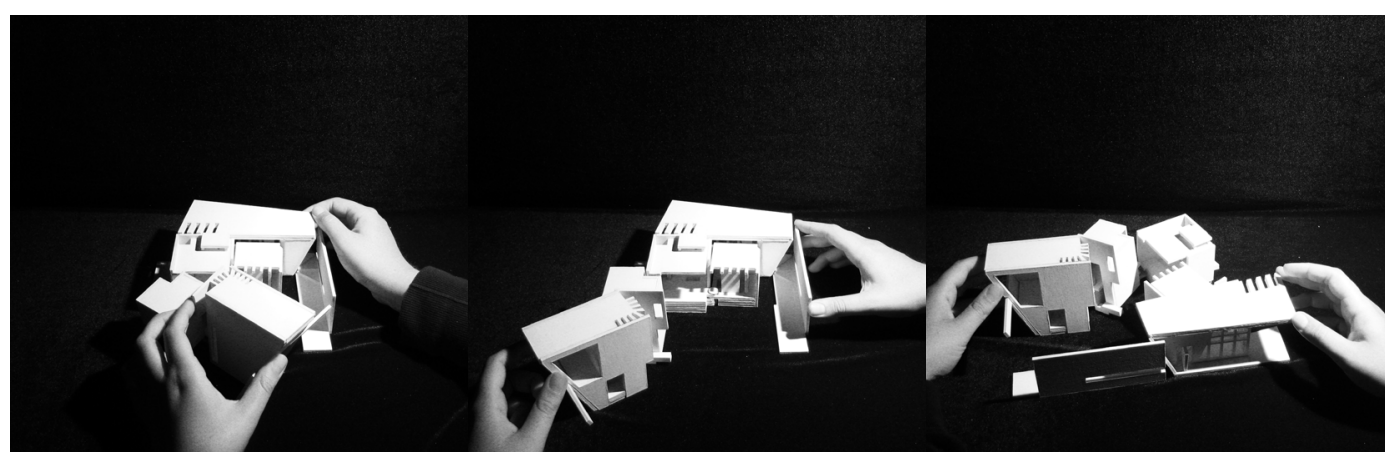

FIGURE 6.I.OC Hinged Wood Model for the Dwelling of Walt Whitman project - Journey B 


\subsection{0 \\ TONE OF THE SHADOW}

\section{Defining Shadow}

A shadow is defined as "an area of darkness created when a source of light is blocked," ("Shadow," n.d.-a). To shadow something is to protect from light or heat and provide shade ("Shadow," n.d.-b). The shadow depicts a reflected image and partial darkness within the space. While shadows have the connotation of gloom and unhappiness they simultaneously represent protection and comfort ("Shadow," n.d.-b).

Tone of Light and Shadow

Tone is achieved from the absence of light to the abundance of bright light and all the subtle qualities in between. Juhani Pallasmaa discussed the need for shadow and darkness in The Eyes of the Skin. He posited that shadows dim the precision of visual space, blur the depth of space and heighten the haptic experience. The inclusion of shadow in architecture restricts our vision intensifying our experience through the other bodily senses. Not only does the dim light and presence of shadow strengthen our senses of smell, sounds and touch but our imagination is stimulated. The restriction of vision calls upon the mind to complete the image and borrow from memory to comprehend the surroundings. Light becomes valuable with the presence of shadow; directional light enhances textures and forms while bright uniform light washes out those haptic details.

Light and shadow play an important role in understanding the change in time within architecture from the movement of shadows throughout the day to the direction of light to guide the way. Peter Zumthor's Thermal Baths in Vals Switzerland, utilise light and temperature to guide (but not dictate) how an individual might move through the space. Zumthor designed the thermal baths with the understanding that people are drawn towards light and away from shadow. However, this chapter looks at shadow alternatively as an atmospheric condition to be drawn towards for its nurturing of the imagination and its comforting protective nature. Pallasmaa states that "Homogeneous bright light paralyses the imagination," (Pallasmaa, 1996a) and therefore, the presence of shadow plays an important role in creating an engaging experience of space, inspiring wonder and exploration. The Dwelling of Walt Whitman plays with directional daylighting that intensify the shadow of the space. The shadows are constantly changing but the directionality of them symbolise an emotional connection with the space. Casting tall vertical shadows from the curtain wall mullions to emulate a sense of confidence in the gathering space is juxtaposed with the horizontal curtain wall mullions in the nourishing space, symbolising grief. The lack of uniform light within the dwelling ensures that the textures of the timber formed concrete walls are highlighted. The light intensity penetrating in through the windows and openings mediates the level of transparency, causing certain openings to almost disappear into nothingness. The boundary between interior and exterior is signified by windows and openings, brightly lit, contrasting the most interior spaces cast in shadow. 


\subsection{0 \\ tone of the enclosuhe}

\section{Defining Enclosure}

An area partially or entirely surrounded by walls or buildings is defined as an enclosure. To enclose means to surround something, to include something (“Enclose," n.d.-a) or contain it (“Enclose," n.d.-b). Enclosure encompasses the closing in of space and therefore it requires the presence of a boundary condition. Enclosure achieves connection to place in architecture as is mediates between interior and exterior space. In The Four Elements of Architecture, Architect Gottfried Semper proposed that the origin of architecture was the instinct to enclose space. Semper's Volumetric Theory notes that the essential goal of architecture is to enclose space and separate the interior from the exterior (Schwarzer, 1991). Semper asserts that the material components of walls serve to make the enclosed spaces visible. Christian Norberg-Schulz discusses the origins of architecture in relation to enclosure in his text Intentions in Architecture. He utilises the example of the first permanent huts as a response not only to the need for physical protection from the environment but also the security of visually representing the union of the group (Norberg-Schulz, 1965).

FIGURE 6.2.01 - FIGURE 6.2.0E Revealing the enclosed spaces of the Dwelling of Walt Whitman project with a hinged wood model

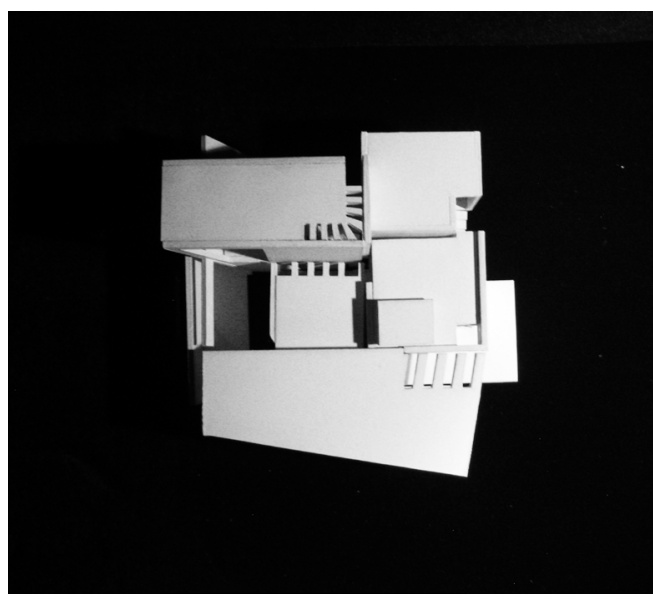

FIGURE 6.2.01

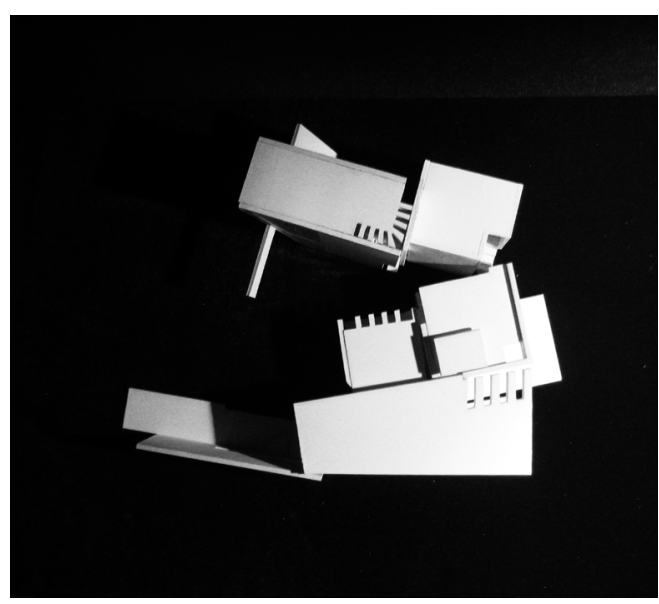

FIGURE 6.2.0B

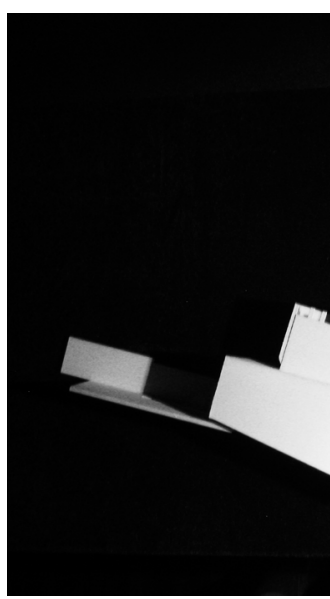

FIGURE 6.2.0C 
Tone of Enclosure

Enclosure encompasses the feeling of security, warmth, shelter, protection and privacy. Enclosure may utilise gestures such as raising and lowering ceiling heights, textures and shadows to signify the change of state from open to enclosed. A lack of enclosure means something that is open, bright, public and exposed. Humans find comfort and protection in enclosure as this was their first experience on earth. Everyone was born, nurtured and protected from inside the womb during the process of growth. The Dwelling of Walt Whitman encloses light, shadow and movement for a temporal exploration of spaces, thresholds and a narrative that intertwines them. The contrasting spaces of light and dark reveal varying degrees of enclosure to evoke a variety of emotional responses within the spaces. The manipulation of materials mediate the enclosed boundary of the dwelling connecting and disconnecting the inhabitant from the site. The inhabitant choreographs their own experience through the dwelling, transitioning between heavy concrete caves to permeable glazed spaces, each providing varying levels of enclosure.

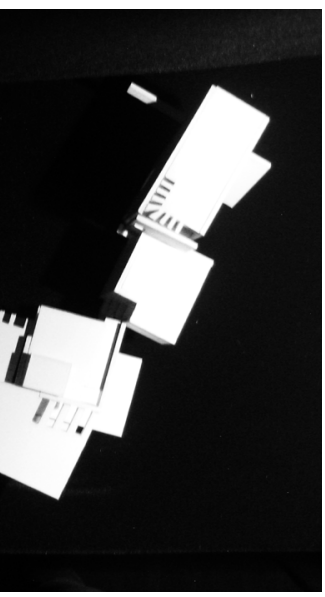

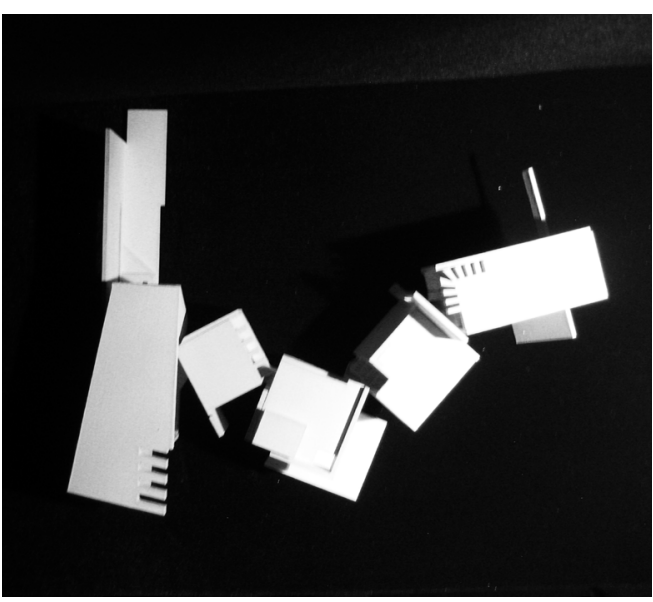

FIGURE 6.2.0D

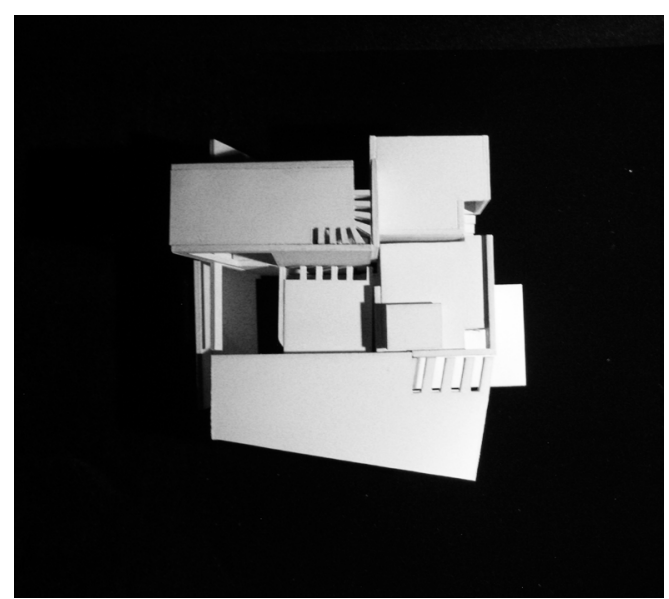

FIGURE 6.2.0E 


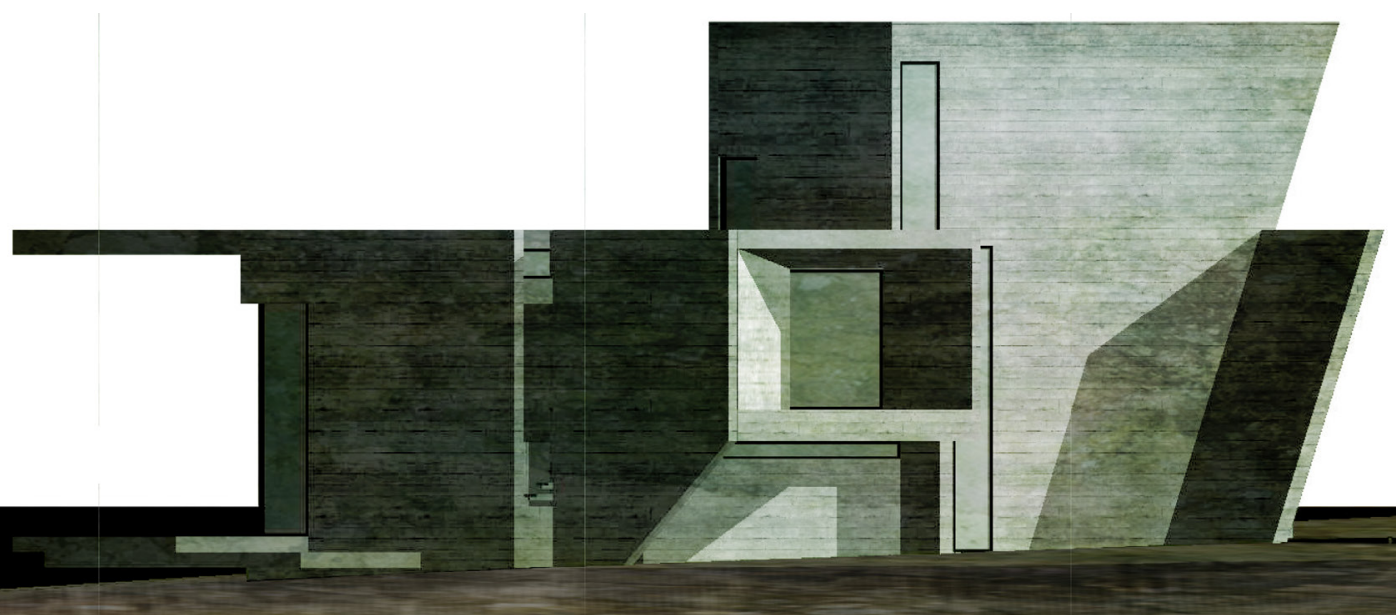




\subsection{0 \\ TONE OF THE MATERIALITY}

\section{Defining Materiality}

Materiality relates to physical substances rather than spiritual or intellectual matter ("Material," n.d.-a). It may also be a group of ideas or things that combine into an integrated work ("Material," n.d.-b).

\section{Tone of Materiality}

The emotional experience of a material is influence by how it is treated, placed, formed and integrated into the whole. The material expression can be true or not true to its actual characteristics of soft and hard, heavy and light. A heavy material can be expressed as something light by cantilevering it or changing its colour and a light material can be made to feel heavy by the juxtaposition of other materials and patterns. Materiality can change over time based on how one perceives the emotions it evokes, how the light and colours of the environment penetrate and how it degrades over time. The essay "Hapticity and Time: Notes on a Fragile Architecture" discusses the language of materials and surface textures that evolve and change over time, creating a sensory architecture. Tadao Ando furthers this by stating that "Light changes expression with time. I believe that the architectural materials do not end with wood and concrete that have tangible forms but go beyond to include light and wind which appeal to our senses..." (Nesbitt, 1996, p.480). Materiality establishes a connection between architecture and the body. Louis Kahn's infamous quote that "The Sun never knew how wonderful it was until it fell on the wall of a building" depicts the dependant relationship between material and light in the quality of architectural space. The material enclosure manipulates and controls light that defines the spaces and atmospheric conditions. The Dwelling of Walt Whitman utilises a minimal palate of materials to ensure the patterns of shadow and light animate the space. In some areas the slabs of the roof sit apart from the walls and, in other areas, the walls do not meet in order to allow slivers of light to penetrate the space. The dwelling utilises timberformed concrete to render the surface appearance as a rough wood texture. The conventional concrete texture is moulded here with the timber of the surrounding forest to create a boundary condition from the exterior. The materials of concrete and glass mediate between interior and exterior conditions by filtering light and framing views to the exterior. The heaviness of the concrete is broken by slivers of light from all directions and the glass provides large views of the surrounding environment. 


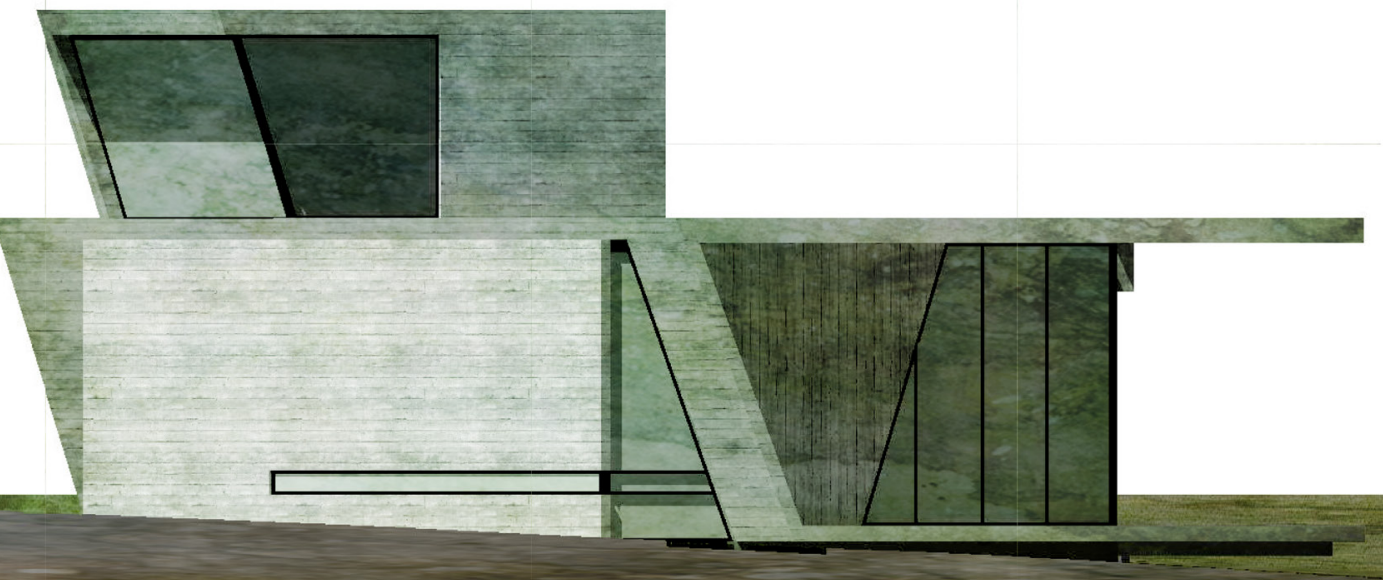




\section{CHAPTER 7 \\ JOURNEY ARChItecture}

: the creation of an order or conceptual

structure for a change in time 


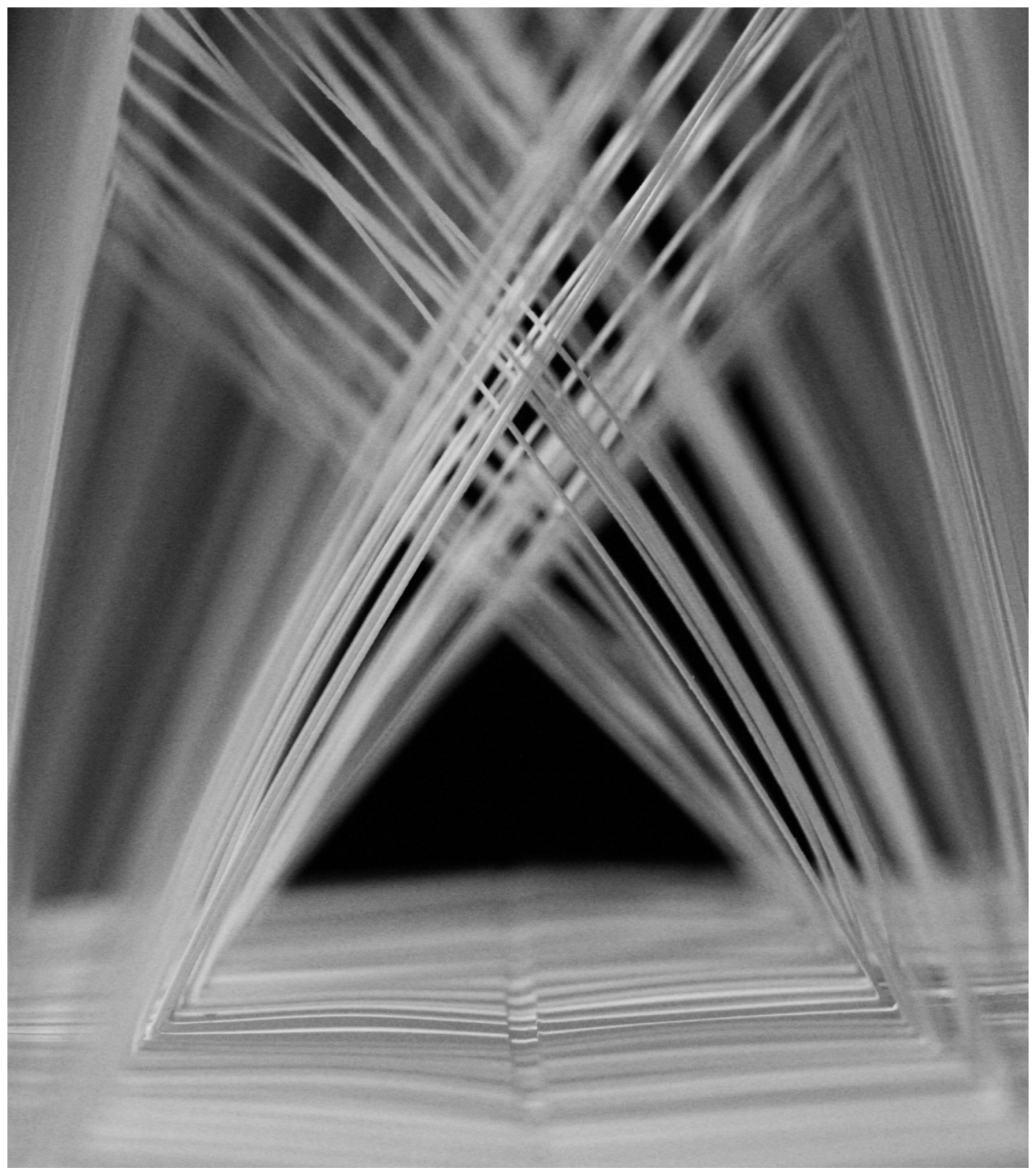

FIGURE 7.1.0^ Paper Pop-up Model

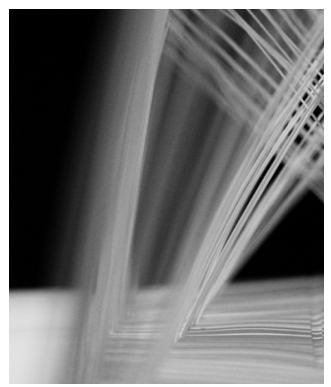

FIGURE 7.I.0B Paper Pop-up Model

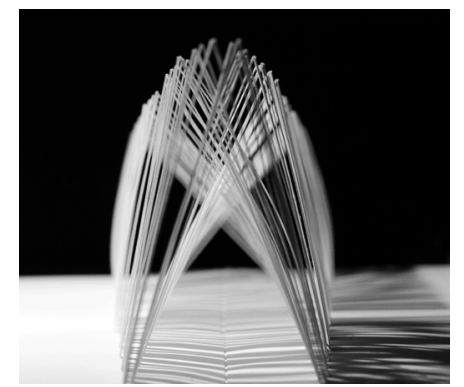

FIGURE 7.I.0C Paper Pop-up Model

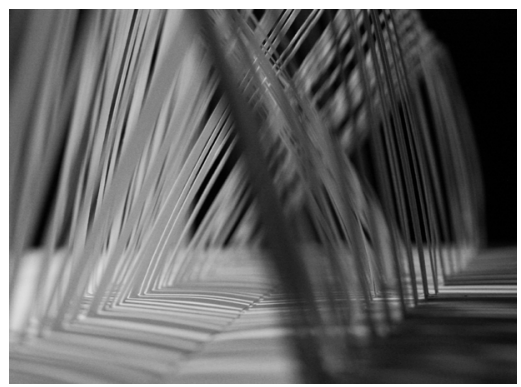

FIGURE 7.I.0D Paper Pop-up Model 


\subsection{0 \\ PRESENCE OF THE ENTERING SPACE}

Analysis of the First Edition of Leaves of Grass

In 1855, Walt Whitman self-published his first edition of Leaves of Grass. He believed he could bring poetry to the common people, and with this edition, assumed the role of the All-American poet, referring to himself as "one of the roughs," a common man. Whitman thought of himself as a spokesman of the nation and became a relatable character by writing poems like "Song of Myself" and utilising a portrait of himself in labourer's clothes as the frontispiece. Through visual images and poetic devices, Whitman positioned himself as an accessible and relatable figure to the public. The first edition is an entry point into the work and life of Walt Whitman.

\section{Initial Concept}

The entering space in the dwelling is symbolic of the first edition of Leaves of Grass. I interpreted this edition to be an accessible and relatable entry point into the journey of Walt Whitman's life. This edition acts as a reference point for the entering space in the dwelling. Whitman's painting of himself as an all-American icon is seen in the initial concept design through the pitched roof forms of the entering space (figure 7.1.0a-7.1.0g). The formal symbolism is easily understood by the common man while illuminating the unconventional chaotic structuring of the poetry. The space is situated at an accessible point from the hiking trails and emphasises the procession of entering into the dwelling with an extended rectilinear space. The entering space greets the inhabitant on the hiking trail that leads to the top of Jayne's Hill in West Hills New York. It lies on the path, accessible on foot amidst the forestry.

Presence
a. Enclosure
b. Light (directional)
c. Threshold

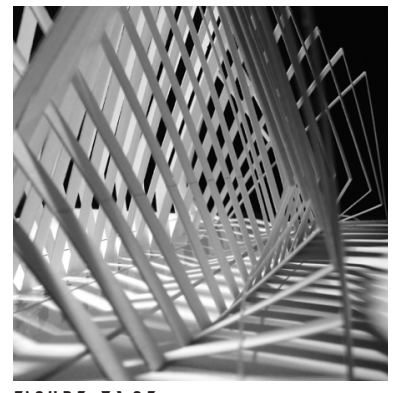

FIGURE 7.I.OE Paper Pop-up Model

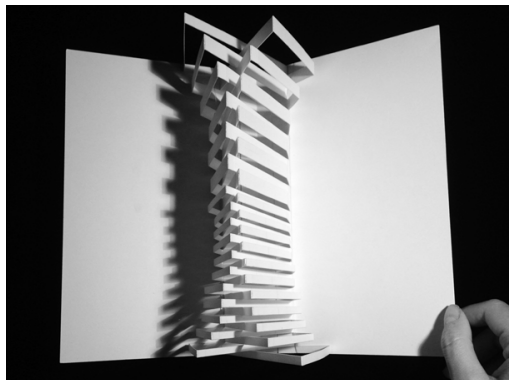

FIGURE 7.I.OF Paper Pop-up Model

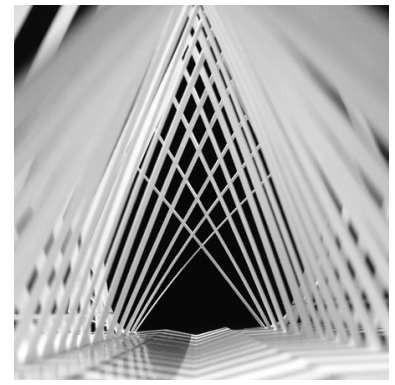

FIGURE 7.I.OG Paper Pop-up Model 


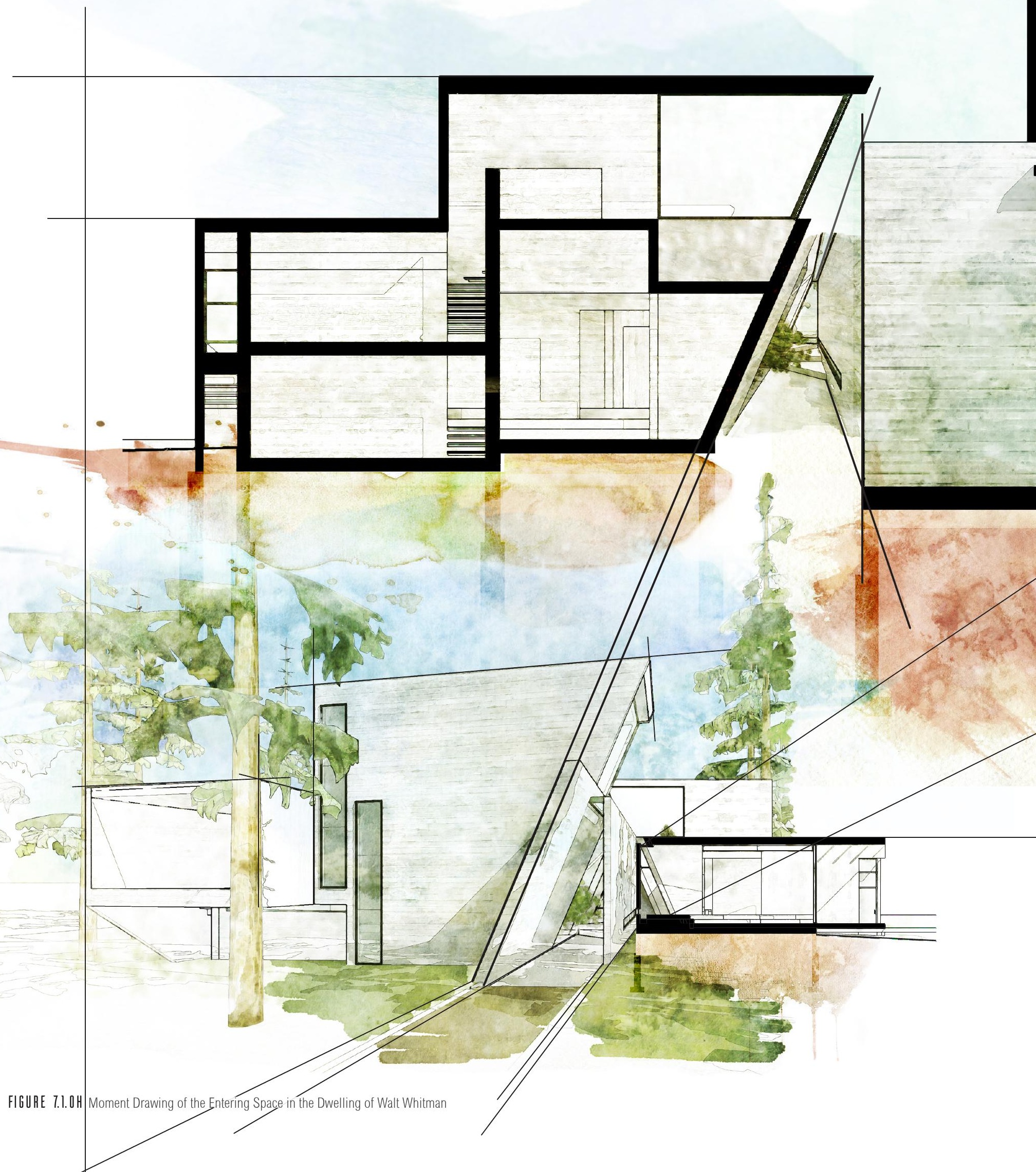




\section{Developed Concept}

The entering space is situated as a temporal beginning to the journey of the architecture just as the first edition of Leaves of Grass began the journey of Walt Whitman's poetic journey. The space is further developed from the popup model by utilising materials and lighting to create a cognisant enclosure that transitions the inhabitant's journey from exterior to interior space. By extending the enclosure beyond the overall massing of the dwelling, it creates a presence on the landscape that signifies this as a place to enter. According to Christopher Alexander, author of A Pattern Language, the main entrance to a building should be placed where it is visible from the main points of access. If the entrance protrudes beyond the building façade it will be visible as one approaches (Alexander et al., 1977, p.543). Alexander posits that the entrance is a threshold space between the exterior environment and the interior environment. There should be a transition from the exterior to the front door marked by a changing sense of enclosure, change of light, direction, level or view (Alexander et al., 1977, p.552). The daylighting on the interior directs the inhabitant toward the body of the architecture while still maintaining a connection to the site through framed views. The boundary of the enclosure is ambiguous as the paths and terraces around the edges extend into the landscape developing continuity between the dwelling and its environment. The presence of the entering space "marks the entrance and straddles the boundary between indoors and outdoors, covering some space outdoors and some space indoors" (Alexander et al., 1977, p.625). 


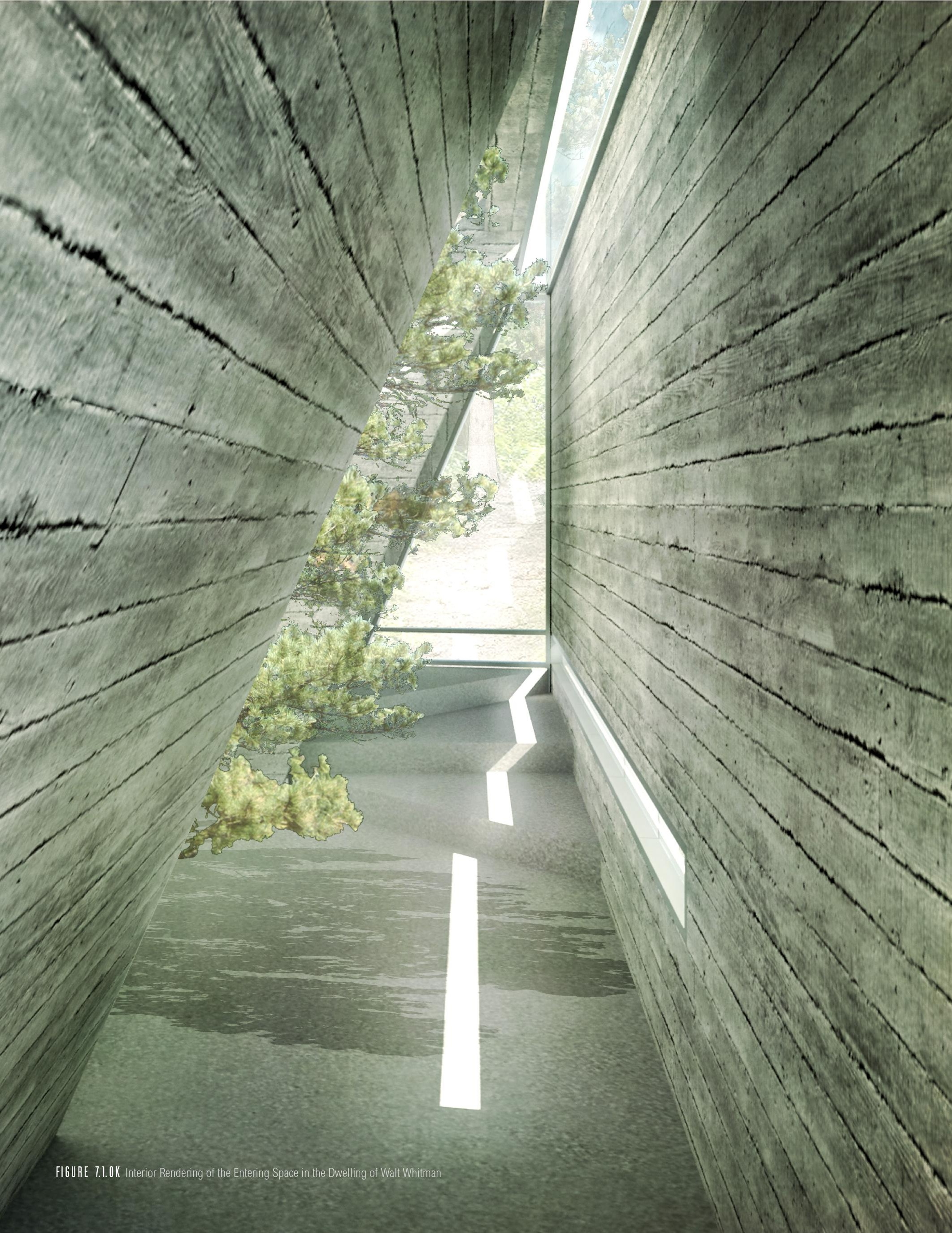




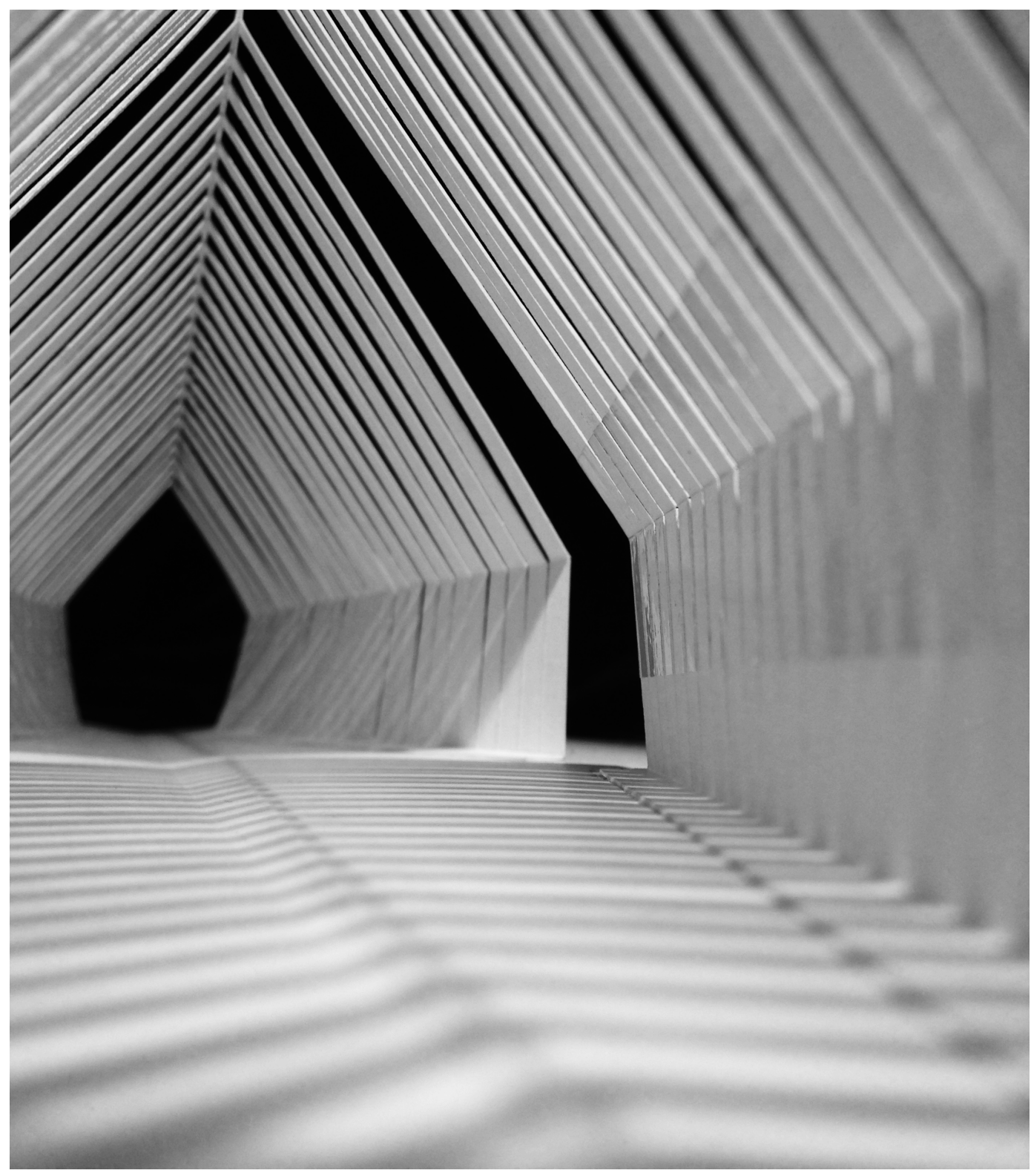

FIGURE 7.2.0^ Paper Pop-up Model

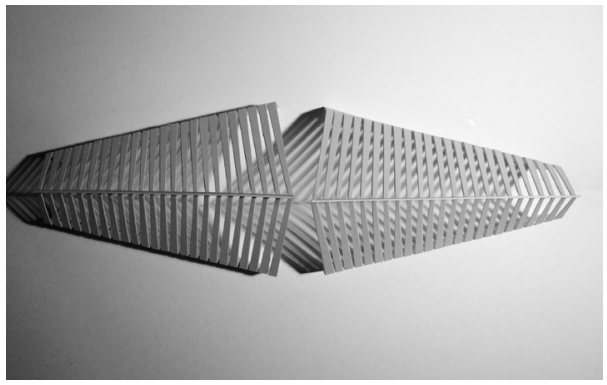

FIGU RE 7.2.0B Paper Pop-up Model

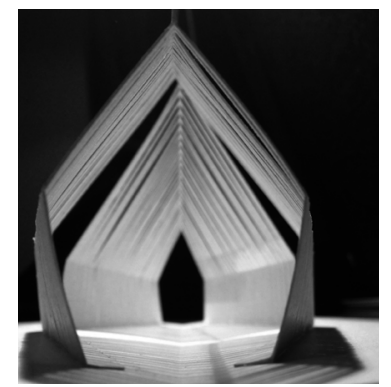

FIGURE 7.2.0C Paper Pop-up Model

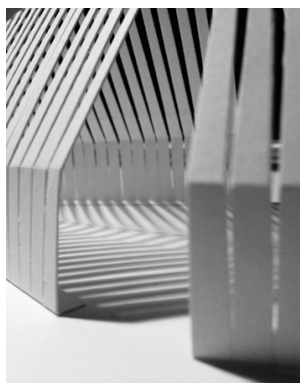

FIGURE 7.200 Paper Pop-up Model 


\subsection{0 \\ CONFIDENCE OF THE GATHERING SPACE}

\section{Analysis of the Second Edition of Leaves of Grass}

Whitman's second edition of Leaves of Grass was published in 1856 in which he asserts that his poetry is intended to unify the nation, "for the union of the parts of the body is not more necessary to this life than the union of These States is to their life". He continues to be concerned with the American masses and positions himself as a 'poet-spokesman'. He utilises personal letters as false self-promotion in the appendix in an attempt to enlarge his relationship with the readers. His poetry in this edition becomes more overtly sexual and personal in poems such as "Spontaneous Me" and "A Woman Waits for Me".

\section{Initial Concept}

The gathering space in the dwelling is symbolic of the second edition of Leaves of Grass. I interpreted the aims of unifying the nation through poetry to act the same way as the act of gathering in the dwelling. The gathering space unifies the inhabitants and deepens the connection between people. It is the space in the dwelling where inhabitants and visitors unite, meet and socialize. It is accessible from all directions and connects multiple spaces while formally suggesting the uniting of two entities.

Whitman's promotion and sexual writing solidifies that he has put himself on display for the nation. This transparency allows him to connect with the readers on a personal level. The gathering space protrudes beyond the other spaces onto the landscape to maintain a view on three sides. A high level of transparency into this space maintains that the inhabitants of this space are on display.

\section{Confidence}
a. Elevation
b. Light
c. Materiality

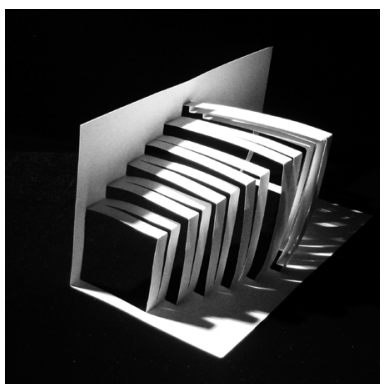

FIGURE 7.2.0E Paper Pop-up Model

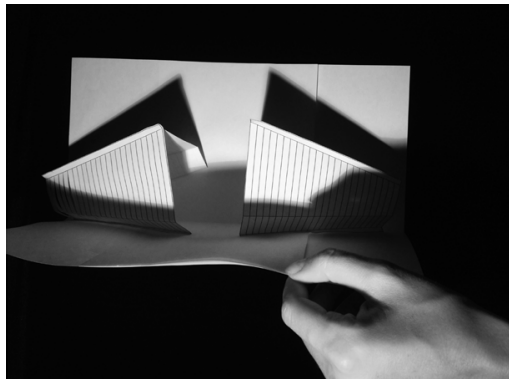

FIGURE 7.2.0F Paper Pop-up Model

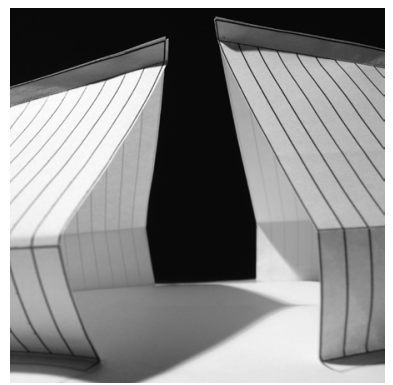

FIGURE 7.2.0G Paper Pop-up Model 


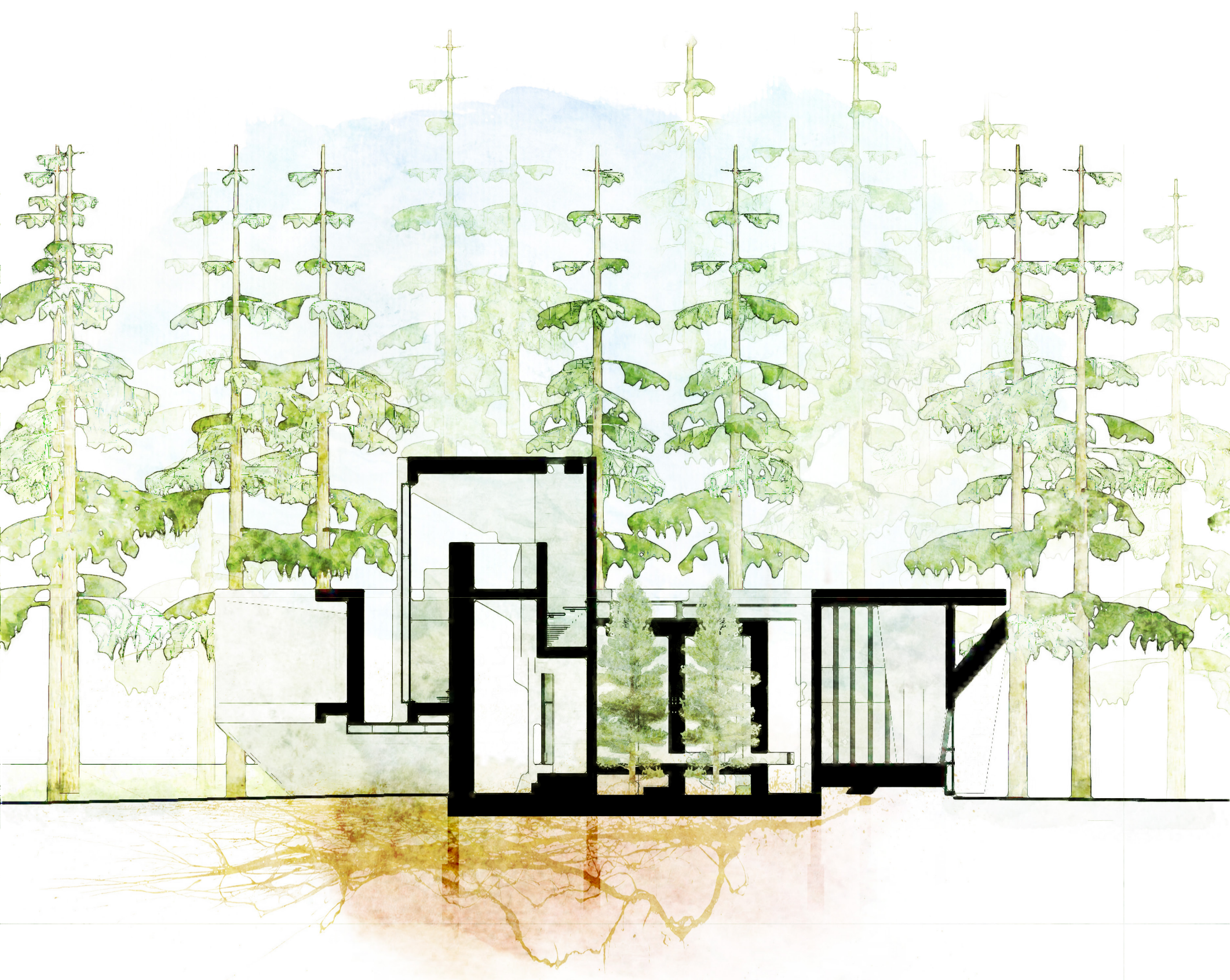





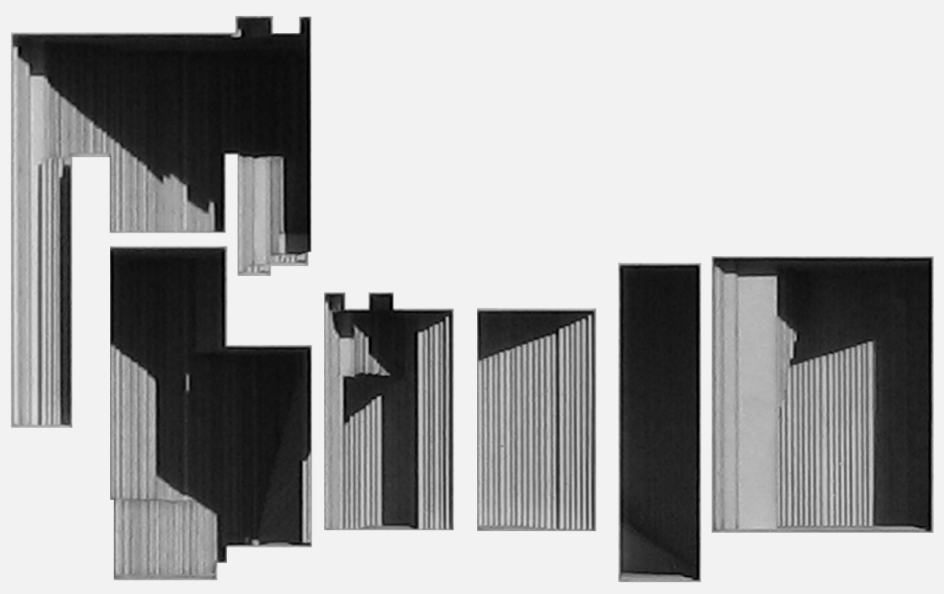




\section{Developed Concept}

The gathering space was further developed in the dwelling to explore emotional changes in space when ascending and descending. A slight stepping of the floor loosely follows the topographical changes in elevation and evokes certain feelings upon entering this gathering space. There is a level of confidence achieved when looking down into the communal gathering space rather than up at it. Upon entering the gathering space the inhabitant has a vantage point above the space. This entry into the gathering space is inviting as it provides the inhabitant with the confidence that they may view before taking part in the action. As one descends into the space they become part of the action of gathering. The stairs together with the room form a socially connected space. Christopher Alexander suggests that gesture of the stairs flaring out towards the bottom invite inhabitants to naturally use this space as seating (Alexander et al., 1977, p.639). The stepping elevation of the space allows for the sitting space to be protected from the paths of circulation connecting the entering space and the resting space. Varied ceiling heights are achieved through the stepping of the floor ensuring that a variance in the levels of intimacy are felt. The ceiling is higher and feels more assertive in the communal gathering space contrasting the lower ceilings of more intimate spaces in the dwelling. The greater floor to floor heights allows more light into the space with a full height window wall. The extensive transparency and light entering the space ensures the inhabitants are drawn towards the space. The lightness of the glazing is felt by the juxtaposition of heavy concrete walls that are angled to reveal the surrounding forestry. The vertical grain of the timber-formed concrete contrasts the rest of the dwellings horizontality and alludes to emotions of poise felt by the inhabitant of the dwelling. The space is cantilevered into the landscape and asserts itself over the natural setting. 



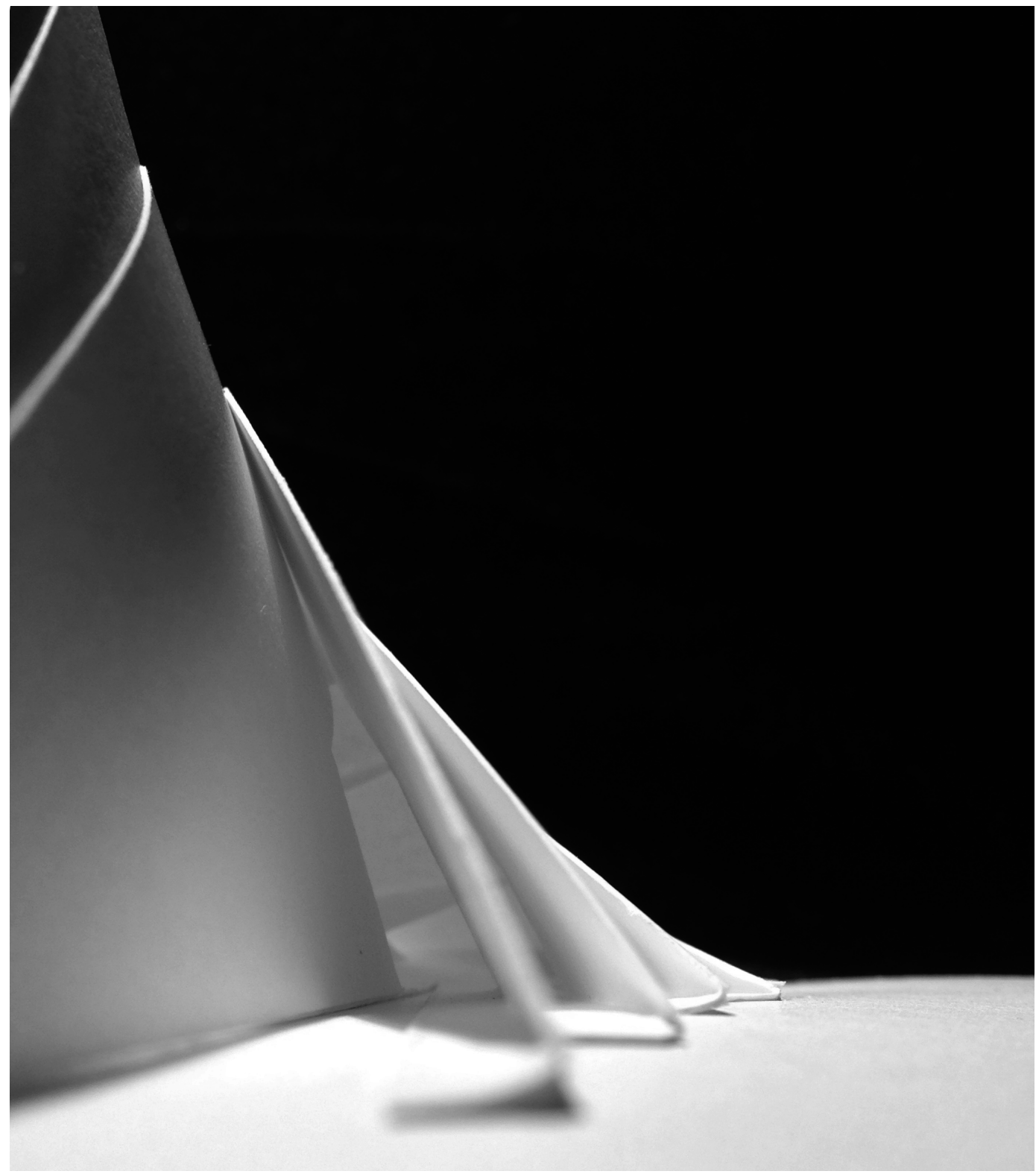

FIGURE 7.3.0^ Paper Pop-up Model

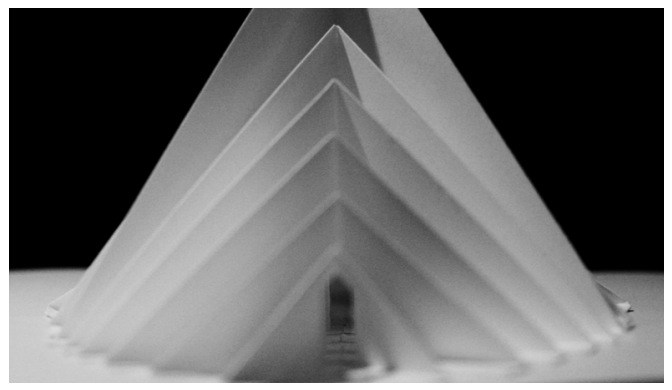

FIGURE 7.3.0B Paper Pop-up Model

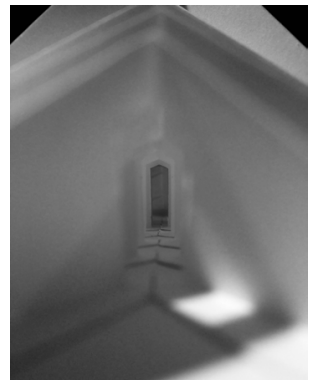

FIGURE 7.3.0C Paper Pop-up Model

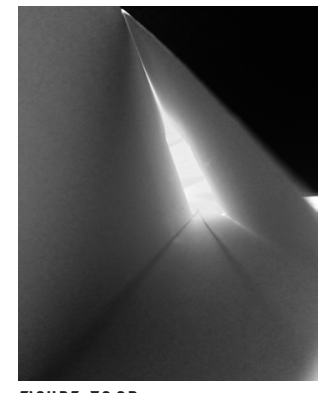

FIGURE 7.3.0D Paper Pop-up Model 


\subsection{0 \\ INTIMACY OF THE RESTING SPACE}

Analysis of the Third Edition of Leaves of Grass

The third edition of Leaves of Grass was published in 1860 and focuses on themes of love and friendship. The poems address sensual, procreative love, heartbreak and comradeship. This edition is the most personal and intimate as Whitman alludes to passion and troubles with his friends and lovers. The poems reveal a darker outlook of worry and angst in the years leading up to the Civil War. This edition contained an increased attentiveness to organization of the clusters of poems and the structuring of them.

\section{Initial Concept}

I interpreted the personal and intimate themes of the third edition as the activities of a resting space. A resting space does not simply involve resting but rather it encompasses all things intimately private and personal within the dwelling. There are morning and evening activities in preparation for sleeping as well as intimate encounters with a loved one. The resting space in the dwelling provides a place for everything regarding privacy and love. This space may be for an individual or two in an intimate relationship. It explores love by providing a warm intimate space to engaging in sexual relations and discuss private matters. In addition it explores protection by offering shelter for inhabitants to rest and prepare for the future. Preparation for the night as well as for the day may be understood as a form of self-protection. The resting space offers three distinct atmospheres upon entering and preparing for rest, resting and departing for the day. The entrance into the 'cave' hugs the inhabitant and welcomes them in open arms and bright light. The internal cave protects the inhabitant while resting in a personal and intimate space, protected from external light and views. The exit from the cave guides the inhabitant into the next space with a single view to the day ahead.

Intimacy
a. Light and shadow
b. Enclosure
c. Threshold

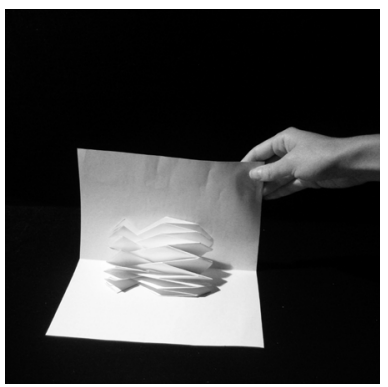

FIGURE 7.3.0E Paper Pop-up Model

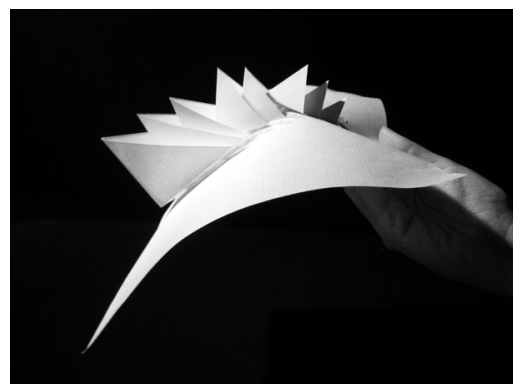

FIGURE 7.3.OF Paper Pop-up Model

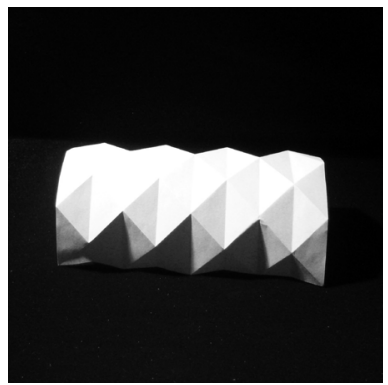

FIGURE 7.3.06 Paper Pop-up Model 


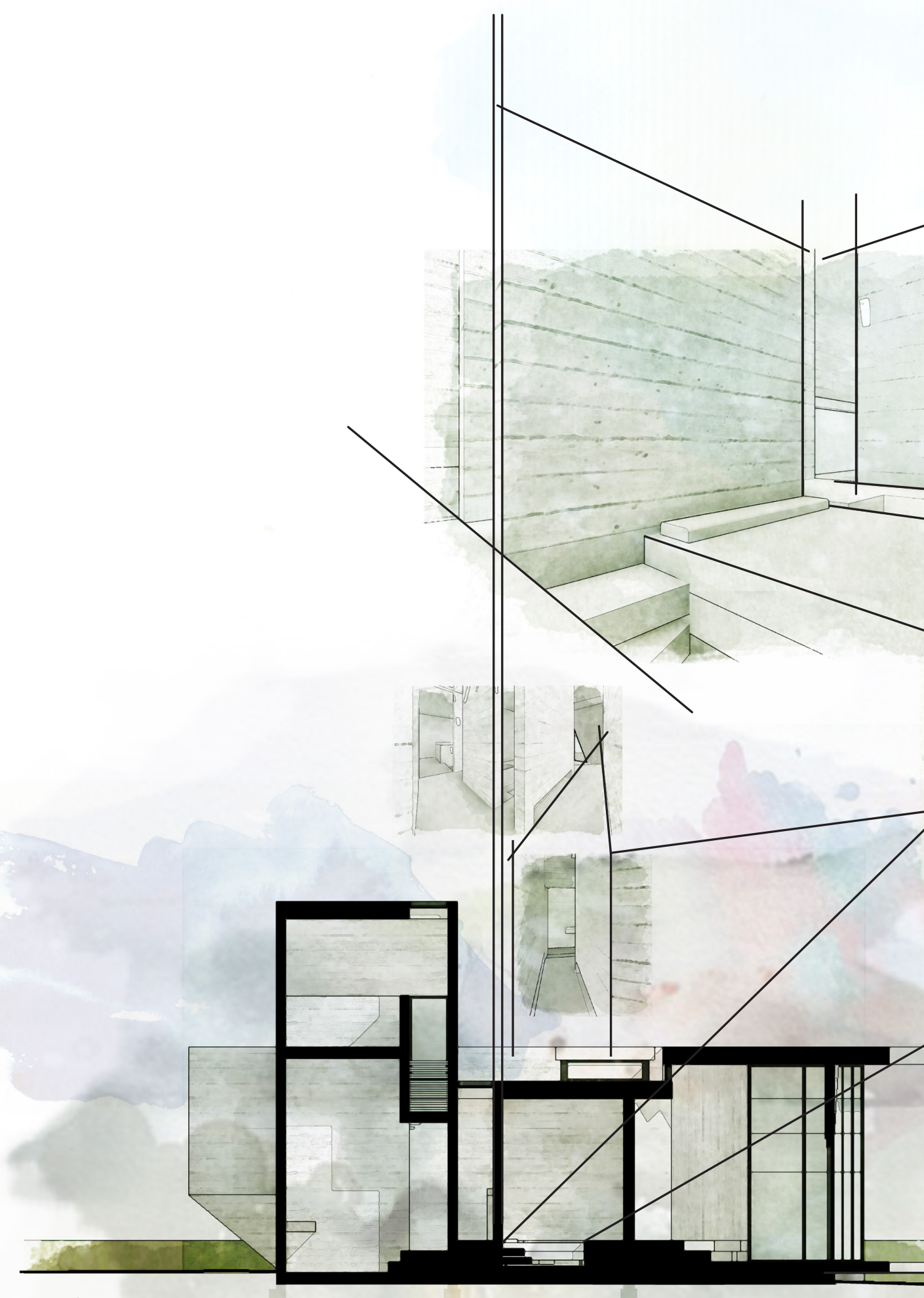




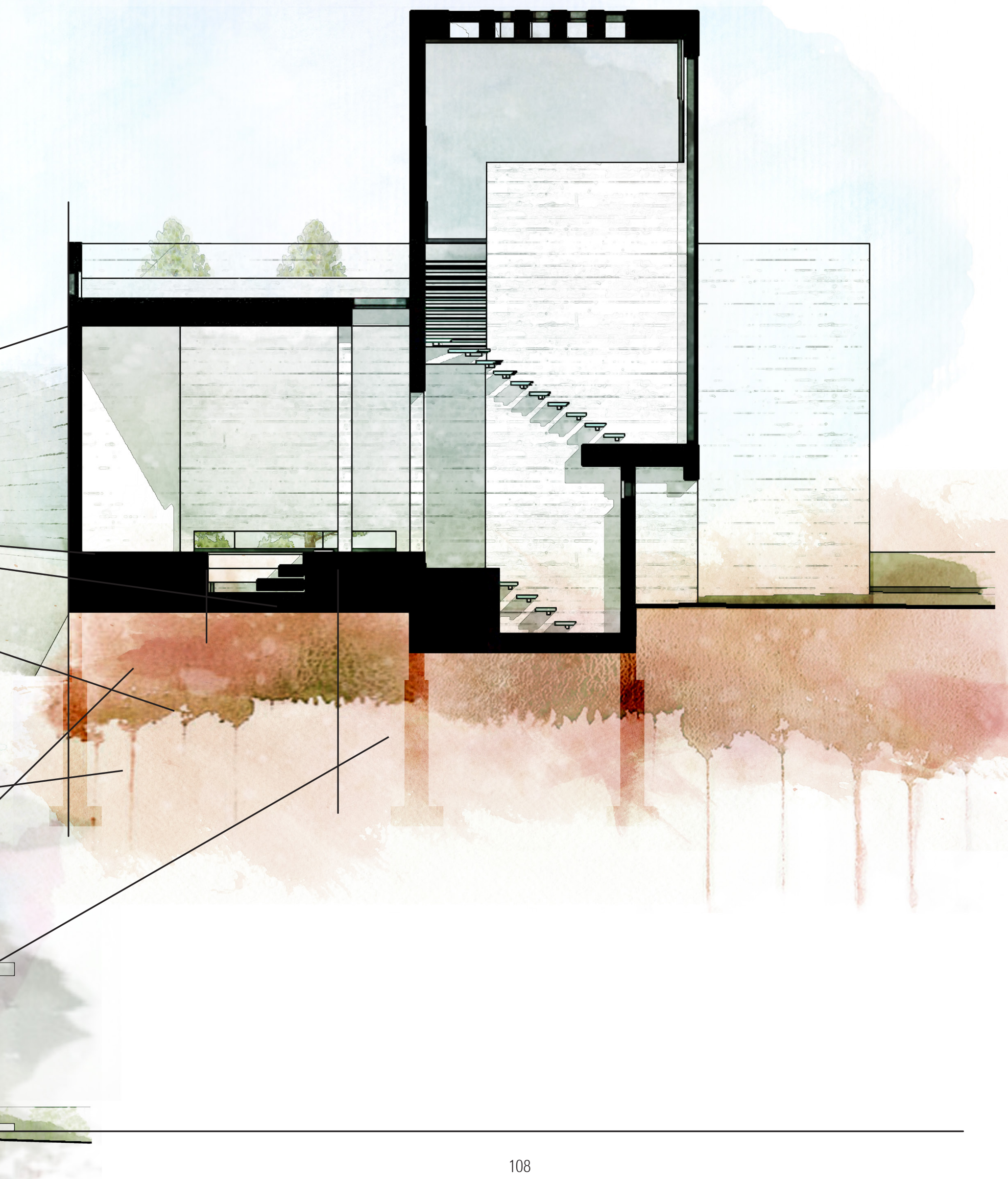




\section{Developed Concept}

Intimacy is felt in the resting space through the use of light, shadow, enclosure and thresholds. The belly of the space is reached via narrow thresholds that block views and light from the other spaces in the dwelling. There are no views to the exterior in order to maintain a calm and private resting place however light is diffused into the space. The entry and exit points allows light to penetrate into the threshold and guide the inhabitant from bright light to a dark retreat. The light that penetrates from the skylights above is diffused by the corridor that protects any direct light from reaching the resting space. Christopher Alexander advocates a loop as a means to flow through rooms. "With a loop it is always possible to come and go in two different directions" (Alexander et al., 1977, p.630). The resting space is designed as a looping series of spaces and thresholds that transition from washing, resting and dressing spaces to prepare for the night and get ready for the day. The threshold space from the gathering space ensure that privacy is maintained and limited light filters to the interior in the evening when one retreats. The threshold into the nourishing space where one may exit the resting space in preparation for the day filters in more light to awaken the inhabitant. The floor level bed creates a tactile enclosure that is intimate in scale and seclusion. The resting space is designed with Alexander's concept that the space around the bed should only be utilised for access to the bed (Alexander et al., 1977, p.869). All other activities associated with resting such as dressing, working and washing require their own space as these activities are not well suited to the remaining area typically surrounding the bed. This space embodies the sense of enclosure through providing the bed with a nook of its own. 


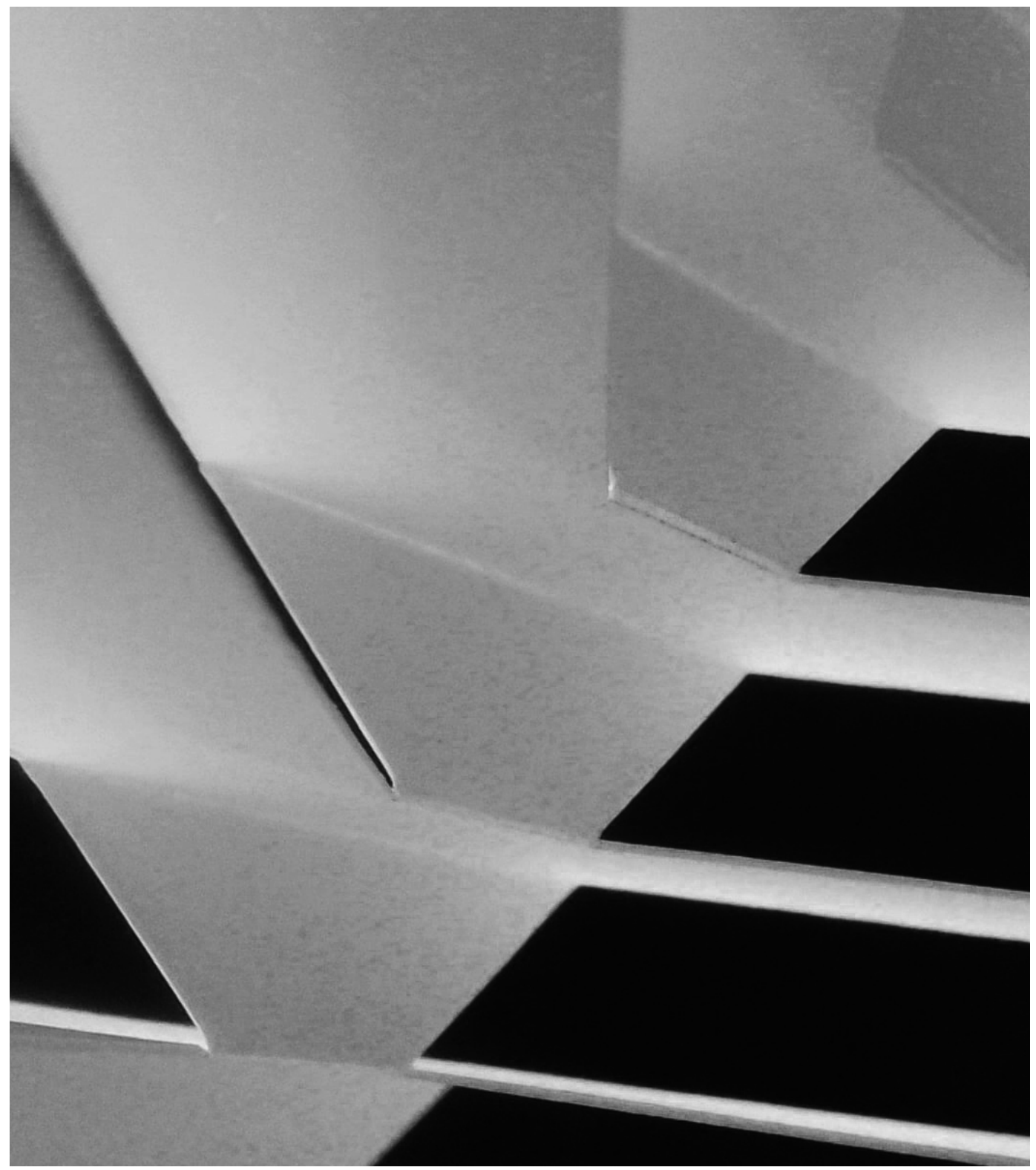

FIGURE 74.0N Paper Pop-up Model

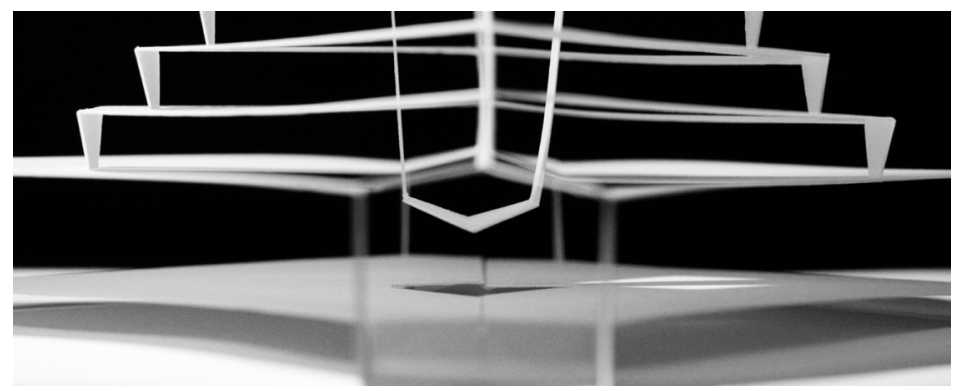

FIGURE 74.0B Paper Pop-up Model

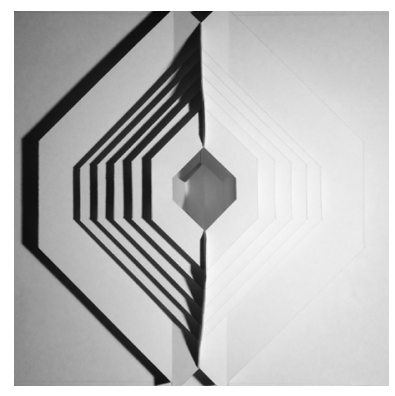

FIGURE 74.0C Paper Pop-up Model 


\title{
7.4.0 \\ GRIEF OF THE NOURISHING SPACE
}

\author{
Analysis of the Fourth Edition of Leaves of Grass
}

In 1867 Walt Whitman published the fourth edition of Leaves of Grass with six new poems. The central image of oneself as the subject of his poetry changed between the individual self and the collective. This edition was centered on social relations and emphasized communal organization and unity, a prominent view in post-civil war reconstruction. The six new poems in this edition are noticeably chaotic, revealing the turmoil of postwar society. At that moment, Whitman experienced grief over first-hand experience with civil war victims and the assassination of President Lincoln. Whitman's grief was expressed through a need for community and the prevalent themes of social cohesion. The postwar emotions had him concerned with the individual self and finding comfort in social relations with the collective.

\section{Initial Concept}

The nourishing space in the dwelling deals with emotion like Walt Whitman did. This space has the capacity to nourish ones grief and provide the space for social engagement and community support. While remembering those whom the inhabitants are grieving over, the nourishing space pushes them out of their private spaces and into a public space to gather with others in the dwelling. Much like the Jewish tradition of the Shiva, community and nourishment have the ability to heal and help move an individual to the next state in their emotional journey. The internalized grief in Whitman's Journey is experienced in this inward looking space that pays homage to the heavens above. Transitioning from the cave to the nourishing space, entering as an individual to unite with the tribe over food, is common practice for many cultures. The nourishing space looks at entering as oneself and uniting at the hearth for nourishment and social activities. The transition of moving from private to public space is something every individual experiences in the dwelling based on how they feel, what activities they need to do and the desire they have to interact with others.

Grief

a. Light and shadow

b. Enclosure

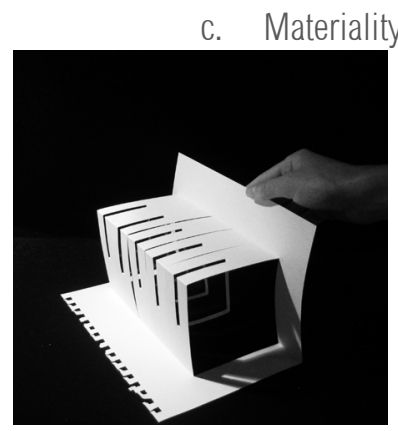

FIGURE 74.0D Paper Pop-up Model

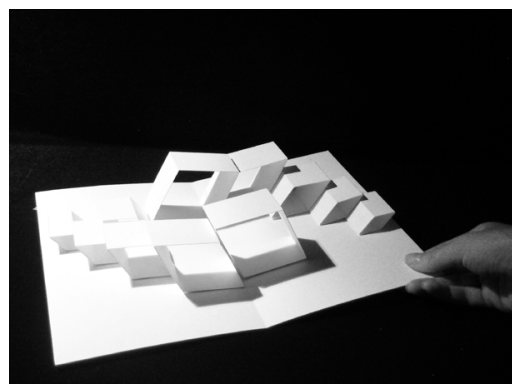

FIGURE 7.4.OE Paper Pop-up Model

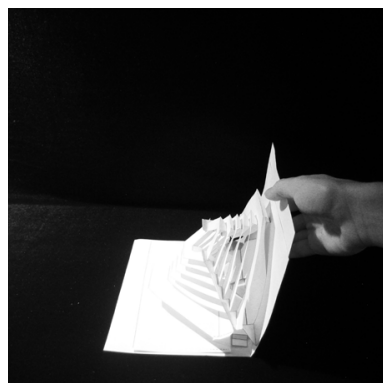

FIguRE 74.OF Paper Pop-up Model 


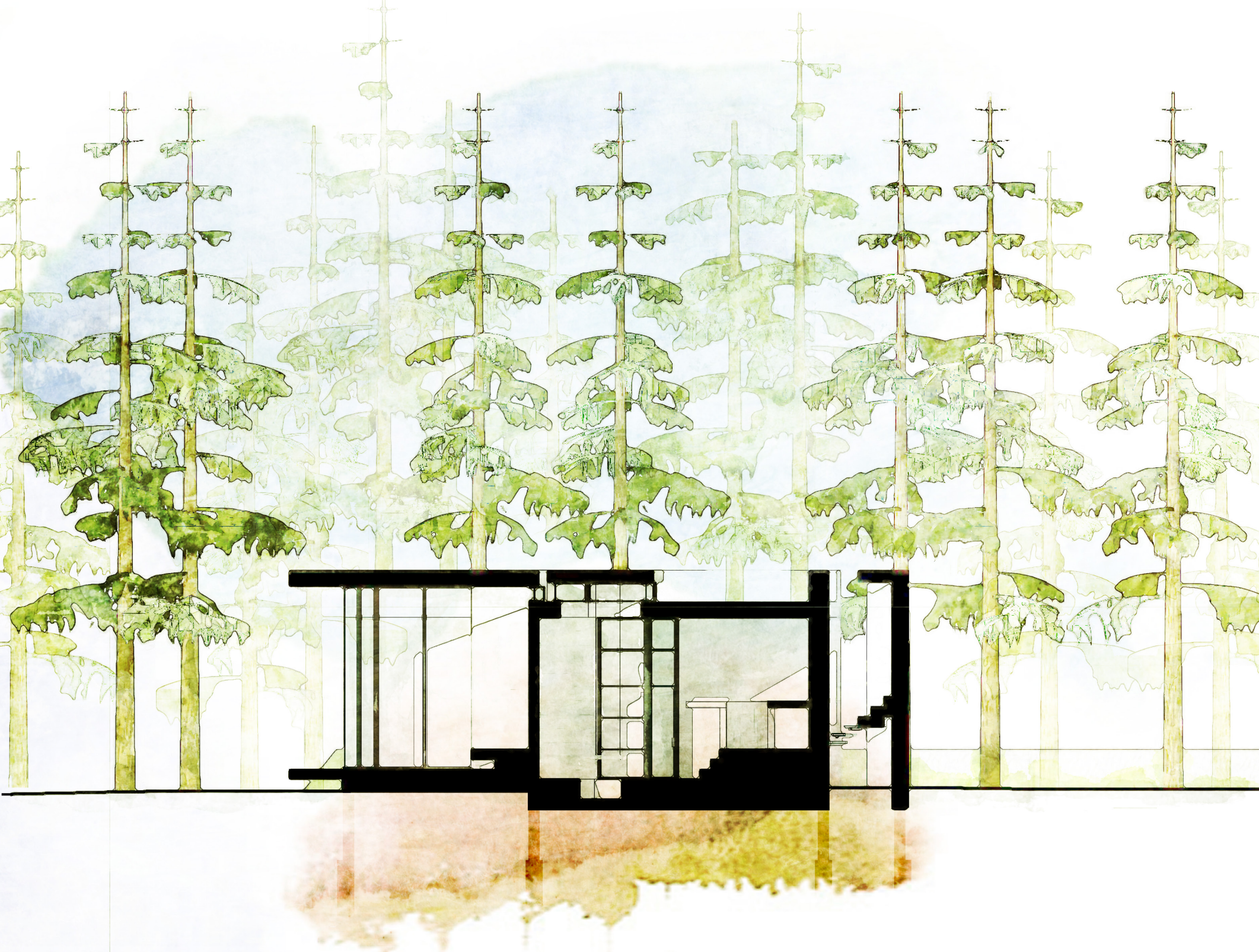




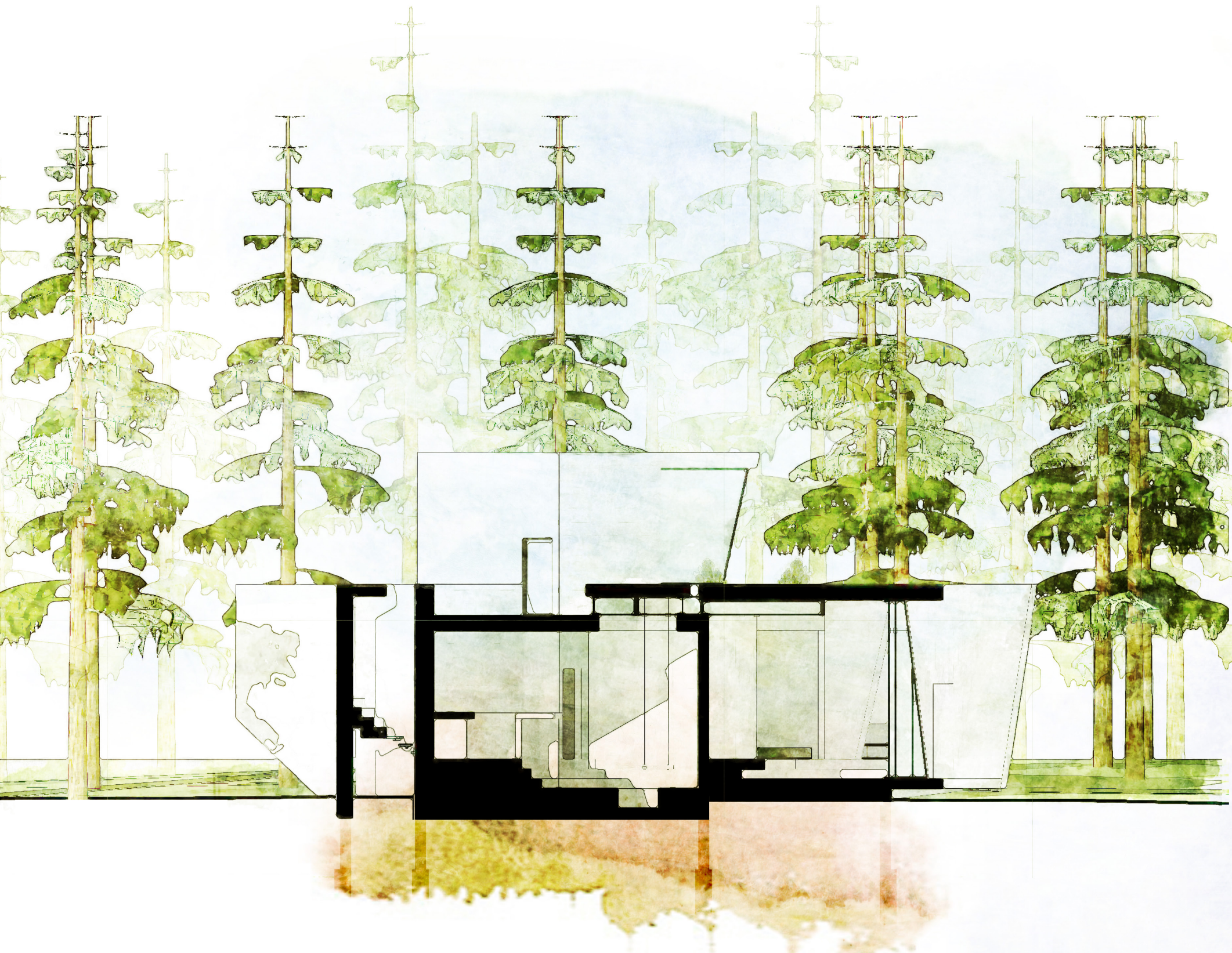





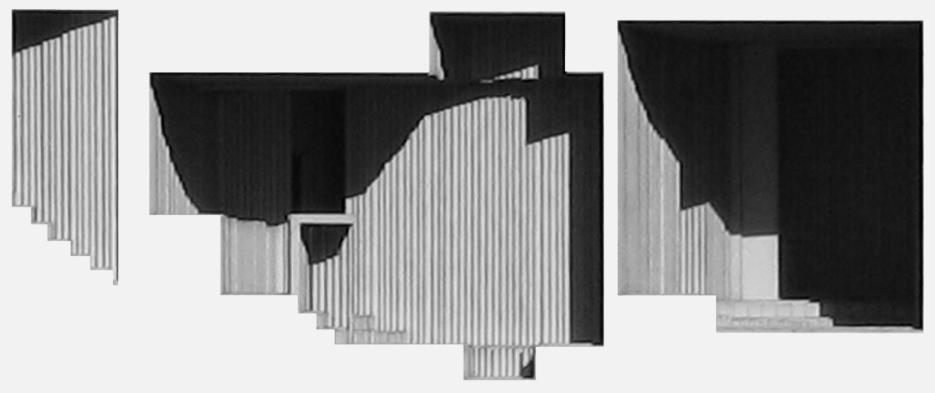

FIGURE 74. OH Building Section through the Nourishing Space - Photograph of Sectional Paper Book Model for the Dwelling of Walt Whitman 


\section{Developed Concept}

The nourishing space was further developed to utilize light, shadow, materiality and enclosure to capture emotion. The feeling of enclosure is captured through the lighting in addition to views of the exterior environment. The table located at the center of the nourishing space is lit from above creating a shaft of light to eat under. The clerestory connects the space vertically and presents a sense of enclosure by the contrasting darkness surrounding it. Christopher Alexander asserts that the atmosphere created for eating helps maintain a bond between people (Alexander et al., 1977, p.844). A soft light over the table holds people together and provides a focal point to gather around (Alexander et al., 1977, p.844). Enclosure is many ways is felt by the presence of boundary conditions that protect, shield or block the inhabitant from the elements. The views to nature are maintained when seated at eye level through the full height glazed walls. The clerestory filters light into the nourishing space and emulates the sense of enclosure by revealing slivers of the sky. The strong presence of the roof condition, the heavy concrete walls and the inward facing glazed walls create a sense of shelter within the space. This nourishing space captures the emotional grief of the fourth edition of Leaves of Grass by creating a tranquil space to nourish and bond with others over food. As everyone experiences and reacts to emotions in their journey differently, the circulation through the dwelling runs tangential to the common area so one has the choice whether to join, view or continue on their path. Alexander proposes the path of circulation to be tangent to the communal spaces rather than utilising corridors where inhabitants must commit to entering a space or forcing circulation through the center (Alexander et al., 1977, p.619). The informal contact between inhabitants ingrained in the circulation allows them to find comfort in others similar to Whitman finding comfort in the community. 



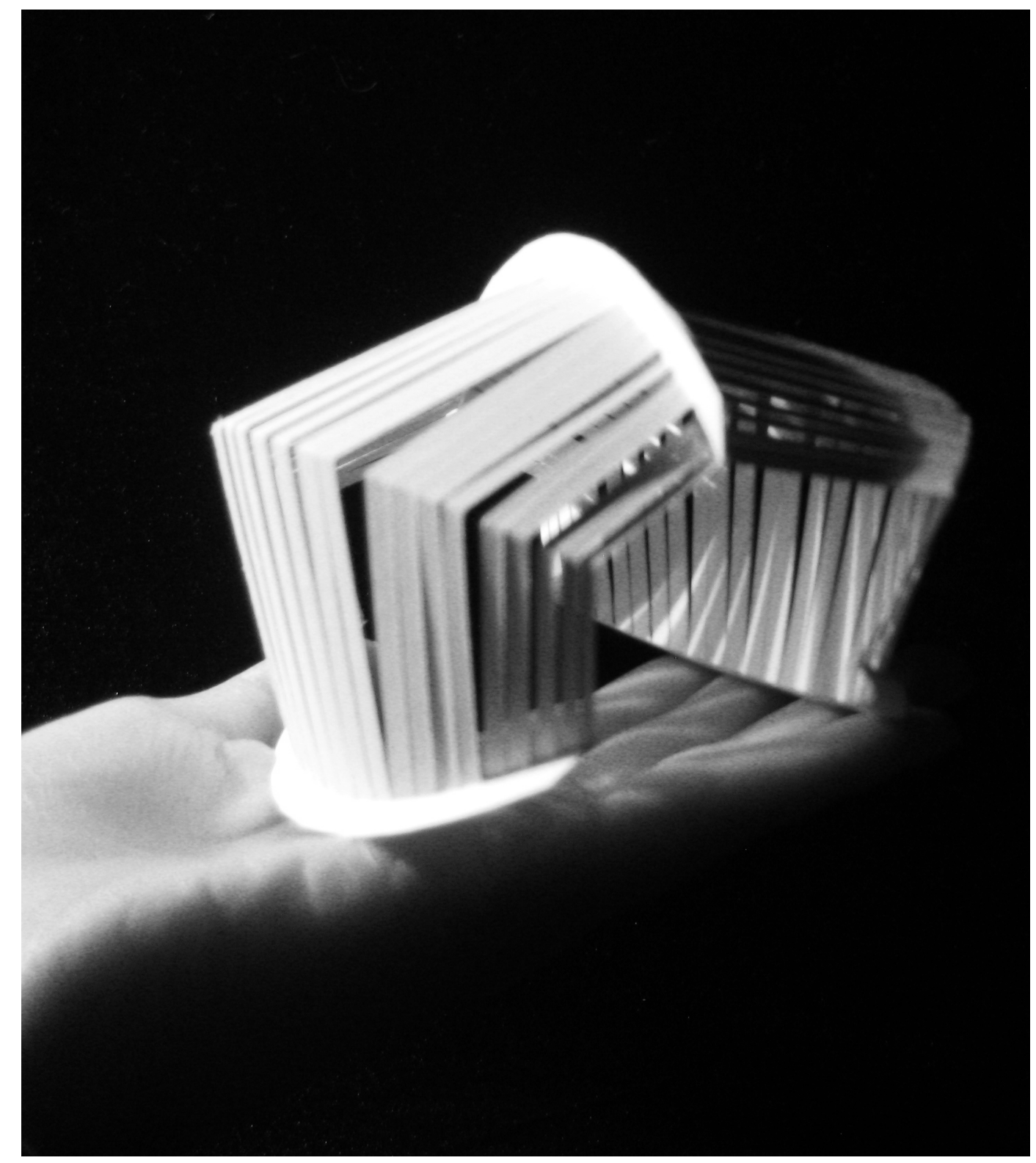

FIGURE 7.5.0^ Paper Pop-up Model

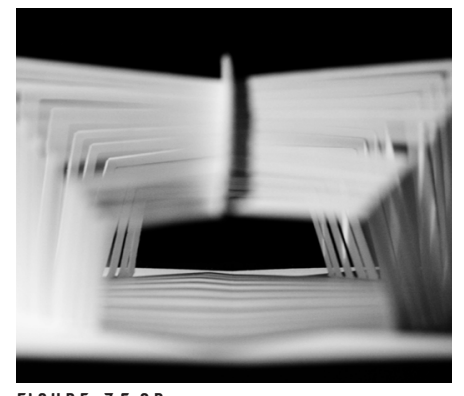

FIGURE 7.5.0B Paper Pop-up Model

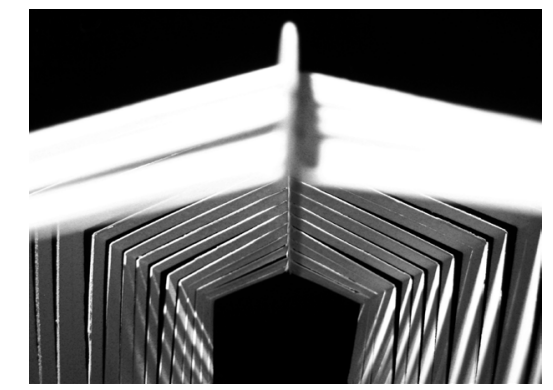

FIGURE 7.5.0C Paper Pop-up Model

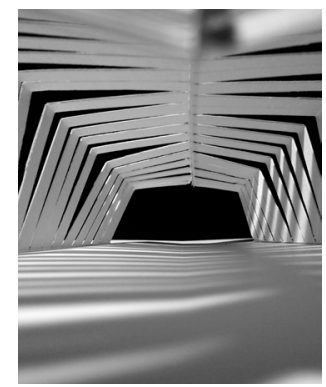

FIGURE 7.5.0D Paper Pop-up Model 


\section{5 .0 \\ PRIDE OF THE CONTEMPLATION SPACE}

\section{Analysis of the Fifth Edition of Leaves of Grass}

In the preface to the fifth edition of Leaves of Grass, Whitman stated that he had finally completed it and there would be no more revisions although in subsequent years he would fail to follow this claim. There is a noticeable shift in emotion from the fourth edition to the fifth. The poems of Drum-Taps and Sequel to Drum Taps were relocated in the text to form the central cluster. The emphasis on these poems suggests that Whitman felt the war had formed the American character. The grief over the war and the fallen victims expressed in the fourth edition was succeeded by the strength it gave to the people. Whitman felt that chaos and despair could provide the framework for a strong nation. Whitman expresses that tragedy brings out strength and he reflects on moments in his life that he has overcome.

\section{Initial Concept}

A feeling of pride is felt when reading the fifth edition, it is a turning point in Whitman's life. Pride is achieved in Whitman's emotional journey through contemplating the hardship and turning it into strength. The contemplation space in the dwelling is where an inhabitant might feel the most pride. An individual may choose to utilize this space to work, study, read, write create, contemplate or meditate. The paper popup model depicts a formal expression whereby the form is a reflection creating an enclosure (figures 7.5.0a - 7.5.0f). Reflection is an integral part of the fifth edition as Whitman reflects on his grief and develops those emotions into pride.

Pride
a. Light (rhythmic)
b. Elevation
c. Enclosure

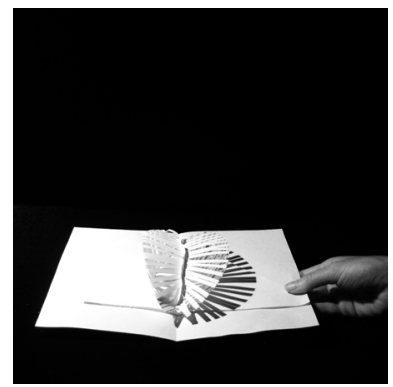

FIGURE 7.5.0E Paper Pop-up Model

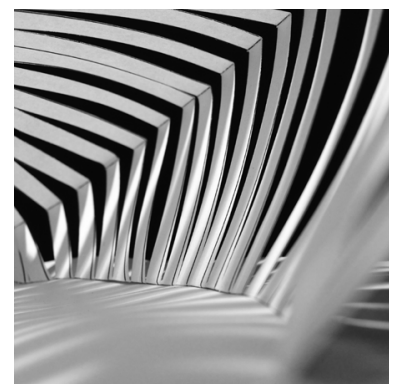

FIGURE 7.5.0F Paper Pop-up Model

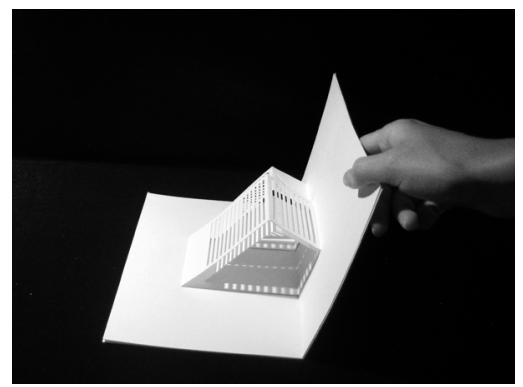

FIGURE 7.5.06 Paper Pop-up Model 


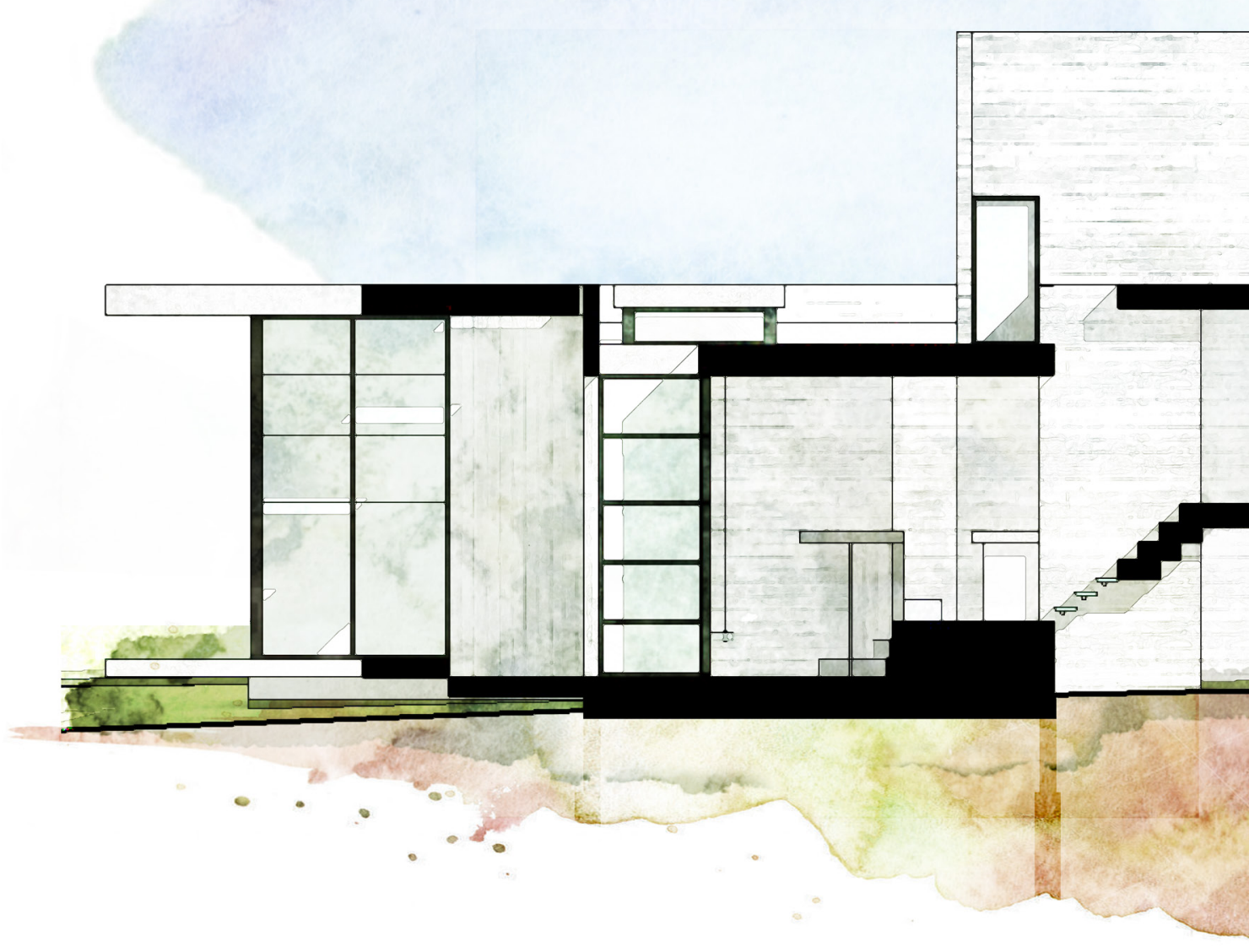




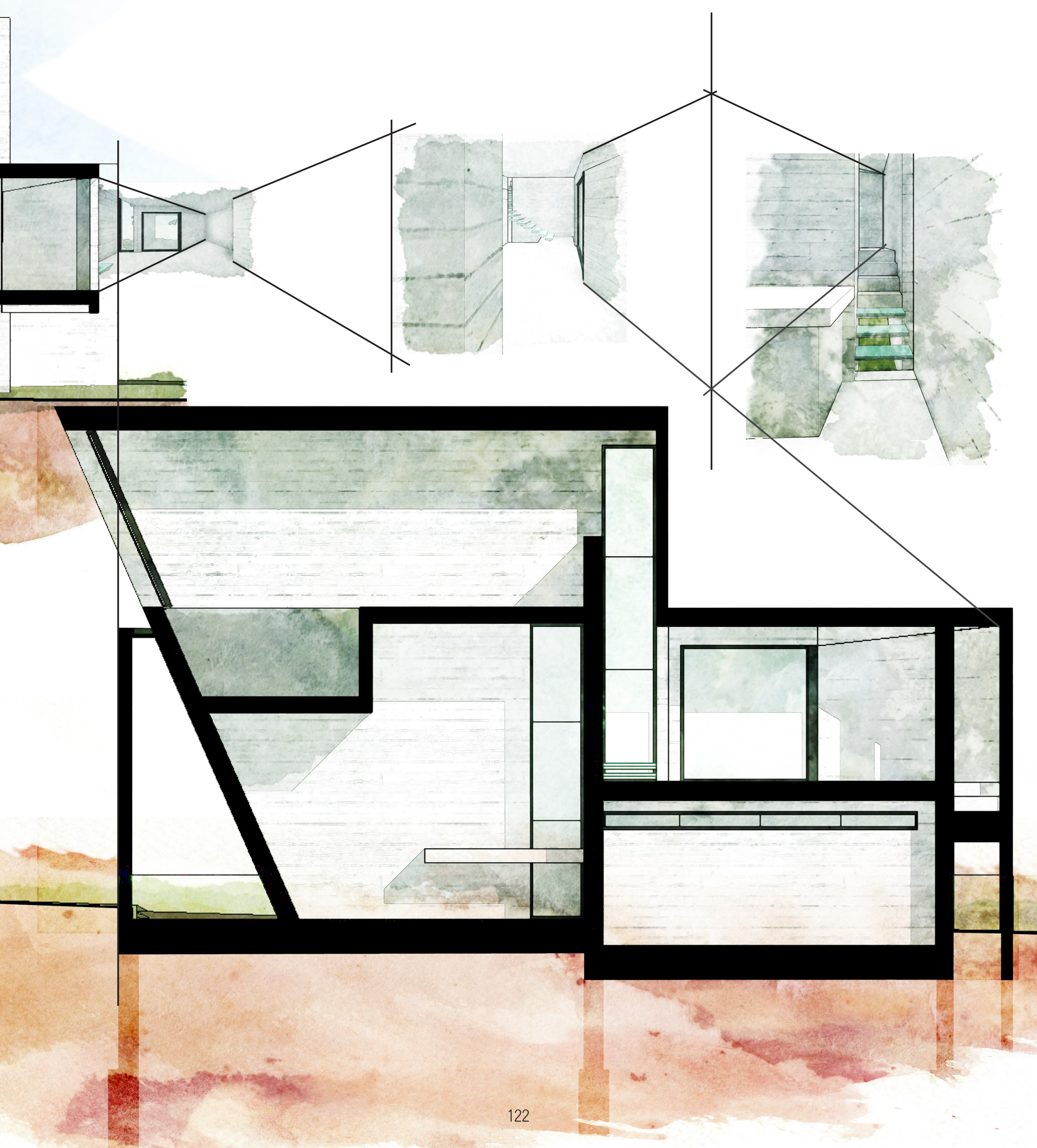




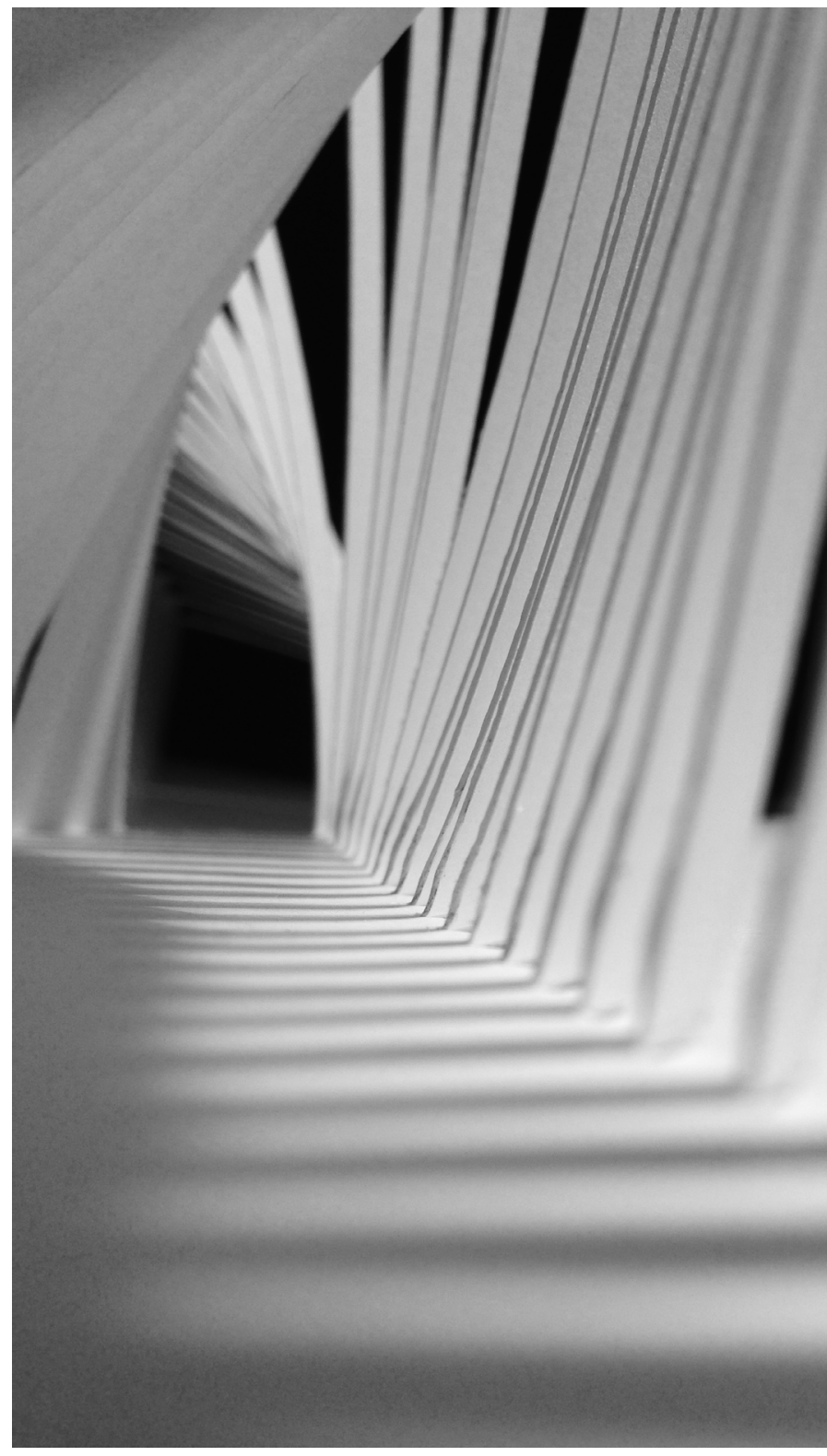

FIGURE 7.6.0^ Paper Pop-up Model

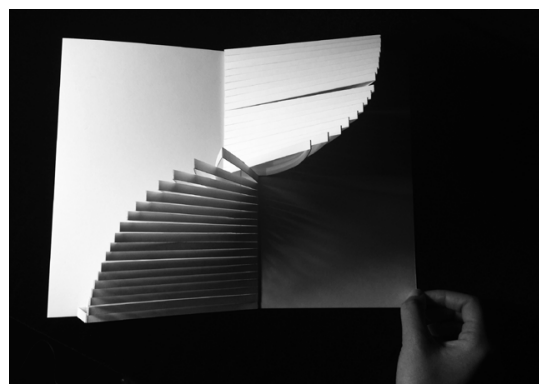

FIgURE 7.6.0B Paper Pop-up Model

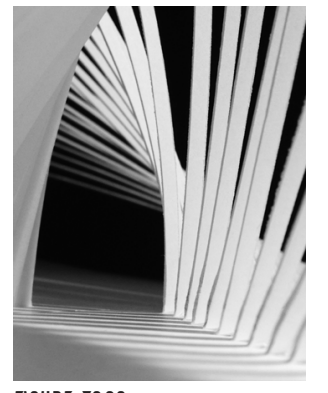

FIGURE 76.OC Paper Pop-up Model

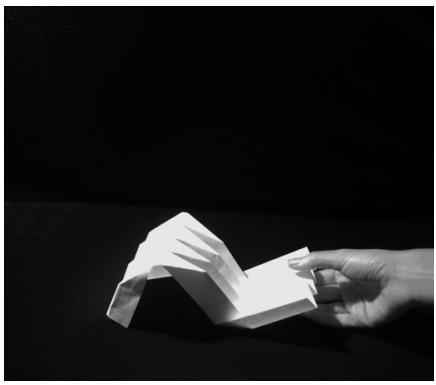

FIGURE 7.6.06 Paper Pop-up Model

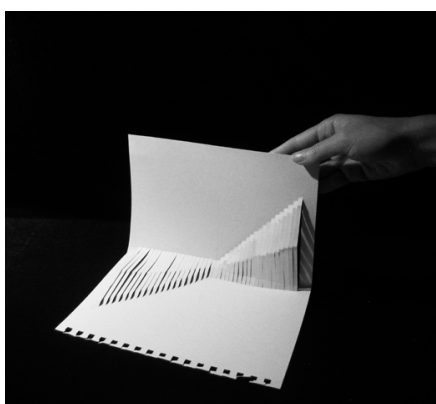

FIGURE 7.6.OF Paper Pop-up Model

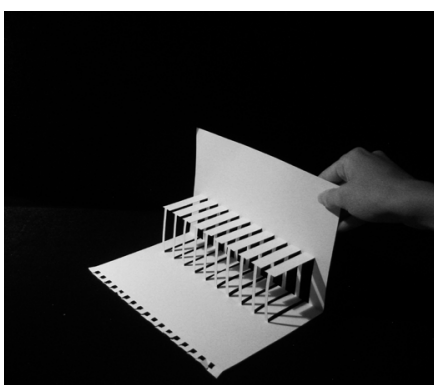

FIGURE 7.6.OE Paper Pop-up Model

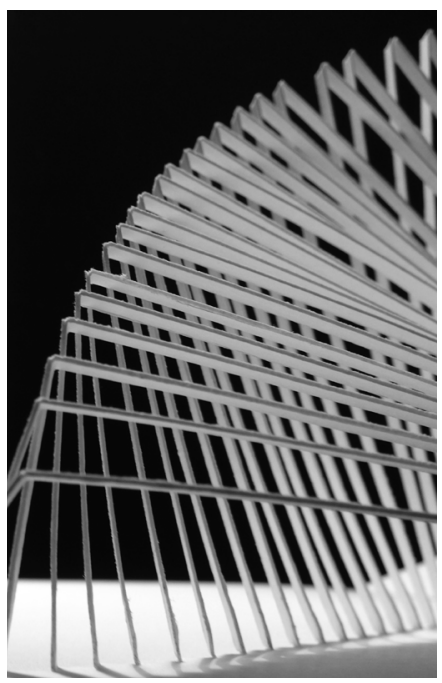

FIGURE 7.6.0D Paper Pop-up Model 


\subsection{0 \\ SPIRITUALITY OF THE CLEANSING SPACE}

Analysis of the Sixth Edition of Leaves of Grass

In 1881 Whitman made the final revisions to Leaves of Grass and all future new material was annexed to the back of the text. Mary Virginia Stark explained, in her dissertation, that Whitman organized his poems in this work like a narrative common in western literature (Stark, 1990). The journey of the protagonist was expressed through the rising action, climax and resolution indicated by each poem cluster. In the preface, Whitman compared his work to an ancient legend or play and stated that the spiritual poems in the final cluster conclude the plot and the protagonist's career (Blodgett \& Bradley, 1965, p.745). Although he would never attest to it, countless literary academics argued that in fact Whitman was the protagonist (LeMaster \& Kummings, 2011). The tragic poems surrounding the civil war were uplifted in this edition with the final cluster of spiritual poems (LeMaster \& Kummings, 2011, p.373). The spiritual poems expressed his emotions on death and poetic imagery of immortality and entering the spiritual world (Blodgett \& Bradley, 1965, p.746). In this edition Whitman was ill and therefore aware of the inevitable end of his life. Symbolic of a sick and dying man, his poetry focused on the spirituality of life and the finality to his life and poetic work. At this moment in Whitman's life he knew he wanted to be remembered by this edition and so he refined it with a more conventional structuring. In 1891 Whitman released a final issue of the sixth edition, nicknamed the deathbed edition, contained "An Executor's Diary Note" stating that the book was complete and shall be left as such. Whitman's conclusion to this edition reveals his ephemeral state of mind; he passed just two months after it went on sale.

Initial Concept

Whitman's spirituality is ever-present in this edition as he contemplates the cycle of life and his own conclusion to life. The cycle of his life's journey harnesses an important quality in the creation of this space. The cleansing space is provided for the spiritual practice of cleansing and not just one performed for necessary hygiene. This is achieved in many cultures through cleansing; by immersing oneself in water we become aware of our body and thoughts. The paper popup model depicts a more refined order and even cadence than that of the initial entering space reflecting the refinement in this edition (figures 7.6.0a - 7.6.0d). As this space turns the corner the finale is revealed but cannot be viewed until the inhabitant reaches it. The space is situated atop Jayne's Hill to view the memorial rock at the peak as a metaphorical finality to Whitman's life in the architectural journey.

Spirituality
a. Materiality
b. Light
c. Elevation (ascend) 


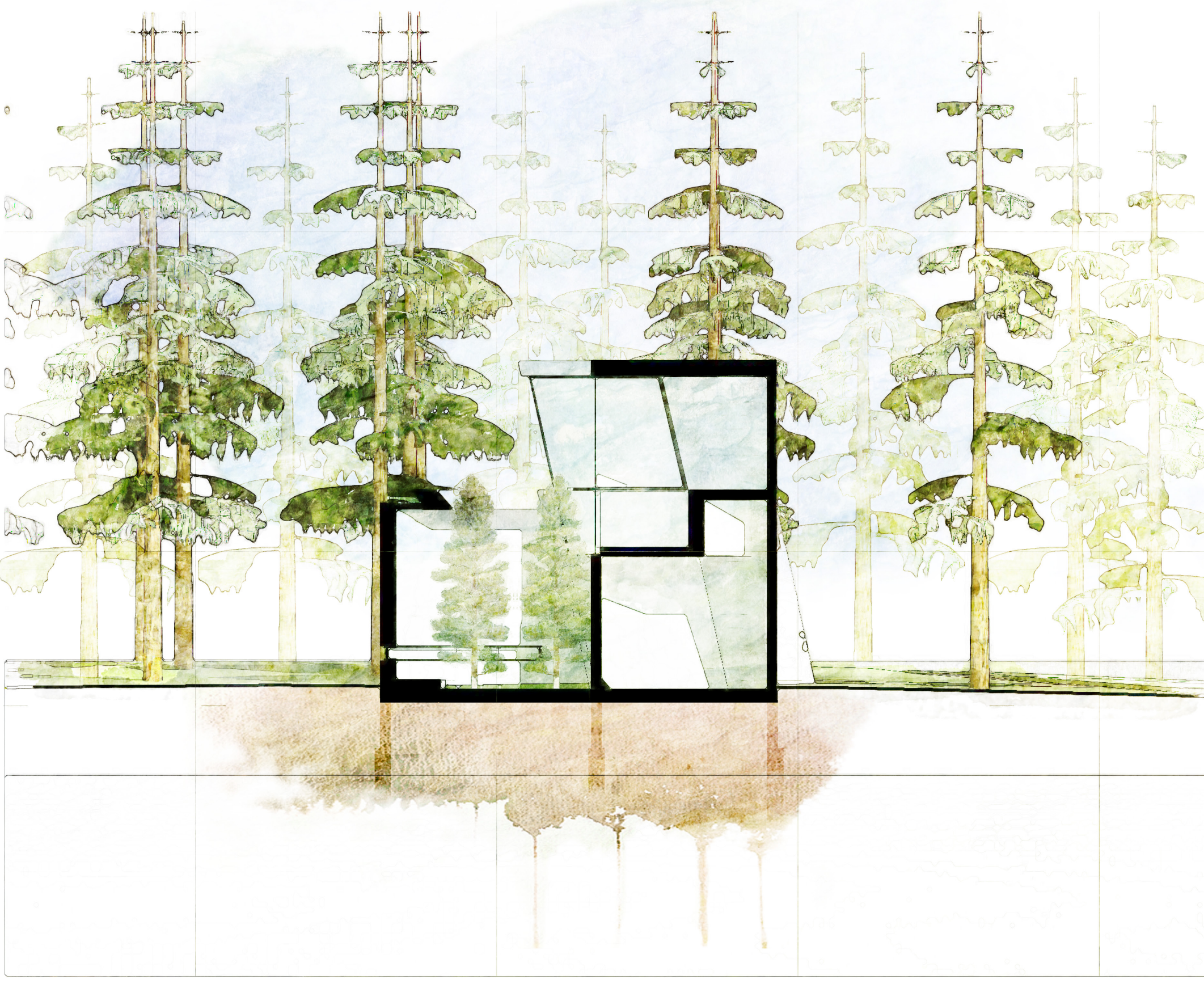





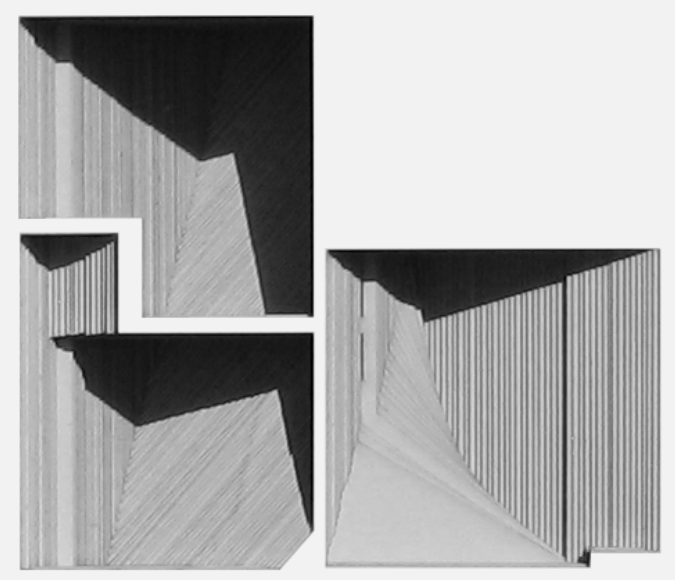


The cleansing space is separated from the washing room that lies adjacent to the resting space. The washing room contains a toilet, shower and sink for the actual business of cleaning. The cleansing space on the other hand "puts us into sensual contact with water" (Alexander et al., 1977, p.682) and is designed for relaxation. In Whitman's spiritual state he was very self-aware and reflective of himself on his journey. It was important for this space to become a cleansing space in order to provide the inhabitant with the means to be aware of themselves. The cleansing space exudes spirituality through the use of materiality, light and elevation. The cleansing space transitions from solid concrete walls and railings to a transparent end that allows for the eyes to take the inhabitant beyond the building envelope. The transparency at the dead end signifies that the journey continues on a spiritual level into nature although one cannot physically continue moving through. The window frames a view of the memorial rock to Walt Whitman located at the peak of Jayne's hill symbolizing the end of Whitman's journey (figure 7.6.0k). The large bath is located with windows on two sides so natural light can filter into the room. The light is diffused into the space by reflecting from the pool and filtering through the steam. The light patterns in the threshold guide the inhabitant to ascend into the space without any knowledge of what lies ahead (figure 7.6.0j). Once the inhabitant reaches the space they are aware of the finality of the journey. The ascent into the next level represents the ascent into the heavens. It was important to have the spiritual cleansing space located to meet in some way the beginning of the journey. The space is located above the entering space and symbolizing the cycle of life's journey. Reflecting and viewing back to the beginning without physically being in that space.

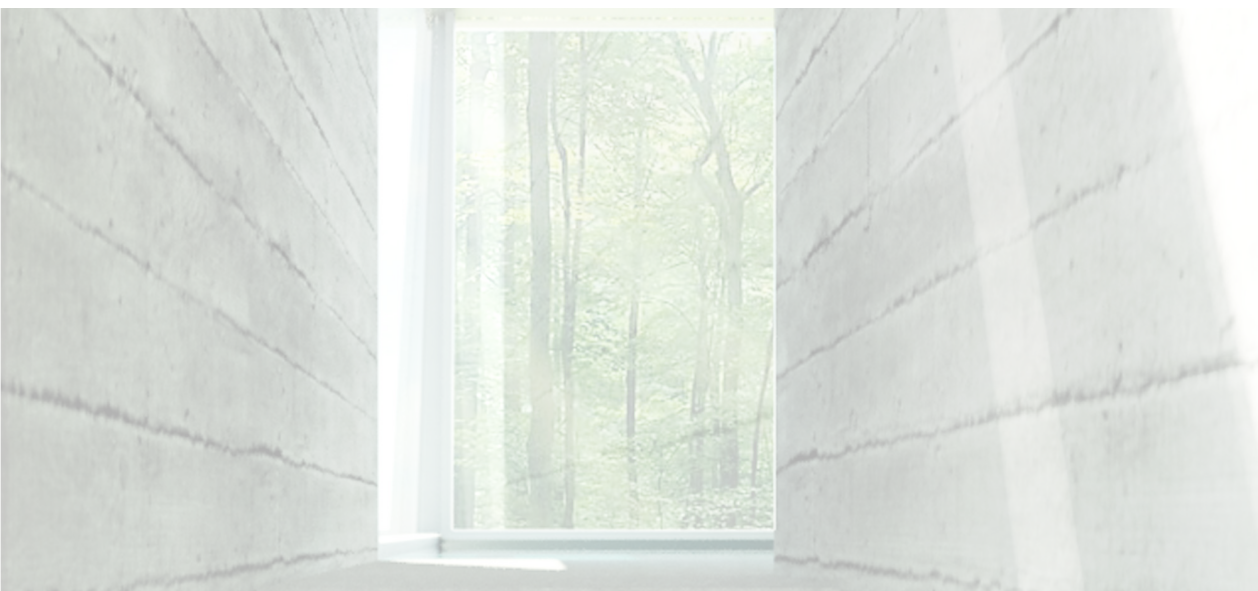



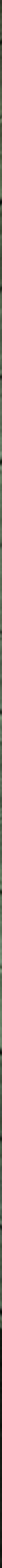



\subsection{0 \\ SPECULATION}

This thesis illustrates my research and synthesis of several other theories to create a design philosophy called Journey Architecture, which provides the foundation for my design work. Journey Architecture stems from the desire to celebrate life within the spaces we design by recognising that memory, emotion and environment all impact our experiences. With an ongoing exploration of the philosophical framework, this thesis seeks to lead architects and designers alike through the iterative process that established my concept of Journey Architecture. The case studies, design experiments and interdisciplinary research came together to develop my theory and continuously advance new ideas and design exploration.

Emphasis on design methodology and process shifted the focus from the creation of a space to the journey itself as a device to develop a set of architectural principles. These principles could then be utilised in the design and in an iterative process to redefine a journey in the context of architecture. This thesis looks at the experiential and symbolic qualities of architecture and utilises them to develop the tangible notion of a journey. The abstract notions of life can be explored through the concrete notions of architecture and evoking ideas and imagination in a rigid world.

What does it mean to us to establish a Journey Architecture? As architects, we can encapsulate the journey in its entirety through the process, the making, the representing and the creation of space. New Zealand architect Claude Megson, states "We are not building buildings, we are building ritual, building occasion, building life itself." Architects design space for human life and it should be judged based on how it reflects this primary purpose. Ayn Rand stated in The Romantic Manifesto that "Architecture ... does not re-create reality, but creates a structure for man's habitation or use, expressing man's values". The Dwelling of Walt Whitman explores this in its entirety, by utilising one man's values and emotions to form spaces for man to inhabit. The life of Walt Whitman presented a unique opportunity to capture one man's life journey as he expressed his emotions in six revised editions of his major work, Leaves of Grass.

This thesis defines Journey Architecture as a methodology for architects to consider when dealing with human exploration. Journey Architecture has the capacity to evoke emotional experiences within physical space and inspire architectural ideas through its representation. A journey is never about the final destination or end product but rather creating a framework of objects, spaces and places to enhance human experience through constant change. Journey Architecture requires an iterative process, exploring multi-media techniques to find methodologies that convey an idea, both visually and in real time. My hope is for this thesis to inspire other architects to remove the limitations of architectural conventions and explore architectural ideas that enrich the perpetual changes in the world. 


\section{0 .0 \\ REFERENCES}

Alexander, C., Ishikawa, S., Silverstein, M., Jacobson, M., Fiksdahl-King, I., \& Angel, S. (1977). A Pattern Language: Towns Buildings Construction. New York: Oxford University Press.

Antoniades, A. (1992). Poetics of Architecture. New York: Van Nostrand Reinhold.

Bachelard, G. (1994). The Poetics of Space (3rd ed.). Boston: Beacon Press.

Bermudez, J. (2007). In the Flesh; Towards an Architecture of Being.

Blair, D., \& Meyer, T. (1997). Tools for an Interactive Virtual Cinema. In R. Trappl \& P. Petta (Eds.), Creating Personalities for SyntheticActors: Towards Autonomous Personality Agents (pp. 83-91). Berlin: Springer Verlag.

Blodgett, H. W., \& Bradley, S. (1965). Preface 1876 — Leaves of Grass and Two Rivulets. In Leaves of Grass: Comprehensive Reader's Edition (pp. 744-754). New York: New York UP.

Bruno, G. (2007). Atlas of Emotion: Journeys in Art, Architecture, and Film.

Copans, R. (2007). Les Thermes de Pierre. Retrieved from https://www.youtube.com/ watch?v=6uGcOACOVUw

Diller, E., \& Scofidio, R. (1994). Flesh. Hong Kong: Princeton Architectural Press.

Dwelling. (n.d.). Retrieved from http://dictionary.reference.com/browse/dwelling

Eco, U. (2014). From the Tree to the Labyrinth: Historical Studies on the Sign and Interpretation. Harvard University Press.

Elevation. (n.d.). Retrieved May 05, 2015, from http://www.merriam-webster.com/dictionary/elevation

Emotion. (n.d.-a). Retrieved December 05, 2014, from http://www.merriam-webster.com/dictionary/ emotion

Emotion. (n.d.-b). Retrieved December 05, 2014, from http://dictionary.reference.com/browse/ emotion?s=t

Enclose. (n.d.-a). Retrieved September 09, 2015, from http://www.merriam-webster.com/dictionary/ enclosed

Enclose. (n.d.-b). Retrieved September 09, 2015, from http://dictionary.reference.com/browse/enclose 
Heidegger, M. (1962). Being in Time. Washington DC: HarperOne Publishing.

Hildebrand, G. (1999). Origins of Architectural Pleasure. Berkeley and Los Angeles: University of California Press.

Interiority. (n.d.-a). Retrieved November 03, 2014, from http://www.merriam-webster.com/dictionary/ interiority

Interiority. (n.d.-b). Retrieved December 05, 2014, from http://dictionary.reference.com/browse/ interiority

Journey - definition and synonyms. (2015). Retrieved from http://www.macmillandictionary.com/ dictionary/british/journey_1

Kern, H. (2000). Through the Labyrinth: Designs and Meanings Over 5,000 Years (Art \& Design) (Ferre Robe). Prestel Publishing.

Klotz, H. (1988). The History of Postmodern Architecture (Present). Massachusetts Institute of Technology.

LeMaster, J. R., \& Kummings, D. D. (Eds.). (2011). The Routledge Encyclopedia of Walt Whitman (Reprint). Routledge.

Light. (n.d.-a). Retrieved May 05, 2015, from http://www.merriam-webster.com/dictionary/light

Light. (n.d.-b). Retrieved May 05, 2015, from http://dictionary.reference.com/browse/light

Macleod, S., Hanks, L., \& Hale, J. (2012). Museum Making: narratives, architectures, exhibitions. Vasa. New York: Routledge.

Marcus, C. C. (1995). House as a Mirror of Self. Conari Press.

Material. (n.d.-a). Retrieved September 09, 2015, from http://www.merriam-webster.com/dictionary/ material

Material. (n.d.-b). Retrieved September 09, 2015, from http://dictionary.reference.com/browse/material

McCarthy, C. (2005). Toward a Definition of Interiority. Space and Culture, 8(2), 112-125. doi:10.1177/1206331205275020 
McQuillan, M. (2000). The Narrative Reader. Routledge.

Merleau-Ponty, M. (2005). Phenomenology of Perception. (C. Smith, Ed.). London: Routledge.

Move. (n.d.). Retrieved December 05, 2014, from http://dictionary.reference.com/browse/move?s=t

Movement. (n.d.-a). Retrieved December 05, 2014, from http://dictionary.reference.com/browse/ movement

Movement. (n.d.-b). Retrieved December 05, 2014, from http://www.merriam-webster.com/dictionary/ movement

Narrative. (n.d.). Retrieved December 05, 2014, from http://dictionary.reference.com/browse/narrative

Norberg-Schulz, C. (1965). Intentions in Architecture. Cambridge, Massachusetts: MIT Press.

Norberg-Schulz, C. (1971). Existence, Space and Architecture. New York: Praeger Publishers.

Pallasmaa, J. (1994). Identity, Intimacy and Domicile: Notes on the phenomenology of home. Arkkitehti - Finnish Architectural Review, 1.

Pallasmaa, J. (1996a). The Eyes of the Skin: Architecture and the Senses. John Wiley and Sons Ltd.

Pallasmaa, J. (1996b). The Geometry of Feeling: A Look at the Phenomenology of Architecture. (K. Nesbitt, Ed.) (Theorizing, pp. 447 - 453). New York: Princeton Architectural Press.

Pallasmaa, J. (2000). Stairways of the Mind. International Forum of Psychoanalysis, 9, 7-18. doi:10.1080/080370600300055814

Paul Cobley. (2001). Narrative (The New Critical Idiom). Routledge.

Pelletier, L. (2006). Architecture in Words: Theatre, Language and the Sensuous Space of Architecture. Routledge.

Rasmussen, S. E. (1964). Experiencing Architecture. MIT Press.

Rhythm. (n.d.). Retrieved May 05, 2015, from http://www.merriam-webster.com/dictionary/rhythm

Ricoeur, P. (1991). Narrative Identity. Philosophy Today, 35(1), 73-81. Retrieved from http://www. scribd.com/doc/24868946/Paul-Ricoeur-Narrative-Identity\#scribd 
Rosenfield, I. (1988). The Invention of Memory: A New View of the Brain. Basic Books.

Samuel, F. (2010). Le Corbusier and the Architectural Promenade (1st ed., p. 224). Birkhäuser Architecture.

Schwarzer, M. W. (1991). The Emergence of Architectural Space: August Schmarsow's Theory of "Raumgestaltung." Assemblage, 15, 48-61.

Shadow. (n.d.-a). Retrieved September 09, 2015, from http://www.merriam-webster.com/dictionary/ shadow

Shadow. (n.d.-b). Retrieved September 09, 2015, from http://dictionary.reference.com/browse/ shadow?s=t

Stark, M. V. (1990). Clustered Meaning in Walt Whitman's Leaves of Grass. University of lowa.

Stern, M. (1994). Passages in the Garden : An Iconology of the Brion Tomb. Landscape Journal, 13(1), $39-57$.

Tabb, P. J., \& Deviren, A. S. (2014). The Greening of Architecture. Ashgate Pub Co.

Threshold. (n.d.). Retrieved May 05, 2015, from http://www.merriam-webster.com/dictionary/threshold

Tschumi, B. (1996). Architecture and Disjunction. Cambridge, Massachusetts: The MIT Press.

Ursprung, P., \& Schneider, R. (2002). Housing Remains: Herzog \& de Meuron and Performance. In Herzog \& de Meuron Natural History (pp. 217-227). Lars Müller Publishers.

Whitman, W. (1855). Leaves of Grass (1st ed.).

Wigley, M. (1995). The Architecture of Deconstruction: Derrida’s Haunt (New, p. 294). The MIT Press.

Wigley, M., \& Johnson, P. (1988). Deconstructivist Architecture (p. 104). New York. 
